\title{
Integrating Remote Sensing Techniques \\ into Forest Monitoring: Selected Topics with a Focus on \\ Thermal Remote Sensing
}

\author{
Dissertation \\ zur Erlangung des Doktorgrades \\ der Fakultät für Forstwissenschaften und Waldökologie \\ der Georg-August-Universität Göttingen
}

vorgelegt von

Nils Nölke

Göttingen, Januar 2016 
1. Gutachter: Prof. Dr. Christoph Kleinn

2. Gutachter: Prof. Dr. Andrea Polle

Tag der mündlichen Prüfung: 05.04.2016 


\section{Preface}

Four years ago in 2011 I started with the research Project "Estimating forest canopy surface temperature by airborne laser scanning, thermal infrared scanning, and 3D radiation modelling“ funded by the DFG as part of the Priority Program 1374 "Infrastructure-Biodiversity-Exploratories". Within this project, the Chair of Bioclimatology (Prof. Dr. Alexander Knohl) was involved; their main focus was the radiative modelling. I cannot express the long days spent in front of the computer, battling with the thermal data, the hope for good results and the finishing of my first scientific article.

I would like to thank my supervisor Prof. Dr. Christoph Kleinn for his excellent guidance, support, the trust in me during this process and for give me the chance to conduct some of the research abroad. I also wish to thank all of the respondents and involved authors, without whose cooperation I would not have been able to conduct the different studies. In particular, I am thankful to Prof. Dr. Andrea Polle who showed great interest in the topic, acting as co-examiner and co-reviewer of my dissertation and for offering the opportunity, space and the support, also by her team at Chair of Forest Botany, to apply our greenhouse experiment. I would also like to thank Prof. Dr. Thomas Nauss for taking time out of his busy schedule to join my thesis committee as external reviewer.

To my other colleagues at Chair of Forest Inventory and Remote Sensing.: I would like to thank you for your wonderful cooperation as well and for the nice working atmosphere where it is a pleasure to work. It was always helpful to exchange ideas about my research around with you.

I am immensely grateful to my parents for your encouragement and support. If I ever lost interest, you kept me motivated.

A particular note of thanks: Tanja, I am very grateful for your support and your motivation, especially close to the end of my thesis. For the multiple proof-reading. I know my thesis was hard going but now you can explain the term” blackbody”.

Göttingen, January 2016

Nils Nölke 



\section{Table of Contents}

List of Abbreviations ..................................................................................................... i

List of Figures.......................................................................................................................iii

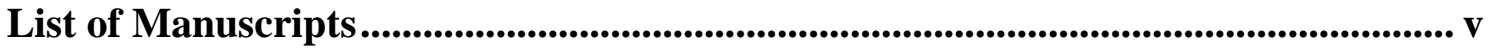

Zusammenfassung ............................................................................................................. vii

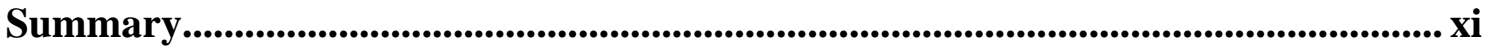

1 Introduction........................................................................................................ 1

1.1 Overview of the Manuscripts ..................................................................... 3

1.2 A Brief History of Forest Monitoring ……………………………………... 5

1.3 The Current Importance of Forest Monitoring................................................. 7

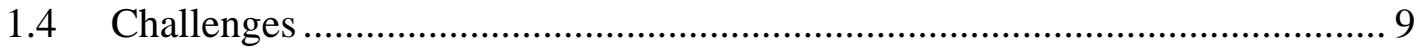

2 Objectives and Research Questions ................................................................... 13

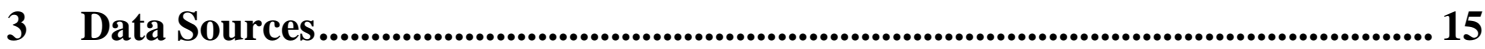

3.1 Field Observations in Forest Monitoring ………………………………..... 15

3.2 Remote Sensing for Forest Monitoring ....................................................... 17

3.2.1 Airborne and Terrestrial LiDAR.......................................................... 18

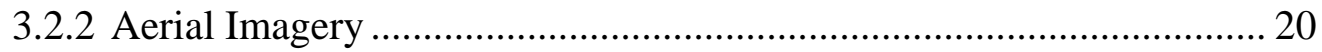

3.2.3 Satellite Imagery ……………………………………………….... 21

4 Empirical Modeling .................................................................................................... 23

5 Sources of Errors ...................................................................................................... 25

6 The Physical Principles of Thermal Infrared Radiation....................................... 27

7 Applications of Thermal Remote Sensing ................................................................ 33

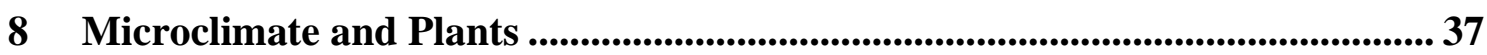

8.1 Preliminary Notes................................................................................ 37

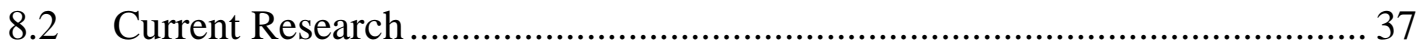

8.4 Leaf Energy Balance ................................................................................. 38

9 Exploratory Studies on Thermal Imaging of Forest Canopies............................. 43

9.1 Research Framework ................................................................................ 43

9.2 Detecting Forest Gaps from Thermal Images ............................................... 43

9.3 Temperature and Stomatal Conductance of Leaves of Three Tree Species... 46

Manuscript Abstracts ...................................................................................................... 53

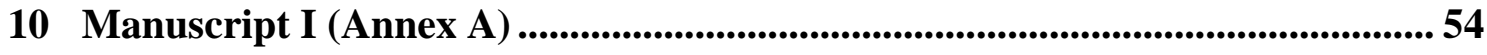

11 Manuscript II (Annex B)..................................................................................... 55

12 Manuscript III (Annex C) .................................................................................. 56

13 Manuscript IV (Annex D) .................................................................................... 57 


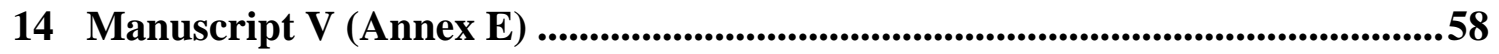

15 Synthesis: Integrating Remote Sensing Techniques into Forest Monitoring ... 59

15.1 The Application of Infrared Thermal Imaging ...............................................59

15.2 Laser Scanning and Biomass of Big Trees .................................................61

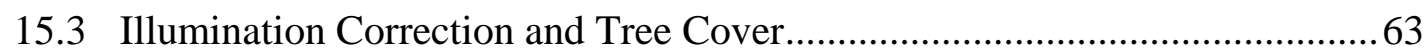

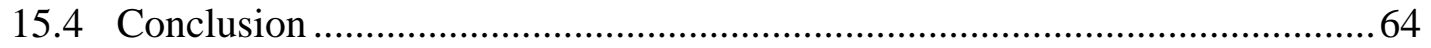

References .................................................................................................................667

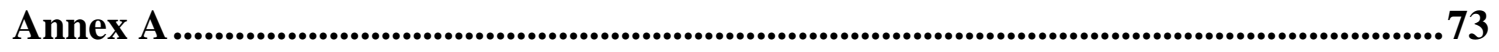

Annex B ...................................................................................................................................... 79

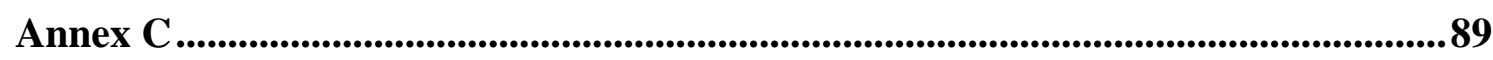

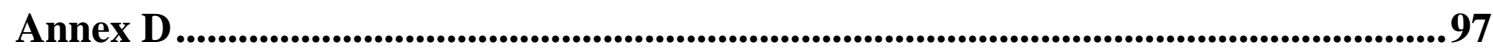

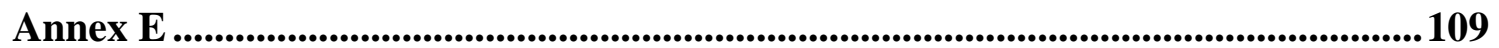




\section{List of Abbreviations}

\begin{tabular}{ll} 
Hm & Micrometer \\
ALS & airborne laser scanning \\
DAB & diameter above buttress \\
DBH & diameter at breast height \\
DEM & digital elevation model \\
DSM & digital surface model \\
FAO & Food and Agriculture Organization of the United Nations \\
GSD & ground surface distance \\
K & Kelvin \\
LiDAR & Light Detection And Ranging \\
LR & long-wave radiation \\
LST & land surface temperature \\
m & meter \\
MRV & Measurement, Reporting and Verification \\
NASA & National Aeronautics and Space Administration \\
NFI & National forest inventory \\
nm & nanometer \\
PAR & photosynthetically active radiation \\
REDD & Reducing Emissions from Deforestation and Forest Degradation \\
SR & short-wave radiation \\
SRTM & Shuttle Radar Topography Mission \\
TIRS & Landsat thermal infrared sensor \\
TLS & terrestrial laser scanning \\
UAV & unmanned aerial vehicle \\
$\boldsymbol{E}$ & emissivity \\
\hline
\end{tabular}





\section{List of Figures}

Figure 1: Integration of the five manuscripts into forest monitoring process 3

Figure 2: Electromagnetic spectrum with thermal infrared spectrum in detail 27

Figure 3: $\quad$ Illustration of Wien's displacement law 29

Figure 4: $\quad$ Illustration of Planck's radiation law 30

Figure 5: $\quad$ Illustration of Stefan-Boltzmann law 31

Figure 6: Illustration of the radiant energy balance during daytime 40

Figure 7: (left) Airborne thermal image with a spatial resolution of $0.2 \mathrm{~m}$. (right) Colored thermal image of the same extent. Temperature is according to the scale to the right.

Figure 8: Temperature profile of two forest gaps (the centre of the two graphs, between each of the depicted border trees) with different ground surface cover. (top) the temperature of the gap is low due to the presence of dense vegetation and shadowing effects. (bottom) the higher temperature of the gap is explained by the lack of vegetation: the bare soil heats up more and emits thermal radiation

Figure 9: (left) Arrangement of thermal camera and the subset of trees in greenhouse. (right) Illustration of the field-of-view of the thermal camera

Figure 10: Illustration of the manual delineated leaf within the red circle. Thermal image was taken on 05/09/2013. (Source: Diers 2013)

Figure 11: Stomatal conductance and leaf temperature categorized into groups of air temperature: Tair $<20^{\circ} \mathrm{C}$, Tair $20-25^{\circ} \mathrm{C}$, Tair $>25^{\circ} \mathrm{C}$. (Source: Diers 2013)

Figure 12: Mean daily temperature cycle between 8:00 am. and 4:00 pm of leaf and air temperature in Acer pseudoplatanus. The grey area represents the global radiation, the middle curve outlines the leafto-air difference. The top curve shows the stomatal conductance 



\section{List of Manuscripts}

This dissertation is presented in cumulative form and its core research part consists of five individual manuscripts, which are referred to by their corresponding Roman numerals in the text. All manuscripts are completely given in Annexes A - E and specify the percentage contribution.

Manuscripts I, II and III are published. Manuscript IV and V are in preparation.

I. Nölke N, P Beckschäfer, C Kleinn. 2014. Thermal canopy photography in forestry - an alternative to optical cover photography. $\underline{\text { iForest - Biogeosciences and }}$ Forestry, 8: 1-5

II. Nölke N, L Fehrmann, I N Surati Jaya, T Tiryana, D Seidel and C Kleinn. 2015. On the geometry and allometry of big-buttressed trees - a challenge for forest monitoring: new insights from 3D-modeling with terrestrial laser scanning. iForest - Biogeosciences and Forestry, 8: 574-581

III. Nölke N, J C Camargo García, C Kleinn and A Polle. 2015. Changes in culm surface temperature with maturity of the bamboo species Guadua angustifolia. Journal of Forest Research (early view): 1-7 [Published online: 03 October 2015].

IV. Vonrüti M, A Spasojevic, N Nölke, T Kneib and C Kleinn. 2015. Comparing Canopy Leaf Temperature of Three Central European Tree Species Based on Simultaneous Confidence Bands for Penalized Splines. Journal of Applied Statistics. [in review: 13 January 2016]

V. Fuchs H and N Nölke. 2015. Influence of four different digital elevation models on estimation of tree cover. Journal of Applied Remote Sensing. [in preparation, submission planned for March, 2016] 



\section{Zusammenfassung}

Eine nachhaltige Bewirtschaftung der natürlichen Ressourcen, insbesondere von Wäldern, ist von großer Bedeutung, damit auch zukünftigen Generationen der gleiche Nutzen des Waldes offensteht. Es gilt die unterschiedlichen Interessen und Bedürfnisse in Einklang zu bringen. Aus diesem Grund ist ein besseres Verständnis der aktuellen Situation und der zukünftigen Entwicklung der Wälder entscheidend um eine nachhaltige Form der Waldbewirtschaftung sicherzustellen. Die Erhebung der dafür notwendigen Daten und die Beobachtung von Trends erfolgt im Rahmen des Waldmonitoring. Zwar gibt es eine Vielzahl von anerkannten Methoden und Techniken zur Datenerhebung und Auswertung sowohl für Nahbereichs- als auch für satellitengestützte Fernerkundung, dennoch beschäftigen sich Wissenschaftler nach wie vor mit zahlreichen spezifischen und ungelöste Fragen im Bereich Waldmonitoring. Das Ziel ist durch den Einsatz fortschrittlicher Methoden und Technologien eine Kostensenkung und Zeitersparnis bei der Datenerfassung zu erreichen und letztlich auch eine vereinfachte Interpretation der Daten sowie eine höhere Genauigkeit.

Im Rahmen dieser Doktorarbeit wurden unterschiedliche Studien durchgeführt, wobei jede einer individuellen und spezifischen Forschungsfrage nachgeht. Das Ziel ist neue und innovative Fernerkundungsmethoden und Technologien vor dem Hintergrund des Waldmonitoring zu untersuchen. Der Schwerpunkt dieser Arbeit ist die Integration von Nahbereichs- und satellitengestützter Fernerkundung mit Schwerpunkt auf thermaler Fernerkundung in das Waldmonitoring.

Manuskript I diskutiert ein neues Anwendungsgebiet, die thermal-hemisphärische Fotografie. Dieser Ansatz nutzt die großen Temperaturunterschiede zwischen „Himmel“ und „NichtHimmel“ Pixel und vereinfacht so die Suche nach einem optimalen Schwellenwert. Aufgrund der eindeutigen Trennung von „Himmel" und „Nicht-Himmel" Pixel, wird ein globaler Schwellenwert von $0^{\circ} \mathrm{C}$ definiert. Derzeit ist die optische-hemisphärische Fotografie die am weitesten verbreitete Methode zur Schätzung des Kronenschlussgrads. Doch eine Reihe von Aspekten, wie Belichtung, Beleuchtungsbedingungen und Schwellenwertdefinition stellen eine Herausforderung in der optischen Fotografie da. Diese hat einen erheblichen Einfluss auf das Ergebnis. Daher ist ein Vergleich der Ergebnisse basierend auf Aufnahmen von unterschiedlichen Zeitpunkten nicht ratsam. Für das Waldmonitoring, bei dem Wiederholungsmessungen auf denselben Plots von großer Bedeutung sind um Änderungen des Kronenschlussgrades zu beschreiben, ist es notwendig ein standardisiertes Verfahren zu entwerfen. Manuskript I zeigt, dass dies durch den Einsatz thermaler Fotografie möglich ist. Die Genauigkeit der Methode zur Schätzung des Kronenschlusses zeigt auch die starke Korrelation $\left(\mathrm{R}^{2}=0.96\right)$ zwischen thermischen und optischen Bildpaar. 
Thermal-Fotografie, als Nahbereichs-Fernerkundungstechnik kann auch in anderen Zusammenhängen die Datenerhebung und Analyse verbessern, zum Beispiel bei der Bestimmung des Alters von Bambus. Informationen über das Alter der Bambushalme ist entscheidend, denn nur in diesem Stadium ist der Prozess der Verholzung beendet ist und der Halm erlangt seine maximale Stabilität. Die Ergebnisse einer Studie (Manuskript III) durchgeführt in Pereira (Kolumbien) zeigen konsistente, wenn auch relativ kleine Unterschiede in der Oberflächentemperatur zwischen Halm unterschiedlichen Alters für die Bambusart Guadua angustifolia K., die in Zusammenhang mit Reifegrad stehen könnten. Die Oberflächentemperatur von 12 Bambushalmen wurde nach Sonnenaufgang mit der Wärmebildkamera FLIR 60Ebx gemessen. Diese Studie zeigt eine innovative Nahbereichs-Fernerkundungstechnik, die Forscher bei der Bestimmung des Alters der Bambushalme unterstützen kann.

Im Rahmen der Analyse von Thermalbildern aus Zeitreihendaten, zeigt Manuskript (IV) eine neue Methode zur Analyse auf Grundlage komplexer statistischer Methoden. "Otsu thresholding“, ein automatisches Segmentierungsverfahren, wird in einem ersten Bearbeitungsschritt verwendet um die unterschiedlichen Temperaturbereiche $\mathrm{zu}$ trennen. O'Sullivan Splines schätzen anschließend das Temperaturprofil, das von der Blattoberfläche extrahiert wurde. Ein abschließender statistischer Vergleich der verschiedenen Profile wird erreicht durch Konstruktion simultaner Konfidenzbänder. Das Ergebnis zeigt kleine aber konsistente Unterschiede in der Blattoberflächentemperatur zwischen den drei Baumarten.

Eine weitere Nahbereichs-Fernerkundungs Technologie ist das terrestrische Laserscanning. Diese wird verwendet, um das Verständnis über Brettwurzel-Bäume zu verbessern. Große Bäume mit einer unregelmäßigen nicht-konvexen Form, leisten einen wesentlichen Beitrag zur oberirdischen Biomasse in den tropischen Wäldern. Bestehende Messmethoden führen gerade für dieses Teilkollektiv häufig zu einer verzerrten Biomasseschätzung. Vor diesem Hintergrund zeigt Manuskript II das Ergebnis der 3D-Analyse von 12 Brettwurzel-Bäumen um hier einen Beitrag zur Methodenverbesserung zu leisten. Die Studie wurde im Botanischen Garten in Bogor (Indonesien) durchgeführt, unter Verwendung eines terrestrischen Laserscanner. Die Ergebnisse der Studie geben neue Einblicke in die unregelmäßige Geometrie der Brettwurzel-Bäumen und der verwendete methodischen Ansatz in dieser Studie trägt zu einer Verbesserung der Volumenund Biomasse-Modelle für diese Art von Baum bei. Die Ergebnisse zeigen eine starke Beziehung $\left(\mathrm{R}^{2}=0.87\right)$ zwischen den Querschnittsflächen in DAB Höhe und der tatsächlichen Grundfläche gemessen in $1,3 \mathrm{~m}$ Höhe.

Die Verbindung neuer Fernerkundungstechnologien und Methodiken im Rahmen des Waldmonitoring führen $\mathrm{zu}$ einer verbesserten und verlässlicheren Schätzung der Baumbedeckung. Die Vorverarbeitung von Satellitenbildern spielt eine entscheidende Rolle in der Prozessierungskette und insbesondere die Beleuchtungskorrektur wirkt sich direkt auf die 
geschätzte Baumabdeckung aus. Manuskript V wertet vier Geländemodelle (Pleiades DSM, SRTM30, SRTM V4.1 und SRTM-X), die für die Region Shitai County (Provinz Anhui, SüdostChina) zur Verfügung stehen vor dem Hintergrund einer optimierten Beleuchtungskorrektur und Schätzung der Baumbedeckung aus RapidEye Satellitenbildern aus. Die in dieser Studie vorgestellten Ergebnisse deuten darauf hin, dass die Veränderung der Baumbedeckung auch abhängig ist von dem jeweiligen digitalen Höhenmodell das in der Vorverarbeitung verwendet wurde. Das mit dem frei verfügbaren Geländemodell SRTM30 mit einer Auflösung von 30 m führt zu einer höheren Genauigkeit bei der Schätzung der Baumabdeckung.

Im Rahmen der Doktorarbeit wurde versucht, einige der Probleme, die sich im Zuge der Umsetzung und Durchführung beim Waldmonitoring ergeben zu lösen und Antworten auf einige der vielen Detailfragen zu finden. Es konnte gezeigt werden, dass besonders Thermalfotografie etablierte Methoden verbessert und daher eine sinnvolle Integration darstellt. 



\section{Summary}

A sustainable management of natural resources, in particular of forests, is of great importance to preserve the ecological, environmental and economic benefits of forests for future generations. An enhanced understanding of the current situation and ongoing trends of forests, e.g. through policy interventions, is crucial to managing the forest wisely. In this context, forest monitoring is essential for collecting the base data required and for observing trends. Despite the wide range of approved methods and techniques for both close-range and satellite-based remote sensing monitoring, ongoing forest monitoring research is still grappling with specific and unresolved questions: The data acquired must be more reliable, in particular over a long-term period; costs need to be reduced through advancements in both methods and technology that offer easier and more feasible ways of interpreting data.

This thesis comprises a number of focused studies, each with their individual and specific research questions, and aims to explore the benefits of innovative methods and technologies. The main emphasis of the studies presented is the integration of close-range and satellite based remote sensing for enhancing the efficiency of forest monitoring.

Manuscript I discusses thermal canopy photography, a new field of application. This approach takes advantage of the large differences in temperature between sky and non-sky pixels and overcomes the inconsistencies of finding an optimal threshold. For an unambiguously separation of "sky" and "non-sky" pixels, a global threshold of $0{ }^{\circ} \mathrm{C}$ was defined. Currently optical or hemispherical canopy photography is the most widely used method to extract crown-related variables. However, a number of aspects, such as exposure, illumination conditions, and threshold definition present a challenge in optical canopy photography and dramatically influence the result; consequently, a comparison of the results from optical canopy photography at a different point in time derived is not advisable. For forest monitoring, where repeated measurements of the canopy cover on the same plots were undertaken, it is therefore of utmost importance to devise a standard protocol to estimate changes in and compare the canopy covers. This paper offers such a protocol by introducing thermal canopy photography. A feasible and accurate method that examines the strong correlation $\left(\mathrm{R}^{2}=0.96\right)$ of canopy closure values derived from thermal and optical image pairs.

Thermal photography, as a close-range remote sensing technique, also aids data collection and analysis in other contexts, for instance to expand our knowledge about bamboo tree species: Information about the maturity of bamboo culms is of utmost 
importance for managing bamboo stands because only then the process of lignification is finished and the culm is technically stronger and more resistant to insect and fungi attacks. The findings of a study (Manuscript III) conducted in Pereira, Colombia, show small differences in culm surface temperature between culms of different ages for the bamboo species Guadua angustifolia K., which may be a sign of maturity. The surface temperature of 12 culms was measured after sunrise using the thermal camera system FLIR 60Ebx. This study shows an innovative close-range remote sensing technique which may support researchers' determination of the maturity of bamboo culms. This research is in its inception phase and our results are the first of this kind.

In the context of analyzing, in particular of thermal imagery time-series data, Manuscript (IV) offers a new methodology using advanced statistical methods. Otsu Thresholding, an automatic segmentation technique is used in a first processing step. O’Sullivan penalized splines estimated the temperature profile extracted from the canopy leaf temperature. A final comparison of the different profiles is done by constructing simultaneous confidence bands. The result shows an approximately significant difference in canopy leaf temperature. For this study, we successfully cooperated with the Center for Statistics at Göttingen University (Prof. Kneib).

The second close-range remote sensing technology employed in this thesis is terrestrial laser scanning which is used here to enhance our understanding about buttressed trees. Big trees with an irregular non-convex shape are important contributors to aboveground biomass in tropical forests, but an accurate estimation of their biomass is still a challenge and often remains biased. Allometric equations including tree diameter and height as predictors are currently used in tropical forests, but they are often not calibrated for such large and irregular trees where measuring the diameter is quite difficult. Against this background, Manuscript II shows the result of the 3D-analysis of 12 buttressed trees. This study was conducted in the Botanical Garden of Bogor, Indonesia, using a state-of-the-art terrestrial laser scanner. The findings allow for new insights into the irregular geometry of buttressed trees and the methodological approach employed in this paper will help to improve volume and biomass models for this kind of tree. The results suggest a strong relationship $\left(\mathrm{R}^{2}=0.87\right)$ between cross-sectional areas at diameter above buttress (DAB) height and the actual tree basal area measured at $1.3 \mathrm{~m}$ height. The accuracy of field biomass estimates is crucial if the data are used to calibrate models to predict the forest biomass on landscape level using remote sensing imagery. 
The linkage between technology and methodology in the context of forest monitoring remote sensing enhance our knowledge in extracting more reliable information on tree cover estimation. The pre-processing of satellite images plays a crucial role in the processing workflow and particularly the illumination correction has a direct effect on the estimated tree cover. Manuscript IV evaluates four DEMs (Pleiades DSM, SRTM30, SRTM V4.1 and SRTM-X) that are available for the area of Shitai County (Anhui Province, Southeast China) for the purpose of an optimized illumination correction and tree cover estimation from optical RapidEye satellite images. The findings presented in this study suggest that the change in tree cover is contingent on the respective digital elevation models used for pre-processing the data. Imagery corrected with the freely available SRTM30 DEM with $30 \mathrm{~m}$ resolution leads to a higher accuracy in the estimation of tree cover based on the high-resolution and cost intensive Pleaides DEM.

These manuscripts eventually seek to resolve some of the issues and provide answers to some of the detailed questions that still persist at different steps of the forest monitoring process. In future, these new and innovate methods and technologies will maybe integrate into forest monitoring programs. 



\section{Introduction}

Around $30 \%$ of the Earth's land area, an area of approximately 4 billion hectares (FAO, 2010), is covered by different types of forest. Forests have a high relevance for society (FAO, 2014) because of their manifold ecological, environmental, and economic functions. They serve as a source of wood, an important renewable raw material for paper that is used for many production processes like lumber and fuel wood. Furthermore, forests clean the air, produce freshwater from mountain watersheds, and provide a habitat for the largest terrestrial biodiversity (FAO, 2014). Additionally, around 1.6 billion people who mainly live in rural areas directly rely on forest resources for their livelihoods. The forest and tree resources enhance food security, generate revenue and offer natural medicine. In 2006, the FAO published a guide with the memorable title "Better forests, less poverty" on how forest interventions can also help to reduce poverty (FAO, 2006). In general, forest as a renewable resource is extremely complex. To protect the forests in a way that maintains their productivity, biodiversity, and regeneration capacity balanced now and in the future, sustainable forest management is crucial to protect the long-term values of the forest. This means that the various production functions of forests are utilized in a way that does not compromise their future functioning.

In order to properly plan and control any aspect of sustainability in forest management both for forest management planning itself and also for the formulation of forest policies data and information about the forest as a resource and as an ecosystem are required. Forest monitoring is the discipline that deals with the efficient provision of such data, where "efficient” means essentially: timely, focused, at reasonable cost, and with suitable precision. As forests are complex, a great number of variables are collected to observe forests and their changes. Variables like growing stock, biomass stock, forest area, and mean annual increment are among the most frequently reported variables, many more are recorded during forest inventory projects. While forest management inventories with the goal of supporting forest management decisions in forest enterprises cover usually between 10 and 20 variables, national forest inventories can comprise up to 250 variables. This huge collection of data gives information about a wide variety of aspects of the forest as a resource and ecosystem. All variables necessitate specific approaches that allow an efficient assessment of the data with regard to accuracy, costs, and required time and manpower.

There are two major sources for original data when observations on a wide range of forest ecosystem and forest resource variables are to be made: field observations and remotely sensed data. Field data collection requires time, manpower, and, depending on 
the degree of development of the forest tracks, it can become cost-intensive. Furthermore, it is not possible to perform a full survey (census) over large geographic areas. Therefore, surveys were conducted through sample-based methods. However, field observations allow the assessment of accurate ground-truth data and estimations of the current status of the forest. The development of new methods and the use of new devices to reduce costs and / or to increase the accuracy of measurements or the precision of estimations is therefore one field of research in forest monitoring. Other research domains regarding field observations refer to the integration of new variables and indicators, the optimization of sampling- and plot design, and the improvement of modelling approaches to variables for which direct measurements are not possible.

Another source of original data is remote sensing. Remote sensing offers the possibility of large area monitoring for core variables like forest cover by producing wallto-wall maps (cf. also Chapter 1.4). Major characteristics of remote sensing data are its spatial, spectral, radiometric, and temporal resolutions. When investigating the potential usage of new or improved satellite sensors to enhance the estimation of e.g. biomass, forestry attributes collected in the field are required to produce wall-to-wall maps of biomass. Multi-source forest inventories take an advantage of the combination of remote sensing data with simultaneously collected sample-based field observations. For this reason, the majority of forest monitoring programs employs such an integrated approach, e.g. for a country-wide model-based biomass or carbon stock prediction. Currently, this approach is applied on different geographical levels of forest inventories: local, national, and global. One example for the latter is the pantropical carbon map by Saatchi et al. (2011). Although such global maps of biomass or carbon estimation are well established, there is still uncertainty in the spatial distribution (Mitchard et al., 2013). Furthermore, they tend to raise critical questions when it comes to the realization of forest monitoring, for instance when trees with irregular shapes need to be measured, when the age of bamboo culms needs to be estimated or when the effects of digital elevation models (DEMs) on tree cover estimates need to be assessed. Accordingly, this thesis will concentrate on such questions and offer new and innovative approaches that integrate remote sensing techniques into forest monitoring. 


\subsection{Overview of the Manuscripts}

This cumulative thesis intends to contribute to the further development of forest monitoring sciences and applications by addressing a number of relevant and specific scientific and technical questions in the context of new methods and techniques. Field observations in forest monitoring include close-range remote sensing techniques: the use of thermal camera systems and the application of terrestrial laser scanning. These techniques are implemented in both plot design and data collection and provide new and alternative ways of analyzing and modelling data (Figure 1). The remote sensing forest monitoring process employs high-resolution satellite imagery in two essential steps, namely for the pre-processing of images and their classification (Figure 1). The studies were undertaken in different study sites in Germany, Indonesia and Colombia, and are presented here as five paper manuscripts.

Forest Monitoring Process

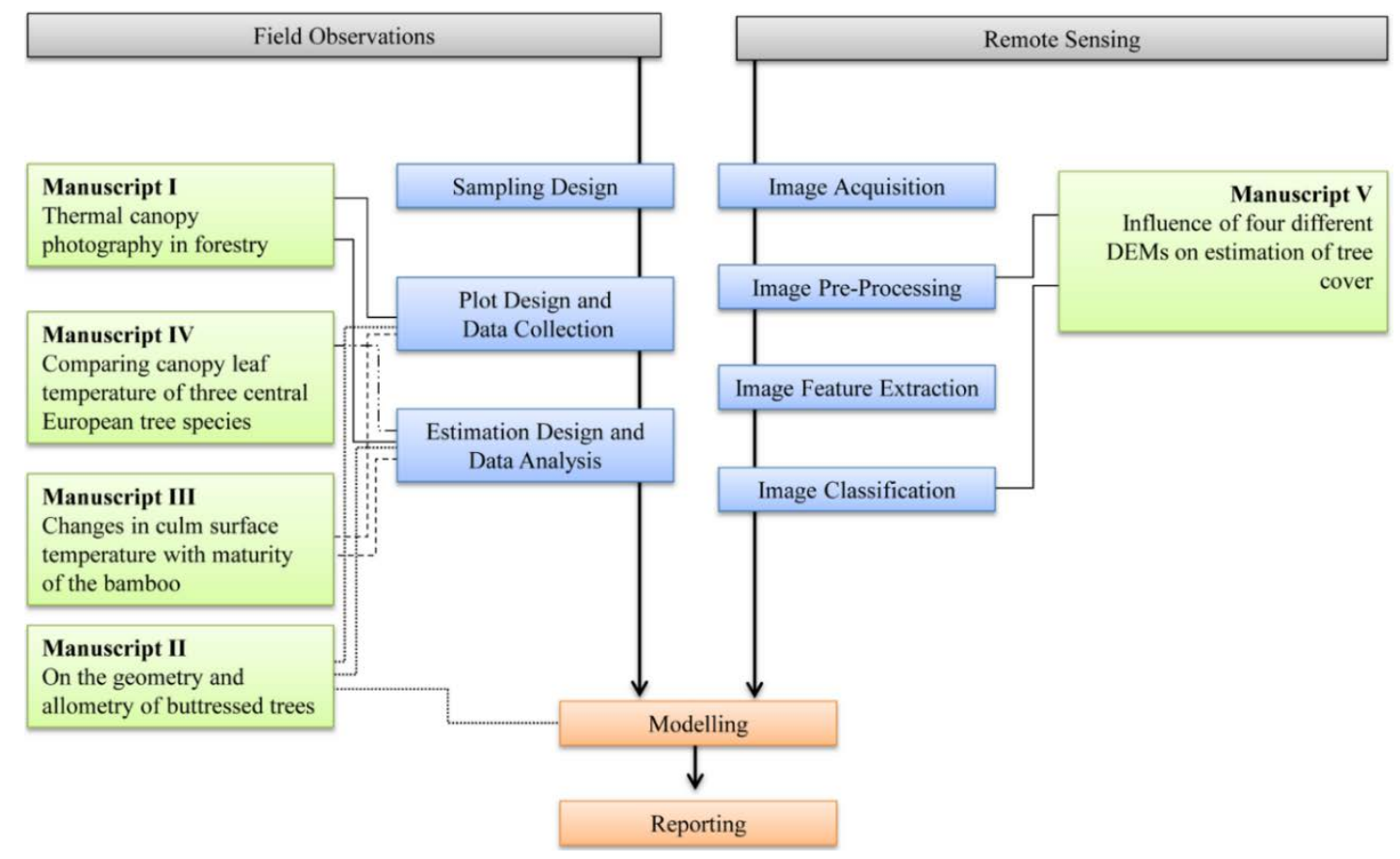

Figure 1. Integration of research topics of the five manuscripts into a general flow of the forest monitoring process

Manuscript I describes the application of thermal imagery for the estimation of canopy cover by means of hemispherical photography independent of the common confounding factors "exposure," "threshold settings," and "time of the day," which are sources of variability in optical hemispherical canopy photography. This is an absolutely novel approach that has not been described before and that is promising, because it is simple to use and overcomes a number of practical problems. This study has a purely 
methodological character; data collection was undertaken in the Forest Botanical Garden of the Faculty of Forest Sciences and Forest Ecology of Georg-August-Universität Göttingen.

Manuscript IV shows the application of complex statistical approaches for extracting canopy surface temperature from a large set of thermal images, taken with a thermal camera mounted on a climate tower. The analysis of a potential relationship between the different tree species and their canopy surface temperature was based on the simultaneous construction of confidence bands. This data set and study stems from the broadleaved forests in Hainich National Park in Central Germany and was conducted in cooperation with the Center for Statistics at the Georg-August-Universität Göttingen (Prof. Kneib).

Terrestrial laser scanning, already a well-established method of extracting tree data and structural attributes of forest stands, is applied here to study the geometry of very irregularly shaped buttressed trees that cannot be simply tape measured for $d b h$ (Manuscript II). Based on the TLS-generated high-resolution point cloud, a 3D reconstruction of the buttressed part was done that allows for a realistic and accurate estimation of the volume, thus preparing the grounds for deriving operational allometric models for individual tree volume and biomass. Such information is urgently needed, because it is known that particularly in tropical moist forests these large trees, though very small in number, do considerably contribute to the total biomass. Field measurements for this study were done in Bogor Botanical Garden in Bogor, Indonesia.

When managing bamboo-dominated forests, determining the culm age of bamboo presents a challenge. The age of the bamboo culms is a decisive factor for their successful management because there is only a relatively small time-window in which bamboo culms can be harvested without compromising the quality of the wood. Only experienced bamboo managers, however, know how to estimate the maturity of the culms along surface characteristics of the culms, such as color and patterns of lichens. As of yet, clear, observable, and objective variables that indicate culm age or maturity have not been identified. Manuscript III hence introduces an innovative and promising method to determine the maturity of guadua bamboo (Guadua angustifolia. Kunth) by taking into account the relationship between culm surface temperature and age. This is the first study ever that looks into culm surface temperature as a potential indicator for bamboo culm maturity. This study was implemented near Pereira in the coffee region of Colombia in 
collaboration with UTP, the partner faculty to the Faculty of Forest Science of the GeorgAugust-Universität Göttingen.

Monitoring changes in forest cover at landscape level with the help of satellite remote sensing requires a well-performed pre-processing of the satellite images. A critical step is the topographic correction which is required to eliminate the influence of shadows and varying illumination. Topographic correction requires a digital elevation model (DEM) from which the illumination can be modeled once the sun angle at the image taking time is known. The aim of this pre-processing step is to reduce differences in ground reflectance that do not derive from different land use classes but merely from differences in the illumination conditions. These differences affect the quality of the interpretation and classification, as well as their correction. Manuscript V focuses on this issue by using a set of different DEMs for topographic correction and eventually analyzes how the vertical resolution of the DEM affects the classification of "forest". This study was carried out in a mountainous forested area in Anhui Province, China in collaboration with the Shitai Forest Bureau within project Lin4Carbon

\subsection{A Brief History of Forest Monitoring}

The term 'inventory' commonly describes measurements at a given point in time. The history of forest inventory dates back to the 14th and 15th century (Kleinn, 2015) when the first, at this time non-statistical forest surveys, were conducted in Europe. Only in the late 18th century a systematic collection of forest information was begun. Before that, at the beginning of 18th century, mining activities put strong pressure on adjacent forests and wood shortage was an imminent threat. There was an urgent need for securing the resources of the forest. The mining engineer Hans Carl von Carlowitz (1713) wrote that people should save wood, conserve forests by sowing and planting trees, and seek "surrogata" or alternatives to wood (Gelpke, 2015). Indeed, his work is considered to be one of the first treatises on sustainable forest management in Germany. Moreover, it was the beginning of the development of a forestry based on scientific principles.

Sustainability in its current meaning is based on following three pillars: environmental, economic, and social. Variables, such as the extent of forest area, which are assessed in current forest monitoring programs and describe the changes in forest cover, are important for a sustainable forest management. At the beginning of the 19th century foresters performed ocular estimates of volume and stocking in small areas (Pfeil, 1858). In the following years forest mensuration devices were developed and improved 
to measure simple parameters like diameter or height. One of the first known references of a patent describing an instrument called dendrometer that explains how to measure tree height was mentioned in the late 18th century by Whittell and Ducombe (1786). Progress in measurement techniques then allowed for the discovery of relationships between diameter, height, and volume. Around 1840, the first large area inventory in Sweden was established using linear strip surveys (Schreuder et al., 1993).

Around 1900, statistical sampling was developed and applied in inventories. Since the 1920s national forest inventories (NFIs) have been carried out in the Nordic countries. Since then NFIs have been conducted regularly in an interval of 10 years. In 1948, three years after its founding, the FAO provided the first information about the world's forest resources based on questionnaires which were sent to individual countries. This repeated data collection on the status of the forest was the beginning of what was at that time called 'long-term observations.' In the 1970s, the definition of the term 'monitoring' was extended and applied to forest monitoring. Thus the term 'forest monitoring' has been in use for at least 40 years and is generally understood as the repeated observation of a defined forest entity over time as the basis for decision making. A current definition by Lovett et al. (2007) defines forest monitoring as “a time series of measurements of physical/chemical/biological variables designed to answer questions about environmental change.”

Before satellite imagery became a forest monitoring data source, aerial photographs have been used, mostly for visual interpretation. Further, aerial images were used for double sampling (Bickford, 1952). With the rapid technological development driven by advancements in camera systems, computer technology, and improved algorithms in image analysis and with the availability of Landsat in 1972, the usage of remote sensing technologies has gained an important role in national forest monitoring systems. Since the late 1980s Finland has conducted a satellite image based multi-source NFI using Landsat TM and SPOT data (Tomppo et al., 2008). Currently, a variety of sensors are available which can be mounted on an aircraft, e.g. hyperspectral, thermal, or LIDAR sensors.

Moreover, with the availability of the satellites NOAA-AVHRR and MODIS, remote sensing forest monitoring was extended to the detection of forest fires or monitoring thermal anomalies of the forest (Jimenez-Munoz, 2015). Over time, remote sensing has therefore become increasingly significant for monitoring the forests on various geographic levels, and particularly for acquiring data about volume, biomass, carbon, and their respective trends. Besides the recent development of satellite sensors, 
both terrestrial and airborne laser scanning continue to improve the estimation of forest inventories attributes.

\subsection{The Current Importance of Forest Monitoring}

As part of the ecosystems worldwide, forests are of high importance. On the one hand, they are vital habitats for a plethora of plant and tree species; on the other hand, they also have an essential economic, environmental, and social meaning (FAO, 2014). Therefore, a wide range of information is needed for forest management or reporting that touches on diverse categories, such as conservation, jurisdiction, production processes, e.g. timber stocks, or, on a more abstract level, on issues such as structural or habitat diversity and biodiversity. Moreover, monitoring is indispensable for preservation and future planning, as these are based on data about the current status and the changes of the forest. Quantifying forest cover change, improving climate change modeling, and using forest resources to their best capacity thus warrants forest monitoring and the establishment of national forest inventories (NFIs). The FAO (2015) writes in their current FRA report: "Forest monitoring is the foundation of forest management and investment in forests and forestry by governments, private companies, international donors and civil society.”

For instance, when trends in forest cover resulting from deforestation, afforestation, and the natural expansion of forests or forest carbon stock changes are examined, forest monitoring is of great significance, because it generates the required information. As an essential tool for an improved decision-making, it contributes to the preservation of the global forests and their ecosystem services. NFIs should then also provide answers to questions pertaining to the resources, their respective locations and owners, as well as their usage. Consequently, an increasing amount of forest data are collected during forest inventories on permanent but also on temporary plots and through remote sensing time series analyses. Yet with these traditional data not all questions, in particular for policy decisions, can be answered. For this reason, the FAO has established the NFMA program, an alternative approach with the purpose of generating cost-effective information on forests and trees outside forests that includes all their benefits and uses (FAO, 2008); thus the NFMA program supports the national forest policy.

The current rise in the implementation of national forest monitoring systems (NFMS) on international level is politically motivated and mainly driven by international agreements for which such information plays a key role for reporting and fulfilling the requirements of the United Nations Framework Convention on Climate Change (UNFCCC) or the Convention on Biological Biodiversity (CBD). Additionally, NFMS are one of mandatory requirements for the implementation of REDD+. REDD+ is a climate change mitigation program that is developed 
and supported by initiatives such as The United Nations Collaborative Program on Reducing Emissions from Deforestation and Forest Degradation (UN-REDD) (United Nations, 2014; Herold et al., 2011). The main purpose of REDD+ are results-based payments for reducing emissions from forest degradation and deforestation through different forest management options.

Apart from this international interest, there is still a national incentive that warrants a multi-purpose forest monitoring including the documentation of the contributions of the forest owners to a sustainable forest management; these data then contribute to an enhanced understanding of the activities driving deforestation. In developing countries, however, there often is an information gap due the given structural and administrative contexts or a lack of previous inventories. In order to fill this information gap and establish national forest inventories or forest management inventories, the respective information need is assessed by means of questionnaires, where target variables and their expected accuracies are identified. Such information allows researchers to develop specific guidelines for national forest monitoring. With future development and changing information needs, these lists can then be extended or modified to meet the new requirements, like the addition of socio-economic data which provide valuable information about how rural and urban population growth or other socio-economic issues are linked to forest change. Therefore, forest monitoring programs may go beyond the biophysical forest variables and integrate data on e.g. rural social conditions to enhance the understanding of the socio-economic benefits of forests (De Sy, 2012). For 15 years, this has been encouraged by the NFMA program where the information generated is based on wide set of variables from biophysical to socioeconomic aspects.

The relevance of forest monitoring can be seen from different perspectives: national governments, companies, and NGOs. The fact that the UN has assigned a high priority to forest on their global agenda underlines their importance from an international perspective. Finally, data from forest monitoring should reach the same importance like for example census data and researchers should, as stated in the Voluntary Guidelines on National Forest Monitoring (FAO, 2013), “look at forest monitoring as a normal data provision requirement for good 'environmental governance.” 


\subsection{Challenges}

In a national forest monitoring system one of the most important data sources for the estimation of forest biomass are sample-based observations in the field. Biomass per tree, however, cannot be directly measured. Tree height and diameter lend themselves as auxiliary variables for biomass. These data, collected during the forest inventory, allow researchers to estimate forest tree stem volume. To estimate the total forest biomass from the volume, a simple method may be employed that uses biomass expansion and conversion factors (BEF), but these factors should be handled with care. The problem associated with this approach is that there are differently defined BEF values which may result in an underestimation of biomass, as was the case in Ireland (Tobin, 2007). Winjum et al. (1998) showed that a $10 \%$ change in BEF, causes a change in the estimated total emission of a country by $7 \%$. Therefore, locally derived biomass equations which may compensate the local environmental conditions are utterly necessary.

Another way of predicting AGB are allometric models. The list of equations includes thousands of models worldwide, many of them unpublished or in gray literature and at times difficult to locate. Furthermore, information about the quality and application range of a specific allometric equation is often found lacking. The use of these models in particular, but even more generalized models may lead to biased results when they are applied for the estimation of AGB for a specific species (Chave, 2004). Hence the FAO has developed the first international web-based platform “GlobAllomeTree,” a source of tree allometric equations, with the aim of compiling a consistent and harmonized database of models along with information related to development of the respective tree allometric equation. For tree species in temperate broadleaf and mixed forests, such as in Europe, well investigated allometric equations are available for the most common species. Yet in tropical forests, where a great variety of tree species exists, more research and development are needed to make the available allometric equations more reliable and establish new ones. Particularly areas of tropical rainforests, where a small number of very large and buttressed trees contribute considerably to the basal area and forest biomass, a more precise method of estimation and an enhanced understanding of the contribution of large trees is necessary and improves the accuracy of ground-based carbon stock estimation. Particularly if regionalizing methods are applied to produce more accurate wall-to-wall maps, improved field data accuracy is crucial. When large-area satellite imagery is used, these large trees often remain undiscovered; consequently, the carbon stocks are underestimated. Airborne LiDAR techniques, however, cover these big 
trees more adequately. Therefore, a combination of LiDAR and high-resolution satellite imagery reduces uncertainty in carbon emissions (Asner, 2010).

Within the context of UN-REDD, MRV - short for Measurement, Reporting, and Verification - has gradually been established and describes all measures a country performs when collecting data on emissions, mitigation actions, and support. Therefore, the MRV system for REDD+ is an important tool for the successful implementation of climate change mitigation strategies as well as for the evaluation of climate change actions. Developing countries depend on the data generated as they enable them to demonstrate reductions in forest degradation and, consequently, make them eligible for results-based payments from developed countries. The MRV of carbon emission for REDD+ requires both activity data and emission factors. Activity data document changes in land use and forestry, which is normally done by means of remote sensing data. The emission factor describes the estimates of the carbon stock changes related to land cover change (Luttrell, 2011). The calculation of this factor is based on local data sources, such as forest inventories and allometric equations. As part of international agreements on climate change, MRV can be seen as a key to reporting and delivering information in a standardized, well-explained, and documented form. The MRV of forest carbon pools is expected to generate accurate and precise estimates, track changes in carbon stocks, and verify emissions reduction efforts. The accurate calculation of these factors and their adjustment to each country requires a focus on the questions of how this information may be gathered.

In bamboo forests, as one exemplary forest type, the estimation of the above-ground carbon (AGC) is quite challenging and prone to uncertainty. This is problematic, since accurate information about carbon stock and carbon stock changes are important for developing countries’ emission factors. Huy (2009) proposes an allometric equation which requires the age of the bamboo culm as an input variable. Estimating the age of bamboo culms during a national forest inventory, though, still presents researchers with a great challenge and there is still uncertainty about the actual age of the culms.

A final important aspect in REDD+ and indeed in any other forest monitoring program is the definition of 'forest' because this bears directly on the forested area. Waggoner (2009) criticizes the inaccuracy of the FAO reports that stems from errors in the estimated forest cover which are based on changing definitions of 'forest.' Currently, the widely-used forest definition of the FAO rests on three main criteria: a minimum area, 
a height threshold of $5 \mathrm{~m}$ of the trees in situ, and minimum of $10 \%$ canopy cover. Apart from this, the definition of forest includes qualitative criteria about its main use. In light of the forest change processes, which play a crucial role in forest policy, notions like deforestation, forest degradation or afforestation are mainly defined by the $10 \%$ canopy cover threshold mentioned above.

Therefore, the accurate estimation of forest canopy cover - also referred to as tree canopy cover or tree cover - is essential. All three terms describe the vertical projection of the crown extent upon the ground expressed either in percent or $\mathrm{m}^{2} / \mathrm{ha}$. Tree canopy cover may be assessed using two different approaches: a field-based approach and an image-based approach. The first is based on a sampling scheme on which ground data are collected. One of the most common techniques for the field-based approach is hemispherical photography, a close-range remote sensing technique using a digital camera equipped with a fisheye lens. When this technique is employed, researchers still face challenges in estimating canopy cover due to varying thresholding methods and exposure settings. The latter approach comprises looking down from above and integrates satellite imagery. On the one hand, this approach fails to reliably detect a canopy openness smaller than pixel resolution, but on the other hand, it does have the advantage of an estimation of forest cover on landscape level. This approach is termed "wall-to-wall" mapping. Another way of precisely assessing tree canopy covers or canopy openness is presented by airborne lidar data, where information can be extracted from a canopy height model. However, these data come with added costs, so that the REDD program rather utilizes medium-resolution Landsat imagery which has been free-of-charge since 2008 to monitor forest degradation and estimate tree cover over large areas. Nevertheless, monitoring small-scale changes in forest cover (e.g. selective logging) requires a spatial resolution below $1 \mathrm{~m}$, like the one provided by WorldView or Pleaides. Both have a resolution high enough to identify homogenous and small groups of trees so that these pixels may be grouped into an image object and can then be classified for each point in time. 



\section{Objectives and Research Questions}

Forest monitoring is complex, since, indeed, the forest itself is complex - characterized by a multitude of different variables in different landscape settings and management situations - and the measurement and assessment techniques are equally demanding, both methodologically and technologically. While there are many publications on global forest resources and estimations of forest biomass of all kinds, a plethora of detailed questions yet remain to be solved in order to reduce the impact of the sources of residual variability and to improve the precision of estimates. Of course, also aspects of operationally, cost and capacity building are urgent matters, as is the translation of the usually technically demanding forest monitoring results into meaningful information and, eventually, into suggestions for the stakeholders and decision makers.

This thesis focuses on detailed technical questions at various points in the implementation of forest monitoring systems and, on the basis of this, the overall objective is to develop and test novel remote sensing approaches which help to improve forest monitoring systems. State-of-the-art instruments like terrestrial laser scanners (TLS), thermal cameras, and high-resolution space-borne cameras offer new perspectives on estimating forest-related variables from integrated field and remote sensing campaigns.

One focus of this thesis is on temperature data from both close-range and remote sensing, which may serve as indicator variables for composite variables, such as forest health and vitality. In the context of remote sensing based forest monitoring, there are two research questions that are addressed in this thesis and that contribute to both field and remote sensing based forest monitoring:

- To what extent can the use of thermal camera systems and terrestrial laser scanning in field surveys enhance forest monitoring?

- How does the spatial resolution of digital elevation models affect land cover classification in mountainous landscapes?

To explore these research questions, a number of studies in three countries were conducted. 



\section{Data Sources}

\subsection{Field Observations in Forest Monitoring}

Field observations are an important data source to assess, detect, and enhance the understanding of forest resources, ecosystems, and their changes. According to FAO (2014), the coverage of national forest inventories (NFI) varies across different sub-regions: $77 \%$ of the world's forest area are covered by high levels of NFI. This sub-region includes for example: Europe, South to North America, South and East Asia. Furthermore, 4 \% of the world's forest are located in subregions with lower (40-79 \%) NFI coverage (e.g. Caribbean, North Africa). West and Central Africa have a NFI coverage of only $10 \%$ of their sub-regional forest area which corresponds to $0.8 \%$ of the global inventories forest area. The data collected within NFIs are used for timely and accurate estimations on the current status of forest attributes, such as volume, biomass, carbon stock or basal area. Field measurements are commonly implemented as sample-based observations. On defined sample plots, a multitude of variables on individual trees, topography, management, and environment are recorded. The resulting estimations depend on the chosen sampling and plot design and for this reason the planning phase, which should be in line with the goal of the inventory, is fundamental.

First of all, the sampling design that describes the number and selection (or the spatial distribution) of the sampling elements needs to defined. In large area forest inventories the most common sampling design is the systematic sampling. After the sample point has been selected, the defined plot design is applied, i.e. the question of how to include the trees around the sample point is resolved. The inclusion of sample trees around a sample point can based on fixed area plots or on distance-based plots. For the analysis, and therefore for the estimation, knowledge of the principles of statistical sampling is required. This allows for a proper interpretation of the data.

While most of the developed countries have NFIs based on statistical sampling, in developing countries the situation is different, but there is an ascertainable change. In 2001, only 22 from a total of 137 developing countries conducted repeated inventories, whereas 54 relied on a single inventory, 33 had a partial forest inventory, and 28 countries did not have inventories at all (FAO, 2001). Within the framework of REDD+, the implementation of national forest inventories (NFIs) for developing countries hence continues to constitute an important task and pushed by the FAO. Due to their activities, a positive change is now detectable: as of yet, 112 countries have a forest inventory that covers $81 \%$ of the global forest area. $96 \%$ of the NFI are based on ground plots and $70 \%$ integrate aerial and satellite imagery (FRA, 2015). As mentioned above (cf. Chapter 
1.3), establishing national forest monitoring systems is vital for these countries, as they generate the data required to participate in REDD+.

To reduce the cost of an NFI, and the field measurements in particular, developing countries integrate close time series of freely available Landsat images or high-resolution satellite images, such as RapidEye. These satellite data are a useful adjunct to their national forest monitoring programs and help to retrieve data at landscape level e.g. for reporting the forest cover extent or tracking forest cover changes. In Guyana, for instance, RapidEye imagery is used to estimate areas of forest degradation (Bholanath and Cort, 2015). Not only is satellite imagery used to overcome time gaps but also to perform a forest pre-stratification or large-area predictions. For such predictions, the integration of remote sensing data requires accurate plot positions and plot sizes already while planning the field measurements. Plot center deviations within a range of $5 \mathrm{~m}$ occur when determining the position using a standard GPS device, especially under a closed canopy, where the GPS signal is weak. Such variations are in the magnitude of the pixel size of e.g. RapidEye. There is a high risk that the data measured on the ground will be coregistered with the neighboring pixel value and thus have a deviating pixel value, to name an example for a common challenge in forest monitoring which, for reasons of scope, is not addressed in this thesis, but it is an important aspect when field data is linked to remote sensing data. 


\subsection{Remote Sensing for Forest Monitoring}

Remote sensing can be defined as "the acquisition and recording of information about an object without being in direct contact with that object” (Gibson, 2000). Due to rapid technological developments, there are various sensors with different spatial and spectral characteristics available, each with a specific application. Aside from field observations, remote sensing is another crucial data source for forest monitoring, most importantly in developing countries, where data gaps on forest monitoring data as well as capacity gaps often exist (Romijn et al., 2012; cf. Chapter 1.3). More than that, there are further reasons for integrating remote sensing data into NFIs: Firstly, these data complement the information offered by maps and, secondly, they help to increase the economic efficiency of the sampling design (Li et al., 2008). For instance, before the sampling study is carried out, remote sensing data can be used for pre-stratification. The integration of remote sensing includes decisions on where, how and which sensors should be used. Eventually, this depends on the specific aims of the respective forest monitoring. The NFI system of Germany for example based solely on terrestrial methods, but there are studies which proofed the integration of remote sensing into the German NFI (Oehmichen, 2006). In tropical forests in particular, deforestation has grown to an issue of great concern and in recent years, the rate of deforestation has increased due to illegal logging. Therefore, a highly flexible and cost-effective form of monitoring is necessary to not only estimate the deforestation rate in large or inaccessible areas but to also observe its impacts and predict above-ground biomass at the landscape level. Prediction requires remotely-sensed imagery that provides auxiliary data which can then be used as input for modelling the spatial distribution of biomass, basal area or forest structure (cf. Chapter $4)$.

Above all, optical satellite images, airborne and terrestrial LiDAR, or aerial imagery have the potential to explore land-use change, disturbance processes and forest dynamics on large spatial scales. Of course, remote sensing will not replace field observations; instead, it should rather be understood as enhancing field surveys. The different remote sensing systems, which can be divided into active and passive sensors, will be introduced in the following chapters. 


\subsubsection{Airborne and Terrestrial LiDAR}

Airborne LiDAR or airborne laser scanning (ALS) has undergone a rapid development towards commercial use and is now a well-established method for forestry applications. With the integration of GPS and the inertial navigation system (INS) in the 1990s accurate positioning has become possible and studies have found relevant relationships between field-measured and ALSbased height metrics (Naesset 1997, Magnussen and Boudewyn 1998). The general usefulness of ALS for forest management was confirmed in studies by Naesset (2004) and Wulder et al. (2008).

In its initial development phase in the 1970s, LiDAR technology was advanced by NASA. At that time, LiDAR constituted a revolutionary technology and offered a new way of collecting data. Its underlying principle is based on the two equations given below. The round trip time of travel, $t_{L}$, for a LiDAR pulse is defined as:

$$
t_{L}=2 \frac{R}{c}
$$

where $R$ is the range and $c$ is the speed of light (approximately $3 \times 10^{8} \mathrm{~m} \mathrm{~s}^{-1}$ ). The distance between the LiDAR sensor and the object can be calculated using the following equation:

$$
R=\frac{1}{2} c t_{L}
$$

The first study to measure trees by comparing the laser profiles of felled trees with tape measurements was conducted by Solodukin et al. (1976). In the 1980s, LiDAR profile data were used to characterize vertical forest canopy, to estimate heights, and to distinguish coniferous and deciduous trees (Aldred and Bonner, 1985, Nelson et al,. 1984, Schreier et al., 1985). The majority of studies used ALS instruments that were smallfootprint and discrete-return systems capable of producing a maximum of five recorded echoes. The footprint describes the effective area that the laser light encompasses. With the availability of full-waveform laser scanner systems capable of recording the entire sequence of the returned energy as a function of height, studies began to focus more on the differentiation between tree species. The main advantage of this system is that during post-processing the $x, y$, and $z$ coordinates of each recorded echo, as well as additional variables like amplitude, pulse width, intensity, and number of total detectable targets information highly relevant for species detection - are extracted from the entire echo waveform. Orka et al. (2009), for instance, used the intensity value to classify deciduous and coniferous trees with an accuracy of $73 \%$. A relationship between pulse width and 
tree species was first shown by Reitberger et al. (2008), whose study proved differences between three tree species. Heinzel et al. (2011) developed an improved algorithm to isolate the most important variables from full-waveform data to distinguish up to six species with an overall accuracy of $57 \%$. Such accuracy shows the limits of ALS for tree species classification in a European forest, where a greater variety of species is often to be found. Besides this, the Canadian Wood Fibre Centre (CWFC) used aerial LiDAR as part of their forest inventory to map and identify wood fiber properties.

While ALS may cover larger areas from above using an airborne platform, terrestrial laser scanning (TLS) or terrestrial LiDAR is a lightweight and, consequently, a portable, ground-based system with a quite limited range that uses the same physical principles as ALS. The point density of TLS is much higher compared to ALS, but its spatial coverage is limited. When generating a full 3D point cloud of inventory plots, TLS scans are obtained from different positions. This method is called multiple scanning and was applied in Manuscript II. The point clouds permit the estimation of the volume of single trees. Volume calculation depends first of all on the 3D reconstruction of the geometry of a tree from the point cloud, which is quite complex and requires advanced programming skills. The quantitative structure models (QSMs) by Raumonen et al. (2013) present a promising method for this task. In the course of the young history (approx. 10 years) of terrestrial laser scanning, a rapid development in terms of usability, measurement speed, accuracy and algorithms has taken place. An early study by Simonse et al. (2003) used a Hough transformation, a feature extraction technique, to isolate features of a particular shape, detect trees in the point cloud, and determine their diameter at breast height (DBH). Aschoff and Spiecker (2004) built on the Hough transformation followed by an advanced approximation, which fits the points to an ellipse. With this approach, diameters at different heights could be extracted. Kankare et al. (2012) estimated single-tree-level aboveground biomass based on features extracted from TLS, such as stem form and canopy dimensions.

In the context of forest monitoring LiDAR, ALS as well as TLS, can thus serve as an excellent and accurate tool to assess vertical and horizontal forest structures, tree specific attributes, and tree geometry. Nevertheless, despite the advantage of this technology, there are factors that still limit the usage on the national level, particularly in developing countries. The main factors are the high costs, the large dataset and the 
expertise required for analyzing the data. Therefore, LiDAR is often limited to a localized coverage only.

\subsubsection{Aerial Imagery}

Aerial photographs taken with analog cameras were extensively used for forest management issues. The image facilitated measurements of trees and stand characteristics and hence allowed researchers to distinguish different types of forests. Additionally, the different colors of the crowns may aid the identification of tree species or of tree vitality. Myers (1982) elucidated that a color-based identification also works in complex forests, such as tropical rainforests. Nevertheless, the identification is limited due to the ability of our eyes distinguish between color tones. Besides this more general aspect, the visual identification of tropical tree species requires high-level experts and knowledge about the habitats.

Nowadays, high-resolution aerial images covering different parts of the spectra play a key role for monitoring and forest management in general. Because of the rapid development in digital imagery, state-of-the-art full-frame cameras equipped on different types of aircrafts (helicopters, ultralights, fixed wing aircrafts, and unmanned aerial vehicles) produce images with a resolution of up to $1 \mathrm{~cm}$, depending on the flight altitude above ground. This technological advance is essential in the study of forests, not only when it comes to researching individual trees, but also when studying leaves. Studying the latter enables researchers to monitor e.g. forest health and changes in the crown characteristics, like deformation or density. In order to extract such data from aerial image, on the one hand, skilled and experienced photo interpreters are still indispensable, as the human eye is more apt at detecting objects than a computer. Moreover, these interpreters need knowledge of the different tree species and forest types which can occur in the study area. On the other hand, because of the large datasets new algorithms for processing need to be developed.

Over the past years, stereo-photogrammetric processing from aerial stereo image pairs is becoming increasingly popular again and is now being used to extract digital elevation models and generate point clouds. In particular, the latter may serve as a costeffective alternative to ALS point clouds. Currently, with the availability of unmanned aerial vehicles (UAV), another inexpensive way to produce high-density point clouds generated from multiple aerial images covering the same object has arisen. This requires an advanced multi-view stereo matching that results in a 3D reconstruction of the surface. Such algorithms are implemented in user-friendly software, e.g. Pix4D or Agisoft Photoscan. Both software solutions offer researchers a fairly uncomplicated extraction of 
point clouds; the analysis and further processing, however, still requires experience and expert knowledge. The resulting point clouds can be used in the same way as data generated from airborne laser scanners. Digital surface models (DSM) and digital elevation models (DEM) derived from processed aerial stereo image pairs can be utilized in forest research and management, e.g. for single tree detection, as well as the extraction of tree height and crown circumferences. All in all, meaningful variables in combination with allometric models for the estimation of volume or biomass can be derived from aerial photographs, which makes this a very important technology in forest monitoring.

\subsubsection{Satellite Imagery}

Most of the satellite-based sensor systems like Landsat, MODIS, RapidEye, QuickBird or Pleiades use so-called passive sensors, which means that the sun is the source of electromagnetic radiation that interacts with the surface. The amount of energy reflected by an object or an area is then measured by the sensor. Most of these systems work in the visible, near or mid-infrared spectrum.

The launch of the first Landsat satellite in 1972 also constituted the beginning of satellite remote sensing in forests (DeFries, 2008). When the Advanced Very HighResolution Radiometer (AVHRR/2) satellite became available in June 1981, the first classification of land cover and monitoring of vegetation dynamics in Africa was carried out by Tucker et al. (1985). Townshend et al. (1987) characterized and classified South American land cover types using multitemporal data. In 1994, DeFries and Townshend produced a global land cover map with 1-degree resolution. Since then, a number of studies using remote sensing sensors that operate in different spectral regions in order to monitor global forest area have followed.

Since 2008, the originally German satellite system RapidEye which offers largearea coverage, a frequent revisit interval, and a spatial resolution of $5 \mathrm{~m}$, officially provides REDD+ MRV support on both national and local level. This data source has been used by different countries, among them Mexico, Guyana, Nepal, Costa Rica (BlackBridge, 2014), to detect deforestation and forest degradation. Due to the high resolution, the identification of narrow forest gaps caused by illegal logging is another usage of RapidEye imagery.

Moreover, since 2013, a set of new satellites operating in the visible and nearinfrared spectrum have become available - Pleiades-1A and 1B that acquire images with a very high-resolution (GSD: $50 \mathrm{~cm}$ ). Amongst the application presented in Manuscript 
$\mathrm{V}$, such data allows for the quantification and mapping of forest structure as presented by Beguet et al. (2014) for maritime pine forests in France. Andréoli et al. (2014) used multitemporal Pleiades imagery for the monitoring of mangroves. Even though large areas may be covered, these images are often not available in developing countries due to the high costs associated with their acquisition. Nevertheless, an advantage Pleiades satellites present is their capability to rotate around their axes and cover the target area from different viewing directions for the acquisition of tri-stereo image pairs. As a result, a DSM with a resolution of $1 \mathrm{~m}$ that outlines the surface topography may be produced and, at the same time, hidden terrain, e.g. urban canyons or dense built-up areas, cease to pose problems when researchers attempt to extract accurate heights above ground. Additionally, the use of Pleiades tri-stereo DSM offers the possibility to estimate tree height or growth when multi-temporal data are employed.

Another new series of satellites (the Sentinels) is developed by the European Union's Earth Observation programme including the latest satellite Sentinel-2 which is operational since December 2015. The latter offers high-resolution (GSD: 10 m) multispectral observations using 13 spectral bands in the range between 0.433 to $2.19 \mu \mathrm{m}$. The resolution and a revisit time of 5 days will be an improvement for future forest monitoring programs because it allow a more accurate assessment of forest change at a finer scale (Hojas-Gascon et al. 2015). Furthermore, the main aim of Senteinl-2 is the forest monitoring application, one of the priority services of the Global Monitoring for Environment and Security programme. In future, this satellite may contribute to the Baseline Mapping Service for REDD+ (ESA, 2010). 


\section{Empirical Modeling}

"Empirical model building refers to a mindset that lends itself to constructing practical models useful in describing and coping with real-world situations."

Thompson (1989)

In the context of an NFI, two types of variables may be distinguished: the first type can be directly measured or observed on the field plot, like DBH, upper diameter, tree height, crown width, and crown base height. Variables that belong to the second type, on the other hand, are not directly measurable in the field and are usually modeled, such as biomass, volume, carbon or "forest structure.”

Empirical modeling constitutes a common approach in forestry (Burkhart, 2012). This approach combines statistical techniques (e.g. mixed-effects models, generalizedlinear models, regression models, etc.) and field measurements to calibrate the model in order to predict forest attributes. Such modeling processes are for instance employed in the estimation of biomass. Thus far, the most accurate method is harvesting and weighting the individual trees, but this approach is quite expensive and impractical on a larger scale. Therefore, alternative approaches are required that are also suitable for studies on a larger scale, i.e. allometric models which relate biomass to non-destructive measurements, among them stem diameter and height being the most common ones. For example, one of the most frequently used regression models for aboveground biomass (AGB) is the following generalized allometric equation, a simple power function:

$$
A G B=a D^{b}
$$

where $D$ is the diameter at $1.3 \mathrm{~m}, a$ and $b$ are the estimated model parameters. This equation covers the allometry of a wide range species (Kuyah et al., 2012). The biomass value predicted in this allometric equation is not to be understood as a "measurement," but rather as a "modelbased prediction". Once an allometric model is developed, it offers a cost-effective way for an accurate estimation of biomass. One example of a simple fairly general allometric model is demonstrated in Manuscript II, where a relationship between diameter above buttress and basal area at $1.3 \mathrm{~m}$ of height is established. Principles of this approach can be applied to other species of buttressed trees.

The spatial generalization at the landscape level, called regionalization, of pointwise forest stand attributes, like e.g. above ground biomass or basal area, requires the linkage of field measurements as auxiliary variables, with observations from satellite images, aerial images or metrics derived from LiDAR data at the sample locations as well 
as at all prediction location. Naesset (2002) and Holmgren (2004) showed that ALS data can be used as an accurate predictor of basal area and height. This modeled spatial distribution of basal area and height is crucial, particularly with regard to the question of spatial biomass distribution. First of all, researchers need to identify suitable variables which can be extracted from the images and show a correlation with the target variable, e.g. biomass. Secondly, a decision regarding the regression technique used for modeling needs to be made. A fairly simple relationship, for example, can be expressed in the following statistical formula:

$$
y=\beta_{0}+\beta_{1} P V
$$

where $y$ is the forest attribute e.g. the biomass, $\beta_{0}$ and $\beta_{1}$ are the parametric coefficients to be estimated and $P V$ is the pixel value of one single band from the raster image. In addition to the original bands from the raster image, new variables are calculated through image transformation algorithms (e.g. principal component analysis or tasseled cap), texture measurements or vegetation indices (Lu, 2006). For example, when LiDAR (cf. Chapter 3.2.1) is used as an input data source, the original point cloud is often gridded into cells and for each cell, a set of metrics is calculated as a spatially aggregated value; this is referred to as the area-based approach. 


\section{Sources of Errors}

The implementation of forest inventories is a complex task that involves numerous disciplines. Errors cannot be completely avoided. The term 'error' can be interpreted in different ways depending on the respective discipline - but is generally understood as a mistake in the classical sense. In statistical terminology, which is applied here, the term 'error' refers to the difference between the measured and the (unobservable) true value, and may also be referred to an expression of "residual variability."

Generally, errors can be classified as either systematic or random errors. The first type of error may, for instance, be due to a miscalibrated device. In this case, the absolute or relative error always remains in the same order of magnitude. However, systematic errors, also known as bias, do not only occur during a forest inventory but also in remote sensing, e.g. when two satellite images are misaligned or when there are systematic distortions in the geometry of the image product. Such systematic distortions can be corrected by modeling the sources of distortion. During the construction of a DEM, as presented in Manuscript V, where Pleaides stereo satellite imagery was used, systematic as well as random errors can occur. There are different sources of errors, like for instance the inaccurate placement of the GCPs, errors caused due to coordinate transformation and data processing (e.g. inaccurate image matching) and, additionally, distortions in the raw imagery. It is important to be aware of these different errors and to strive to minimize them. Alonso-Carne et al. (2013) reported systematic errors in temperature estimates of up to $5-6{ }^{\circ} \mathrm{C}$ when comparing MODIS data to ground records of surface temperature acquired from climate recording stations and provided by the European Climate Assessment and Dataset (ECA\&D). Furthermore, the error in MODIS temperature estimates could be linked to different ecological regions.

Random errors, on the other hand, vary in size and may occur during the assessment of variables in the field; for example, the measurement of diameter above buttress may be prone to errors (Manuscript II). Although the field data may be precise, uncertainties may exist due to so-called "measurement errors" which usually follow a normal distribution. Many studies focus on the assessment of measurement errors (Barker et al., 2002; Elzinga et al., 2005; Kalliovirta et al., 2004) and errors caused by imperfections in measuring because of the user and/or the measurement device. Diameter at breast height (DBH), for example, is one of the most frequently measured attributes and is commonly collected manually using simple devices, such as a caliper or diameter tape. Yet when 
different people measure the DBH of the same tree with exactly the same device, they will arrive at different results when measuring for example with millimeter accuracy or beyond. Although this source of error is well-known, it is frequently neglected and not made explicit, since in order to specify this type of measurement error, repeated measurements must be conducted and then an evaluation of the variability must follow. Measurement errors do typically also occur when the upper stem diameter is measured using a relascope because an appropriate handling by the user requires care and training. Hence, when the relascope method is used a larger variation in the measurements of the diameter can be expected. The errors in tree measurement described here are also linked to uncertainty associated with AGB estimates and will finally also influence the development of the allometric model. Apart from this, the most important source of error for AGB estimates is the choice of the right allometric equation. On the one hand, the allometric model presented in Manuscript II improves the biomass estimates; on the other hand, if applied to trees of varying species and geometry, the allometric model may increase errors in biomass estimates.

During a forest inventory, errors are always present, but common practice usually takes the field observations as "truth," even though they might strictly speaking only be the best data available. Another error of great importance, in particular in forest inventories, is the "sampling error." Not a typical error in the proper sense, this type of error is rather an expression of the residual variability, a notion that is also preferred by McRoberts (2014), because the estimated statistics are calculated from a subset and not from the true population, which is unknown.

All in all, the reading of inventory reports or the active working with such data requires not only researchers to bear the different sources of errors in mind. 


\section{The Physical Principles of Thermal Infrared Radiation}

This thesis focuses on thermal remote sensing, a technology that is explicitly addressed in Manuscript I and III, as well as in Chapter 9. Therefore it is necessary to introduce the physical principles of thermal measurements. What distinguishes thermal infrared sensors from visible or near infrared sensors, is that the emitted energy is recorded, while outside the long-wave electromagnetic spectrum reflected energy is recorded. Every object with a temperature above absolute zero $\left(0^{\circ} \mathrm{K}\right)$ emits radiation, but - with the exception of very high temperatures (glowing iron, lava, fire, etc.) - this longwave radiation remains invisible to our eyes. In order to make heat "visible," a camera is necessary that operates in the longwave spectral range and passively detects the thermal energy that is emitted by any object that has a temperature above absolute zero.

Thermal infrared radiation refers to the electromagnetic spectrum between 3 and 14 micrometers. Within this spectral region, there are two "atmospheric windows" where the atmosphere is transmissive of energy emitted from the earth. There are two main systems commercially available which are categorized by their wavelength (Figure 1) and operate in the atmospheric window: the first one operates in the spectrum of 3 to 5 micrometers and is termed "shortwave." The second, which is the most commonly used system for thermal imaging, operates in a spectral range between 8 and 14 micrometers and is termed “longwave."

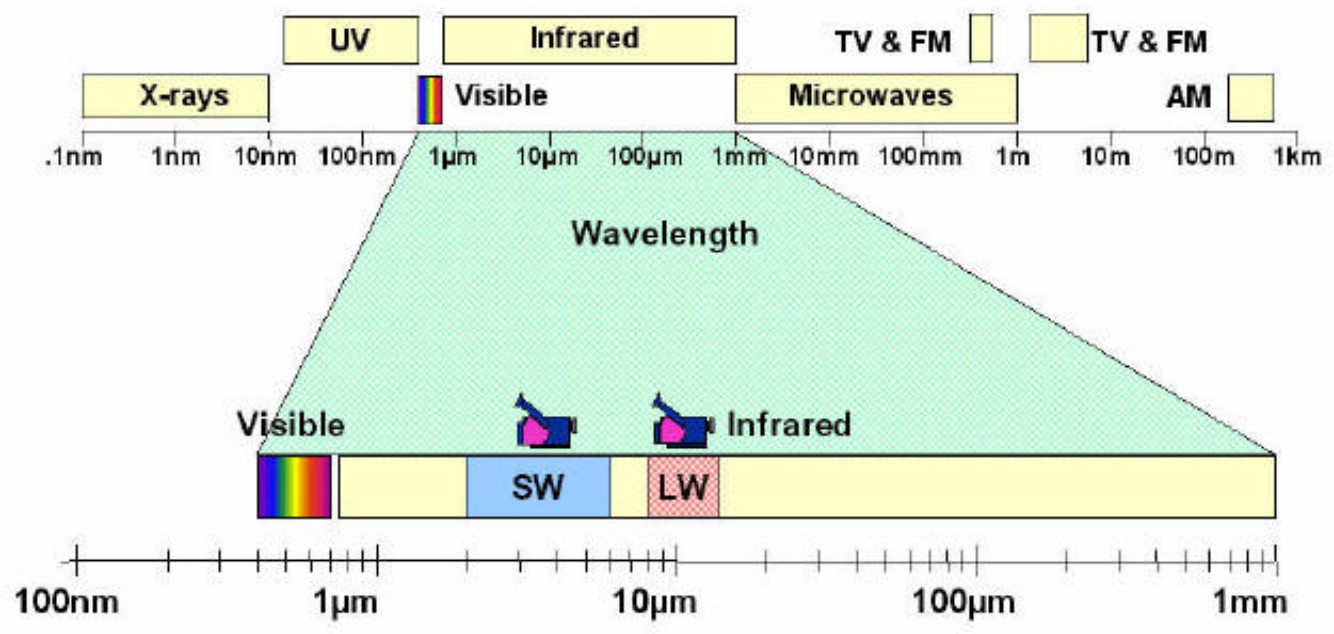

Figure 2. Electromagnetic spectrum with thermal infrared spectrum in detail (Source: http://thermalcities.com)

The physical principles underlying thermal remote sensing become clearer with the concept of the blackbody. The blackbody is a theoretical perfect radiator for which the following applies: the total energy absorbed is re-emitted, which results in zero 
transmittance and zero reflectance. As defined by Kirchhoff's law, the blackbody has an emissivity coefficient of 1 . This coefficient is defined as the ratio between the radiant exitance of an object at a given temperature and the radiant exitance of a blackbody at the same temperature. The emissivity value $(\varepsilon)$ for real surface materials is above 0 and below 1 and is understood as a material surface property which is quite complicated to determine because the emissivity depends on a number of chemical and physical properties. Nevertheless, the knowledge of the emissivity value is important, particularly for noncontact temperature measurements. Thermal cameras are calibrated for a certain emissivity which normally close to 1 ; so if the surface temperature of an object with a lower emissivity value is measured, the temperature will be underestimated. The emissivity of leaves, for example is typically between 0.94 and 0.99 (Rubio et al., 1997), depending on their color or the leaf roughness which is different for a shiny waxy leaf surface compared to a hairy leaf. Furthermore, the blackbody is not actually black: For example, the sun as well as the earth, and also leaves almost behave like a blackbody, although they do not appear black.

Thermal cameras do not directly measure the temperature, but detect the energy emitted. This energy is converted to an electronic signal, which is then further processed inside the camera to produce the thermal image and perform the temperature calculation. Furthermore, thermal cameras can precisely quantify small differences of $0.01 \mathrm{~K}$ in the surface temperature caused by changes in the radiated energy. The total energy radiating from an object and the spectral distribution depends on the surface temperature and is defined by spectral radiation laws, which are introduced in the following.

Wien's displacement law describes the relationship between different temperatures and the peak of emitted energy, which is illustrated by Figure 2. When the temperature increases, the wavelength of the peak exitance shifts towards a shorter wavelength. For instance, temperatures around 4,000 K to 6,000 K peak within the visible wavelength: a fire, for example, is hot enough to radiate visible light and, as a consequence, it becomes visible to our eyes. Depending on the absolute temperature and towards shorter wavelengths, the color changes from red to orange to yellow. Leaves and canopies, however, have an ambient temperature of around $300 \mathrm{~K}$ and thus the dominant wavelength is 9.66 micrometers; due to this the surface temperature is not visible to the human eye. A thermal detector is required to operate in the range of $8-14$ micrometers 
and covering the wavelength of the peak exitance. This range is defined by the extent of the atmospheric window. The peak exitance is calculated using the following equation:

$$
\lambda_{m}=\frac{A}{T}
$$

where $\lambda_{m}$ is the wavelength of the maximum spectral exitance, $A$ is constant (2898 $\mu \mathrm{m} \mathrm{K}$ ) and $T$ is the temperature of the blackbody in Kelvin.

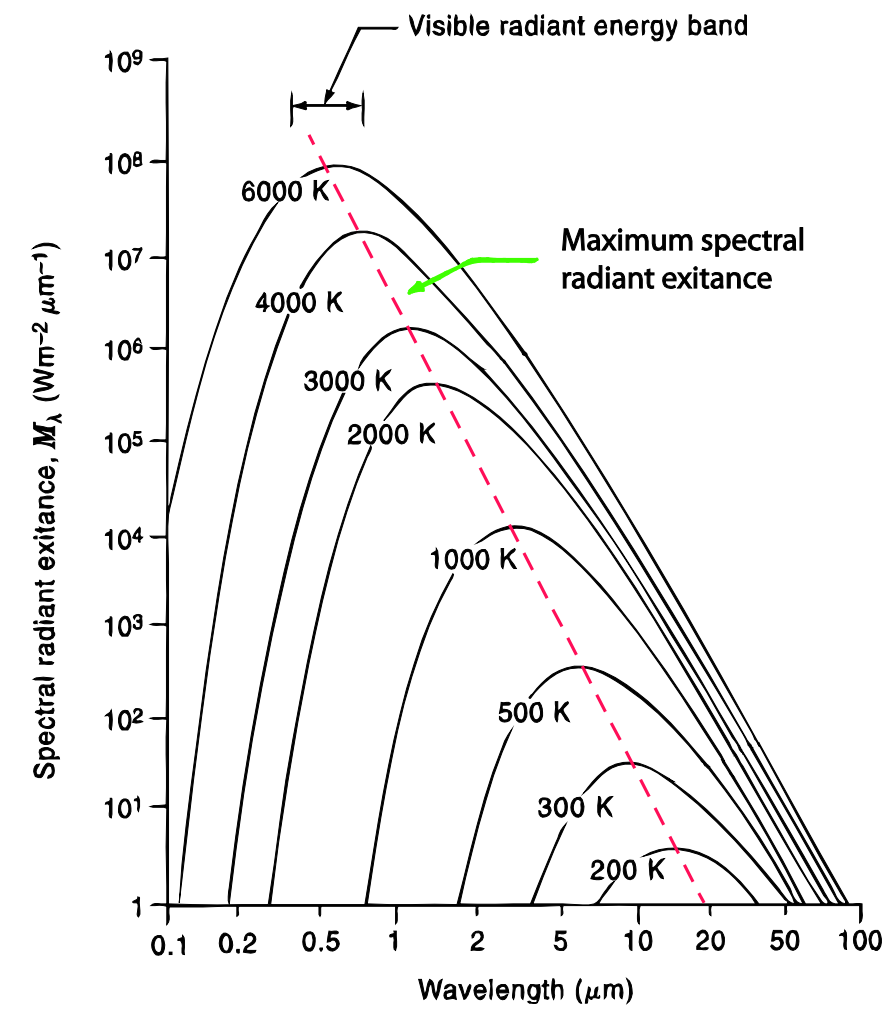

Figure 3. Illustration of Wien's displacement law (Source: Lillesand et al. 2008)

Planck's radiation law describes the spectral radiance distribution of the blackbody for a thermodynamic equilibrium as a function of the wavelength and temperature. This relationship can be formulated in mathematical terms:

$$
B_{\lambda}(T)=\frac{C_{1} \lambda^{-5}}{e^{\frac{C_{2}}{\lambda T}-1}}
$$

where $B(T)$ is the radiance emitted from a blackbody, $C_{1}$ and $C_{2}$ are constants $\left(1.191 \times 10^{10}\right.$ $\mu \mathrm{W} / \mathrm{cm}^{2} \mu \mathrm{msr}$ and $1.143 \times 10^{4} \mu \mathrm{mK}$ respectively), $\lambda$ is the wavelength of the radiation observed (in microns), and $T$ is the temperature of the blackbody in Kelvin. 


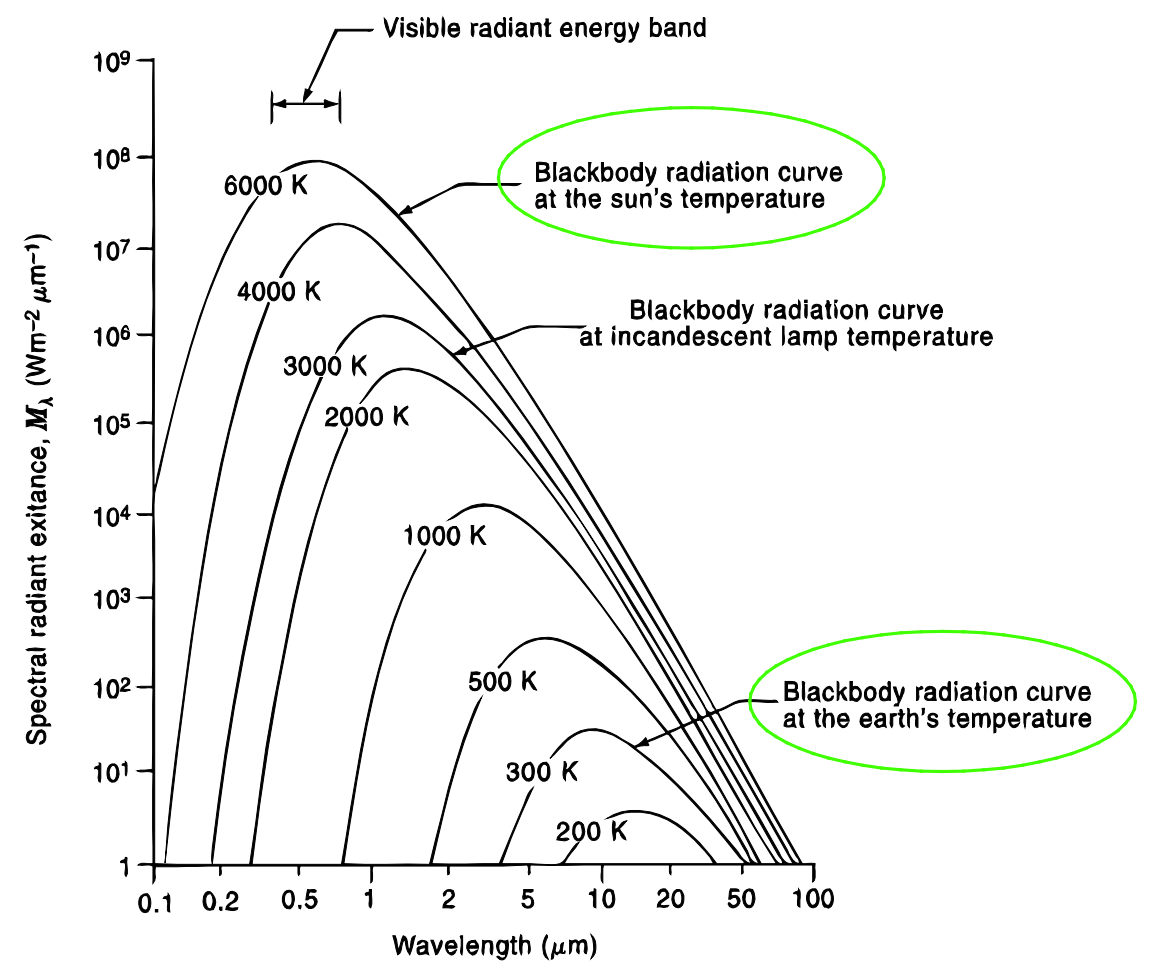

Figure 4. Illustration of Planck's radiation law (Source: Lillesand et al. 2008)

The Stefan-Boltzmann law describes the amount of radiation emitted from an object in proportion to the fourth power of the absolute surface temperature. This relationship is described mathematically in Equation 7:

$$
M=\int_{0}^{\infty} M(\lambda) d \lambda=\sigma T^{4}
$$

where $M$ is the total radiant exitance $\left(\mathrm{W} \mathrm{m}^{-2}\right), \mathrm{M}(\lambda)$ is the spectral radiant exitance $\left(\mathrm{W} \mathrm{m}^{-}\right.$ $\left.{ }^{2} \mu \mathrm{m}^{-1}\right), \sigma$ is the Stefan-Boltzmann constant $\left(5.6697 \times 10^{-8} \mathrm{~W} \mathrm{~m}^{-2} \mathrm{~K}^{-4}\right)$, and $T$ is the temperature of the blackbody in Kelvin. Figure 4 illustrates the amount of energy emitted by the area under the blackbody radiation curve given by the Planck's radiation law. As part of the leaf energy balance (cf. Chapter 6.3) this law allows researchers to calculate the amount of infrared energy lost through the leaf surface, but the energy lost can also be determined for any other surface. Because a leaf has two surfaces, Equation 7 must be multiplied by two. 


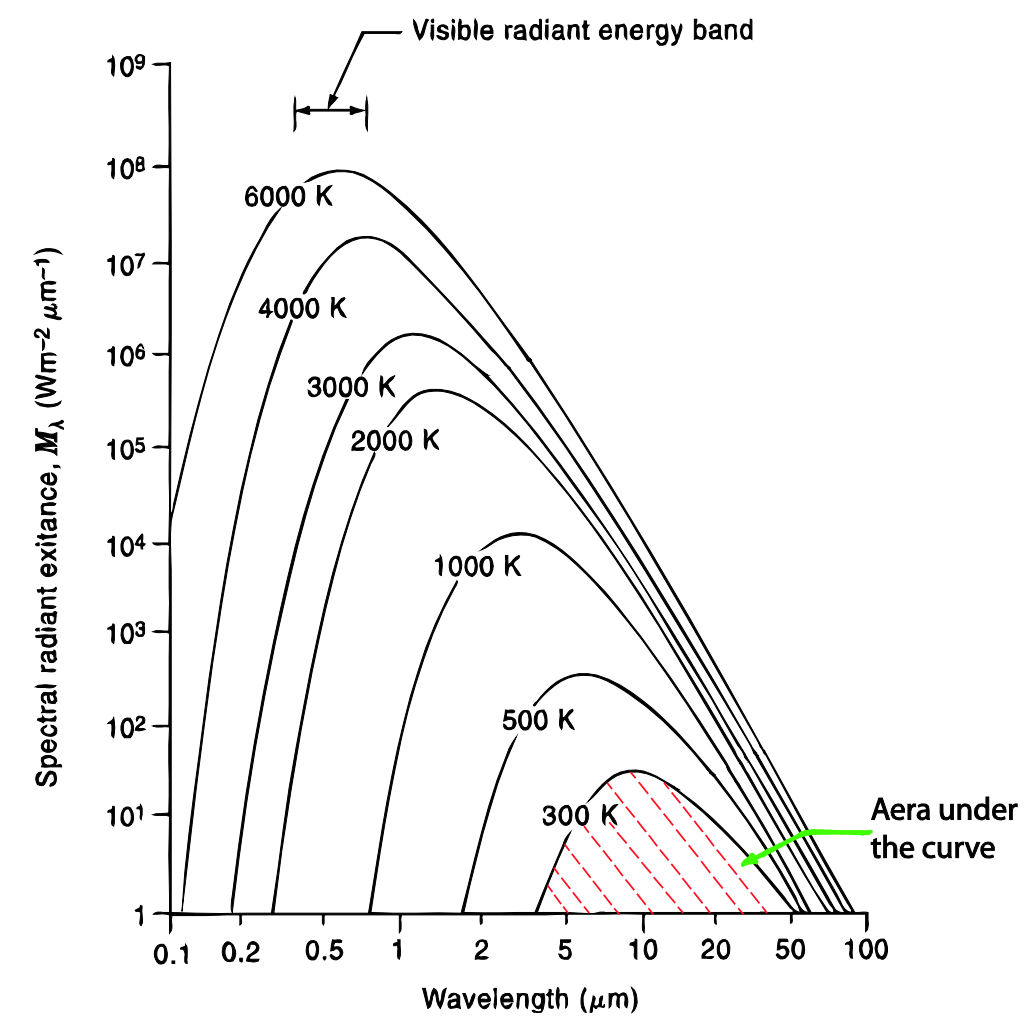

Figure 5. Illustration of Stefan-Boltzmann law (Source: Lillesand et al. 2008)

When working with thermal data, researchers must be sure of the kind of temperature they measuring. There is a distinction between kinetic and radiant temperature. While the first is based on an in situ measurement using a thermometer, the latter denotes the amount of emitted radiant flux in watts measured at some distance to the object. As already stated, real materials may closely resemble the behavior of a blackbody, but they emit only a fraction of the energy for an equivalent temperature, which results in an overestimation of the correct kinetic temperature. For this reason, working with absolute temperature (kinetic temperature) in thermal data requires researchers to account for the emissivity coefficient. As thermal cameras always work with a fixed emissivity value, potential variations in emissivity of the objects studied may cause a systematic error (cf. Chapter 5) in the estimation of surface temperature if the object properties vary (emissivity). 



\section{Applications of Thermal Remote Sensing}

Thermal infrared remote sensing was initially linked to the military and has since been in use for security and surveillance. Around 1964, however, the first weather satellite TIROS-1 was used to acquire thermal imagery from space. Due to the coarse resolution, these satellite data were only used for the analysis of cloud patterns and ocean temperatures. With the launch of NASA's experimental satellite program - the Heat Capacity Mapping Mission (HCCM) - in 1978, monitoring in the thermal spectral region has become scientifically oriented. It was at that time that thermal infrared technology was utilized in a number of geological studies. The potential of this data source was mainly in helping to identify different surface materials. In an early study by Schieldge et al. (1980), thermal inertia properties were used for material identification. Furthermore, thermal data allow researchers to monitor the variations in the earth's thermal field. Nowadays, thermal data are of significance for various areas:

- Agriculture, e.g. for monitoring plant stress (Stoll and Jones, 2007)

- Hydrology, when soil water content is to be estimated (Gillies and Carlson, 1995)

- Seismology, such as earthquake research (Tronin et al., 2002)

- Medical sciences, e.g. the monitoring of the temperature distribution of the human skin (Jones, 1998)

- Military applications, among them surveillance

- Volcanology, such as monitoring active volcanos (Harris, 2013)

- Architecture, for instance when detecting building interior leaks or windows leakage (Flir, 2016)

Currently, one major application of airborne as well as satellite thermal imagery in forestry is the monitoring of forest fires: the warmest points on the ground and the area affected by the fire can be discerned and integrated into maps, where they may benefit operational fire management. The advantage of using airborne thermal remote sensing for this tasks is that airborne systems can operate continuously with high repetition frequencies in order to detect short-time changes of forest fires. Moreover, such sensors provide up to sub-meter resolution and may deliver quantitatively useful datasets to support an analysis of active fires. Another data source for fire management are satellitebased thermal sensors which have been applied on a global scale to monitor forest fires; for instance, in the early study by Flannigan and Haar (1986), the NOAA satellite AVHRR with a spatial resolution of $1 \mathrm{~km}$ was used. Currently, the sensors Terra-ASTER or Terra-MODIS still have the same resolution but their improvement is the temporal 
resolution of 1 - 2 days. These sensors are applied in the daily detection of forest fires worldwide using a specific fire detection algorithm developed by NASA (Giglio et al., 2003). The main restriction of the use of satellite-based thermal imagery for fire management is mainly the coarse spatial resolution, which does not allow the detection of small-scale changes in forest fires.

Besides the application of forest fires detection, thermal remote sensing is useful for vegetation surveys at the landscape level, e.g. for estimating land surface temperature (Dash et al., 2002). Such studies make use of another efficient and popular satellite sensor, the Landsat thermal infrared sensor (TIRS), which, with its two bands and a resolution of $90 \mathrm{~m}$ facilitates the accurate calculation of land surface temperature. Additionally, these data permit researchers to estimate plant physiology related variables, e.g. evapotranspiration or soil water content at the landscape level. Accordingly, the status of forest health may be monitored, since the temperature of plants increases when they are stressed due to water limitations. A study on forest mortality employed an improved temperature vegetation dryness index for this purpose (Ishimura et al., 2011). Scherrer et al. (2011) studied the drought effect on different plant species using thermal imaging. He found that a few species are less competitive at high temperatures and in drier sites. Studies on the vitality of trees and plants play an important role in biodiversity monitoring and the vitality has so far been often determined by visual interpretation only. Thermal remote sensing helps researchers to determine the vitality of single trees during forest inventories by using anomalies in the temperature pattern of the stem to detect invisible infections under the bark. Yuan (2015), for instance, used infrared thermal imaging to diagnose the health of a tree species local in northwestern China.

The availability of new hyperspectral airborne sensors operating in the thermal infrared spectra, which does not only provide temperature but also the full spectral signature, may aid research into the plant properties that effect emissivity. Ullah et al. (2011) showed that the emissivity spectra extracted under laboratory conditions from hyperspectral thermal data serve to distinguish 13 different plant species. This is possible due to the unique thermal properties of the leaf, which are plant-species specific. Buitrago et al. (2015), who worked with a similar hyperspectral data set, showed that variations in thermal infrared spectra of plants are caused by temperature and water stress. For future research on the scale of the single leaf, these analyses of thermal signatures may improve the early detection of diseases. 
In summary, thermal remote sensing appears to be a useful extension of optical remote sensing data when researching forest health, vitality or further aspects related to plant physiology, as the combined analyses of visual and thermal data allow for an improved interpretation of the plant's vitality. With future development the focus will be much more on combined imaging solutions of thermal and other spectral wavelengths which are sensitive for example to chlorophyll fluorescence. As standalone remote sensing data source in future studies, hyperspectral thermal data may help to enhance the understanding of the influence of plant properties on thermal signature and their impact on the leaf energy balance. 



\section{Microclimate and Plants}

\subsection{Preliminary Notes}

"No literature of plant science offers more confusion than the publications concerned with transpiration and plant temperature."

David M. Gates (1968)

Microclimate is directly related to leaf temperature, one of the central factors for functional plant ecology that affects the presence or absence of insects and the incubation of pathogens (Unterseher et al., 2008). Forest canopies are a hot spot of many plant communities and contribute substantially to the overall forest biodiversity (Rinker and Lowman, 2004). The reason for such great diversity cannot yet be fully accounted for, but pertains to the structural and microclimatic complexity inside the tree crowns (Cardelús and Chazdon, 2002). An important linkage between plants and their microclimate is the radiative coupling which is in turn linked to leaf temperature Leaf temperature also has an influence on the plant water content and has an effect on physiological processes (Larcher, 2001; Lösch, 2003). Leaf temperature is directly influenced by both leaf-specific characteristics (morphology, shape, leaf mass, size and reflective properties) which prevent the leaf from overheating (Hatfield and Burke, 1991; Leinonen et al., 2006) and by environmental factors (air temperature, humidity, solar radiation and wind). These complex interrelations make it a challenge to disentangle the contribution of each single factor, i.e. to determine to which extent each factor influences the leaf temperature.

\subsection{Current Research}

A number of different studies have focused on interactions between leaf temperature, microclimate, and physiological processes in plants. As this is an immensely complex and multilayered topic, early studies in the first half of the $20^{\text {th }}$ century revealed controversial results. While Curtis concluded in 1926 that leaf temperature was warmer than air temperature, in a follow-up study (Curtis, 1938) a leaf temperature difference of $7^{\circ} \mathrm{C}$ below air temperature was manifested. Additionally, early research by Ansari and Loomis (1959) studied leaf temperature under a range of taxa and leaf morphologies using thermocouples that measure the direct surface temperature. Matsumoto et al. (2005) highlighted that leaf temperature affects stomatal conductance. This relationship was used before by Jones (1999) to develop methods to estimate stomatal conductance from leaf temperature. The process of transpiration has a direct effect on leaf temperature because of the cooling function. Through a variety of mechanisms, temperature affects all aspects of plant growth (Schulze et al., 2005). For example, at high temperatures of around $30^{\circ} \mathrm{C}$, growth results in an elongation of the stem and on elevated leaves. Furthermore, a 
phenological shift in plant development may be observed that is the result of the small temperature increase due to global warming (Fitter, 2002; Jentsch, 2009). For many plant species, their time of reproduction, too, is temperature sensitive.

Diversity, abundance and distribution of insects, for example, is directly related to the temperature range and leaf surface temperature. In turn, the moisture content of the soil, light intensity, as well as topographic and geological conditions affect the temperature and therefore affect the canopy surface temperature distribution. Meteorological conditions like wind, air temperature, radiation, and humidity influence the difference between leaf and air temperature.

The canopy surface temperature, on the other hand, is influenced by tree-specific leaf and canopy characteristics. Changes in leaf angle distribution, leaf area density, and leaf size as well as the canopy architecture affect the mean temperature (Norman and Becker, 1995; Fuchs, 1990). As these factors also determine temperature and water exchange, they have a direct impact on the leaf transpiration (Jones, 1992). In a study on leaf temperature, Leuzinger and Koerner (2007) emphasize that the mean canopy surface temperature differs substantially from air temperature, yet in a highly species-specific manner. They revealed a significant difference in canopy temperature between broadleaved and coniferous stands and argued that crown characteristics (branching, leaf density, leaf angle, leaf thickness, canopy roughness) have a strong influence on the canopy surface temperature.

\subsection{Leaf Energy Balance}

Leaf temperature can first of all be roughly approached by measuring the air temperature. Both datasets exhibit a high correlation over time in absolute height and variation. This well-known relationship was confirmed in our exploratory studies (cf. Chapter 9). Plants adjust to the surrounding air temperature (Jones, 1992) and because most are poikilotherm organisms, their temperature varies with the environment (Savvides et al., 2013). To date, the list of established variables which are related to leaf surface temperature is quite extensive (e.g. stomatal density and capacity, transpiration, leaf size, orientation and shape, its spatial position in the canopy, leaf optics, pubescence, and roughness), yet the extent of their influence remains unknown in many cases. In order to arrive at a greater understanding of the temperature regime of a leaf, researchers might turn to microclimate and leaf energy balance. The first models evaluating the leaf energy balance were formulated by Raschke (1960) and Gates (1956; 1966). At that time, they were mainly interested in studying the relationship between leaf size, temperature, and transpiration. 
Nowadays, the leaf energy balance is one of the fundamental formulations in biometeorology, since it allows, among other things, the prediction of the leaf temperature if the input variables are known, as well as the study of how climatic changes affect leaf temperature.

The radiative transfer is an important contributor to the leaf energy balance (Jones, 2001) and can be divided into short-wave, i.e. the solar radiation, and long-wave, i.e. thermal radiation. The total short-wave radiation that reaches the earth surface includes direct and diffuse radiation. The latter derives from the scattering of solar radiation by clouds, air molecules, and particles that exist in the air. Solar radiation, on the other hand, can be mainly divided into three regions within the electromagnetic spectrum: ultraviolet, visible, and infrared, which are known as the solar spectrum. Around $44 \%$, which is roughly half of the incoming energy from sun, is in the visible spectral range between 400 to $700 \mathrm{~nm}$. Beyond this spectral range, radiation is not visible to the human eye, but between 700 to $1,000 \mathrm{~nm}$, intensive energy can still be recorded. Below $400 \mathrm{~nm}$, in the ultraviolet spectrum, only $7 \%$ of energy can be detected. In plant physiology, the visible spectral range (400 - $700 \mathrm{~nm}$ ) is of utmost importance. This portion of the spectrum is called Photosynthetically

Active Radiation (PAR) and is needed for photosynthesis and plant growth. It is these wavelengths that are particularly relevant to the leaf energy balance:

$$
R_{n}+C+\lambda E+M=0
$$

where $R_{n}$ is the net flux of all short-wave and long-wave radiation across a unit area and $C$ the convective (sensible) heat transfer which describes the transfer of thermal energy from the leaf surface to the surrounding atmosphere through air movements. $\lambda E$ is the energy loss from transpiration and evaporation of water from the leaf (latent heat loss). $M$ describes the metabolic processes involved in the energy balance. These processes produce heat and when absorbed short-wave radiation is used, energy is consumed; compared to the other components of the energy balance, however, these metabolic processes constitute less than $5 \%$ (Jones, 2013) and are therefore usually neglected. The second term in Equation 8 represents the sensible heat loss $(C)$ due to convection and conduction. $C$ may be positive if the leaf is warmer than the surrounding air. The magnitude of sensible heat loss is affected by the conductance of the boundary layer, a thin layer of air directly above the epidermis. Here, gas concentration, temperature, and the air flow are regulated by the leaf. The dominant term of Equation 8 is the net radiation 
$\left(R_{n}\right)$, which is the difference between the total radiation absorbed and the emitted longwave:

$$
R_{n}=S R_{a b s}+L R_{a b s}-L R_{e m}
$$

where $S R_{a b s}$ is the absorbed solar irradiation, $L R a b s$ the absorbed long-wave radiation which is emitted from surrounding objects and the sky, and $L R_{e m}$ the emission of longwave radiation described by the Stefan-Boltzmann law (Eq. 5). The net radiation represents typical diurnal changes: At night, when the incoming solar radiation is zero, $R_{n}$ is negative. During the day, $R_{n}$ is positive because there is more incoming radiation, but is subject to fluctuations in the surrounding environmental conditions. Furthermore, net radiation depends on processes like transpiration and sensible heat exchange that affect the leaf surface temperature. Figure 6 shows the incoming and outgoing radiation components which comprise the energy balance.

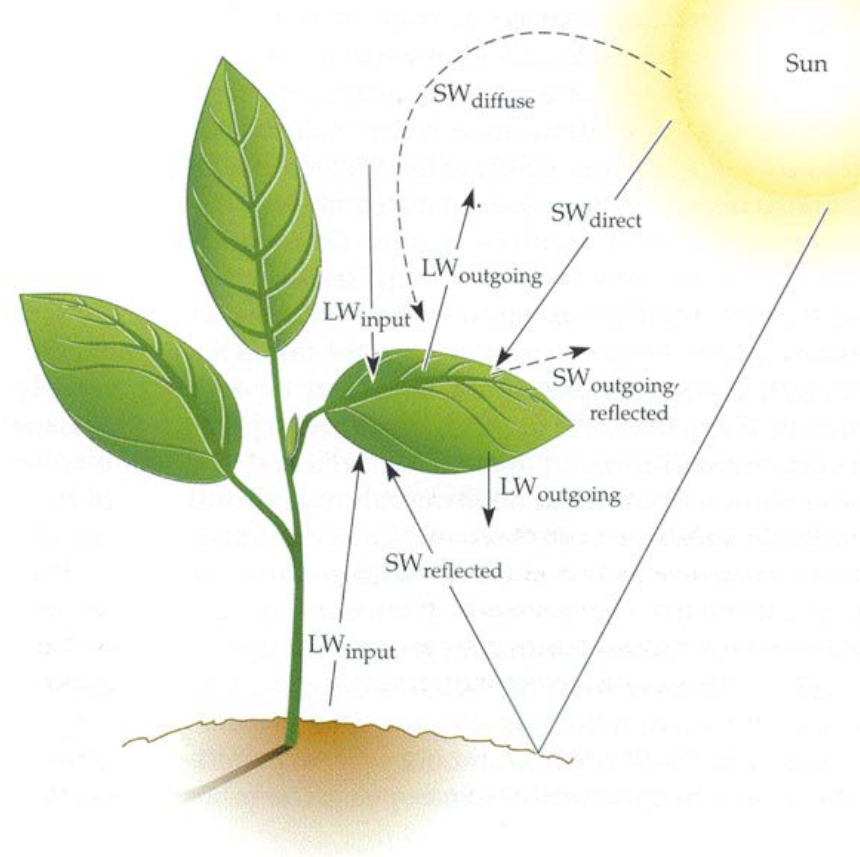

Figure 6. Illustration of the radiant energy balance during daytime (Source: Gurevich et al. 2006)

At night, the leaf energy balance can be expressed in simpler terms than in the illustration above, because there is no transpiration since the stomata are closed. Moreover, radiant energy loss and the gain of sensible and latent heat from the air are in balance (Leuning et al., 1989). Additionally, the shortwave radiation components (SW), 
which are illustrated in Figure 6 do not have any influence. The longwave radiation is the only source of energy radiating from the leaf surface and the longwave emission generally cools the leaf surface faster than the surrounding air. The cooling of a surface continues until shortly before sunrise; at this point in time the coldest temperature is typically reached. For this reason, the fluctuations in temperature during the night are much weaker compared to the day temperatures. The reduced number of influencing factors during the night justify the analyses of nocturnal thermal images only as described in Manuscript IV. 



\section{Exploratory Studies on Thermal Imaging of Forest Canopies}

\subsection{Research Framework}

The following two studies were carried out as a research project (KL 894/14-1) in the DFG Priority Program 1374 "Infrastructure-Biodiversity-Exploratories” described by Fischer et al. (2010). The main objective of this research framework is to understand the relationship between biodiversity, the role of management intensities for biodiversity, and the role of biodiversity for ecosystem processes. Within the scope of the contributing project "Estimating forest canopy surface temperature by airborne laser scanning, thermal infrared scanning, and 3D radiation modeling," the relationship between temperature and the upper forest canopy structure is analyzed with the help of high-resolution thermal images (tower-mounted and airborne), digital surface models, and existing inventory data to explain the function of certain elements of biodiversity. Here, the leaf temperature of the upper canopy was measured for three tree species: Acer pseudoplatanus, Fraxinus excelsior, and Fagus silvatica. In order to account for the differences detected as a function of tree physiological, crown geometric, microclimatological, etc. variables, additional physiological measurements need to be conducted to complement the thermal and meteorological measurements. For the same three tree species, we therefore designed an additional greenhouse experiment in collaboration with the Chair of Forest Botany and Tree Physiology of the Georg-August-Universität Göttingen, Germany, which is discussed in Chapter 9.3. Apart from this study, we were also interested in larger area applications of thermal imagery. It is well known from scaling studies in forest monitoring that features may be better visible at coarser scales and that higher resolution does not necessarily entail more information. One potential large area application is hence discussed in following Chapter 9.2.

\subsection{Detecting Forest Gaps from Thermal Images}

The first exploratory study focused on a new application with great potential, namely an improved detection of forest gaps. Therefore, we analyzed airborne thermal imagery with the goal of identifying its benefits for detection of canopy gaps whose identification by true-color aerial images is still a major methodological challenge, since in true color, both the forest gaps and the shadows of tree crowns often appear in dark colors. Due to variations in the spectral reflectance caused by varying illumination conditions and canopy topography, an effective delineation of forest gaps within true-color imagery is difficult (Figure 7, left). This is one main problem when passive optical sensors are used. We hypothesized that because of the surface temperature difference between canopy cover and gaps, the detection may be simplified using thermal images (Figure 7, right). 


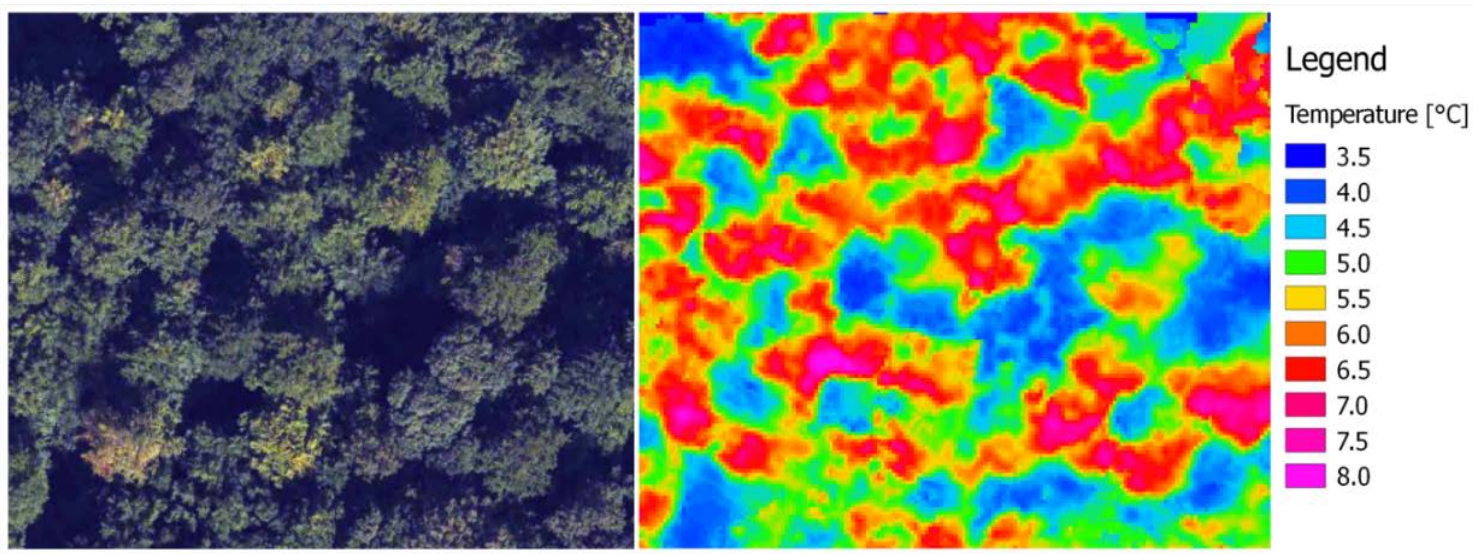

Figure 7. (left) Airborne thermal image with a spatial resolution of $0.2 \mathrm{~m}$. (right) Colored thermal image of the same extent. Temperature is according to the scale to the right. (Source: own image)

This study covers an area of $2 \mathrm{~km}^{2}$ in the Biodiversity Exploratory Hainich-Dün, which is one of the program's three large-area and long-term research sites in Germany.

Two data sources were used: first, a true-color aerial image with $20 \mathrm{~cm}$ resolution, and, second, a thermal aerial image with $50 \mathrm{~cm}$ resolution. Both were acquired simultaneously in October 2013. Capturing airborne thermal imagery requires a special camera which can detect the energy emitted from the surface (cf. Chapter 6). A highresolution thermal camera system, the VarioCam hr head (Infratec, Dresden, Germany) with a resolution of $640 \times 480$ pixel and a spectral range of 7.5 - $14 \mu \mathrm{m}$ was used during this flight campaign. The smallest resolvable temperature difference is around $30 \mathrm{mK}$ $\left(0.030^{\circ} \mathrm{C}\right)$. This camera was equipped with a $30 \mathrm{~mm}$ lens with a field-of-view of $30^{\circ} \mathrm{x}$ $23^{\circ}$ and was mounted on an aircraft. However, the use of such a camera system is not limited to this platform, as it may also be mounted on a climate tower, on canopy cranes, or in a greenhouse (cf. Chapter 9.3), which makes it possible to provide imagery at leaf scale with a spatial resolution below $1 \mathrm{~cm}$. Both aerial imagery products, the true color and the thermal aerial images, were delivered as orthorectified images. However, it was impossible to perfectly align both images due to technical problems that occurred during the orthorectification process. For this reason, we manually selected a number of different gaps in each image. 
The preliminary result of this study shows that there is a temperature gradient of around $4{ }^{\circ} \mathrm{C}$ between the gap border tree canopy surface temperature and gap ground temperature (Figure 8). Because of the variability in environmental conditions and the exposition of trees, this gradient differs for the gaps analyzed. Contrary to the study on thermal hemispherical photography (cf. Manuscript I) we cannot determine a fixed threshold. In our study we hypothesized that the cover of the gap ground has a strong influence on the temperature of the gap: vegetation cover with high emissivity leads to lower temperatures, while bare soil with sand and stones has a lower emissivity and thus leads to much higher temperatures. In order to validate such an assumption, proof of the vegetation cover in the field is necessary. Here, we only analyzed temperature profiles of a small number of large gaps with a radius of around $10 \mathrm{~m}$, which we could retrieve within the very high-resolution Bing imagery.
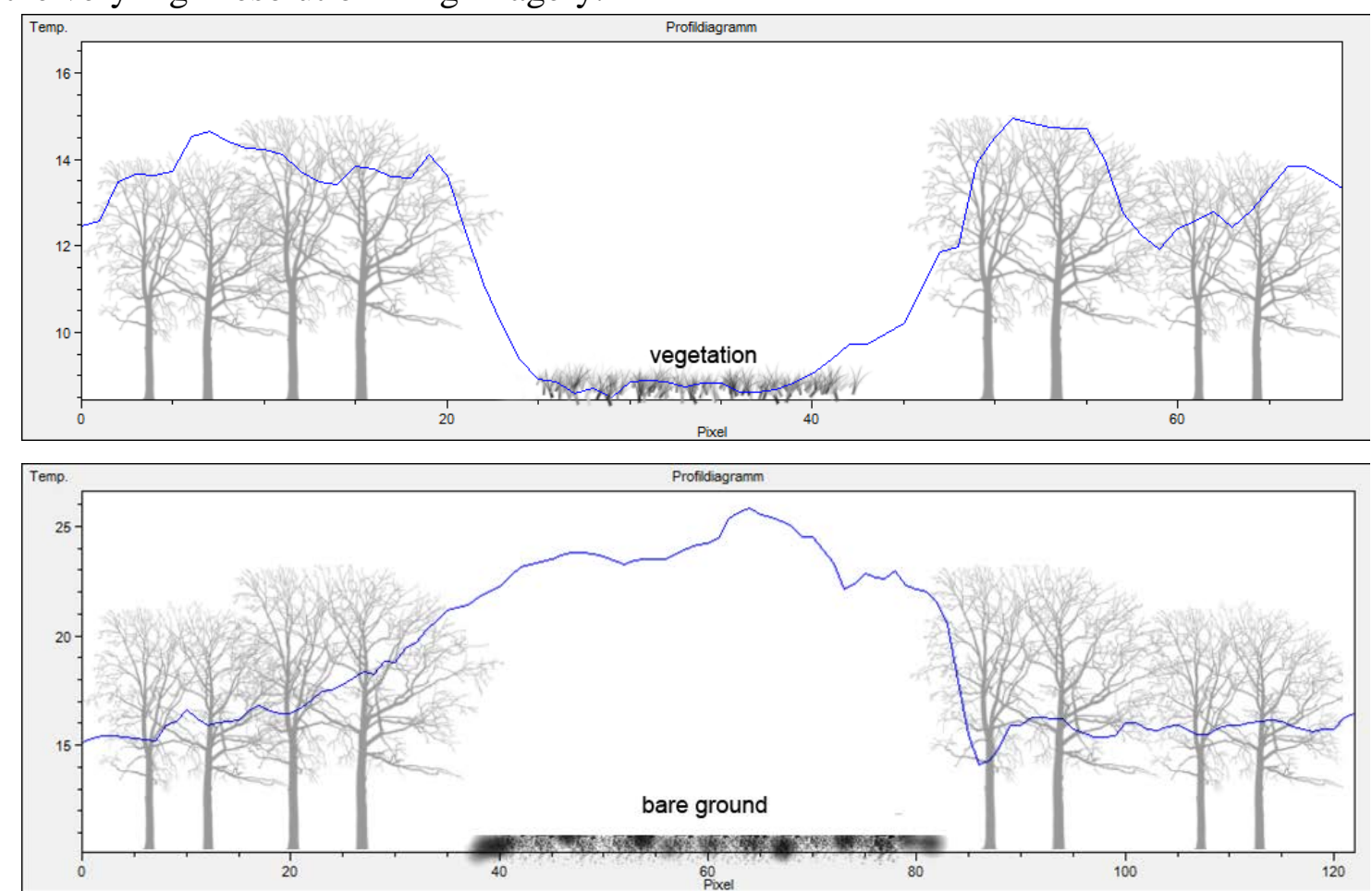

Figure 8. Temperature profile of two forest gaps (the centre of the two graphs, between each of the depicted border trees) with different ground surface cover. (top) the temperature of the gap is low due to the presence of dense vegetation. (bottom) the higher temperature of the gap may be due to the lack of vegetation: the bare soil heats up more due to its material properties (Source: own image).

The potential benefits of thermal remote sensing imagery become evident in this study, as forest gaps can be easily detected because of the clear temperature difference; consequently, a spatially more accurate description of the gaps is possible. Although LiDAR offers the most detailed method for delineation, it remains much more cost- 
intensive compared to thermal imagery. On the basis of this exploratory study, we recommend looking further into thermal imagery and balance reasons for choosing thermal imagery over true color images.

In summary, this new application of thermal aerial images to detect gaps presented here appears to be promising, but still requires further research before it may be more widely applicable. A starting point for further studies could be a simulation study using $3 \mathrm{D}$ radiative transfer models such as DART to identify the optimal point in time for the airborne campaign. Furthermore, other studies may also analyze the effects of different forest structures surrounding the forest gap. In future research, the validation process should become a significant part. Therefore, additional data could be integrated to verify the geometry (shape and size) of the gaps detected. This verification process can be done using different data sets. High-resolution optical satellite imagery allows for a spatially comprehensive description of the gaps. A more accurate measurement of the geometry may be realized using airborne LiDAR or terrestrial laser scanning. Here, single forest gaps are scanned either from above or from below. For all datasets mentioned, the preprocessing is of utmost importance because the data sets have to fit perfectly so that an accurate validation of the gap border may be performed. With the availability of multitemporal thermal images, the analysis of surface temperature changes in forest gaps and canopies may become a useful approach to a number of forest monitoring issues.

\subsection{Temperature and Stomatal Conductance of Leaves of Three Tree Species}

The additional study on temperature and stomatal conductance of the leaves of three deciduous tree species was motivated by the first analyses of 1,300 thermal images taken at the Hainich tower site (cf. Manuscript IV) which produced a series of unsystematic and confusing results that did not exhibit differences in canopy surface temperatures between the three tree species that could be identified as significant. Therefore, an exploratory study in the greenhouse was conducted in collaboration with the Chair of Forest Botany and Tree Physiology of the GeorgAugust-Universität Göttingen in order to study leaf temperature patterns with at least some of the influencing factors controlled, such as air temperature, wind speed, and relative humidity. The objective of this research was to better understand the effects of transpiration and photosynthesis on leaf surface temperature. Here, both processes need to be observed simultaneously, because leaf cooling can be seen as a consequence of transpiration, which is concurrently associated with the stomatal opening for photosynthesis (Lambers et al., 2008). 


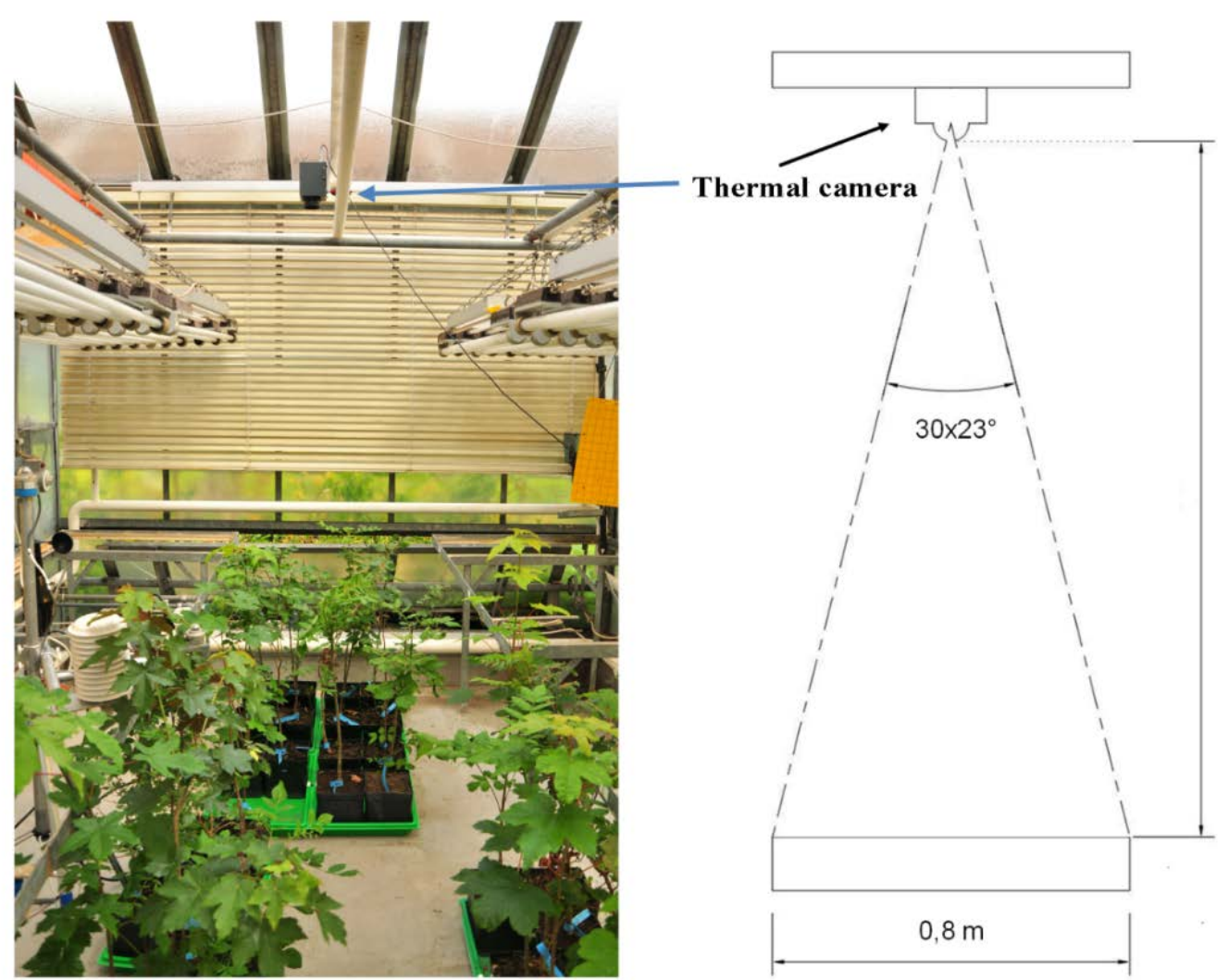

Figure 9. (left) Arrangement of the thermal camera and the subset of trees in the greenhouse. (right) Illustration of the field-of-view of the thermal camera. (Source: Diers 2013)

For this study, 25 trees of each of the three study species Acer pseudoplatanus, Fraxinus excelsior, and Fagus silvatica with a mean height of about $100 \mathrm{~cm}$ were measured. The trees were planted in May 2013, one plant per pot. For the measurements, we then selected a random subset of 12 trees which were arranged in an $80 \times 80 \mathrm{~cm}$ tub. The thermal images were acquired at a 10 min interval using the VarioCam hr head (see Chapter 9.2) mounted under the roof with a nadir orientation (Figure 9, right). The emissivity was set to the value of 0.98 , which represents average forest vegetation (Rubio et al., 1997). To extract the leaf temperature, each single leaf that was on the top and faced towards the thermal camera was manually digitized (Figure 10, right): 

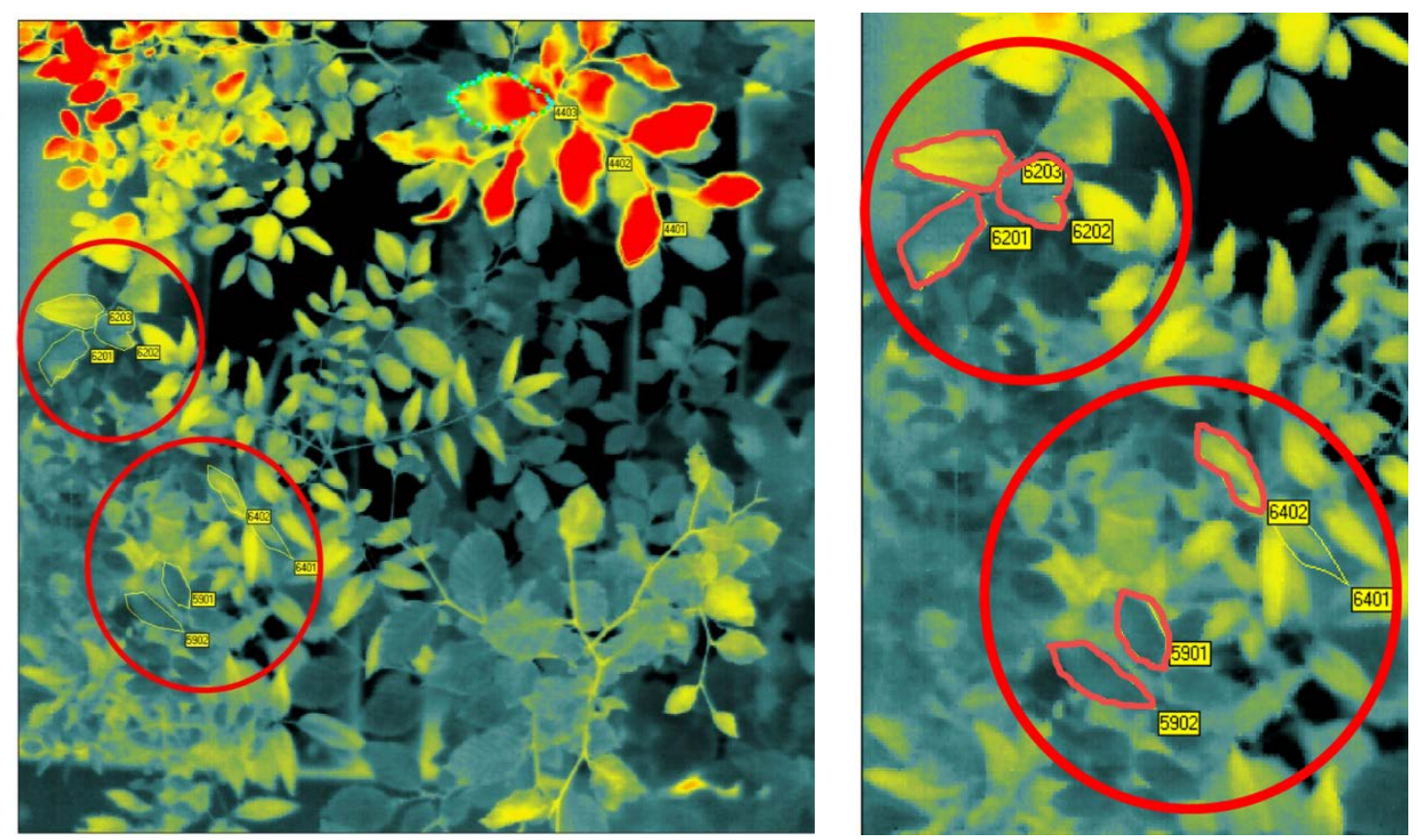

Figure 10. (left) Illustration of the manually delineated leaves within the red circle. (right) Zoom in view showing the delineation. Thermal image was taken on 05/09/2013. (Source: Diers 2013, modified)

Within the polygon the mean temperature was calculated. Additionally, on two toporiented and horizontal-faced leaves of each respective tree, the stomatal conductance was measured using a leaf porometer (AP4-UM-3, Delta-T Devices Ltd., Cambridge [England]). 


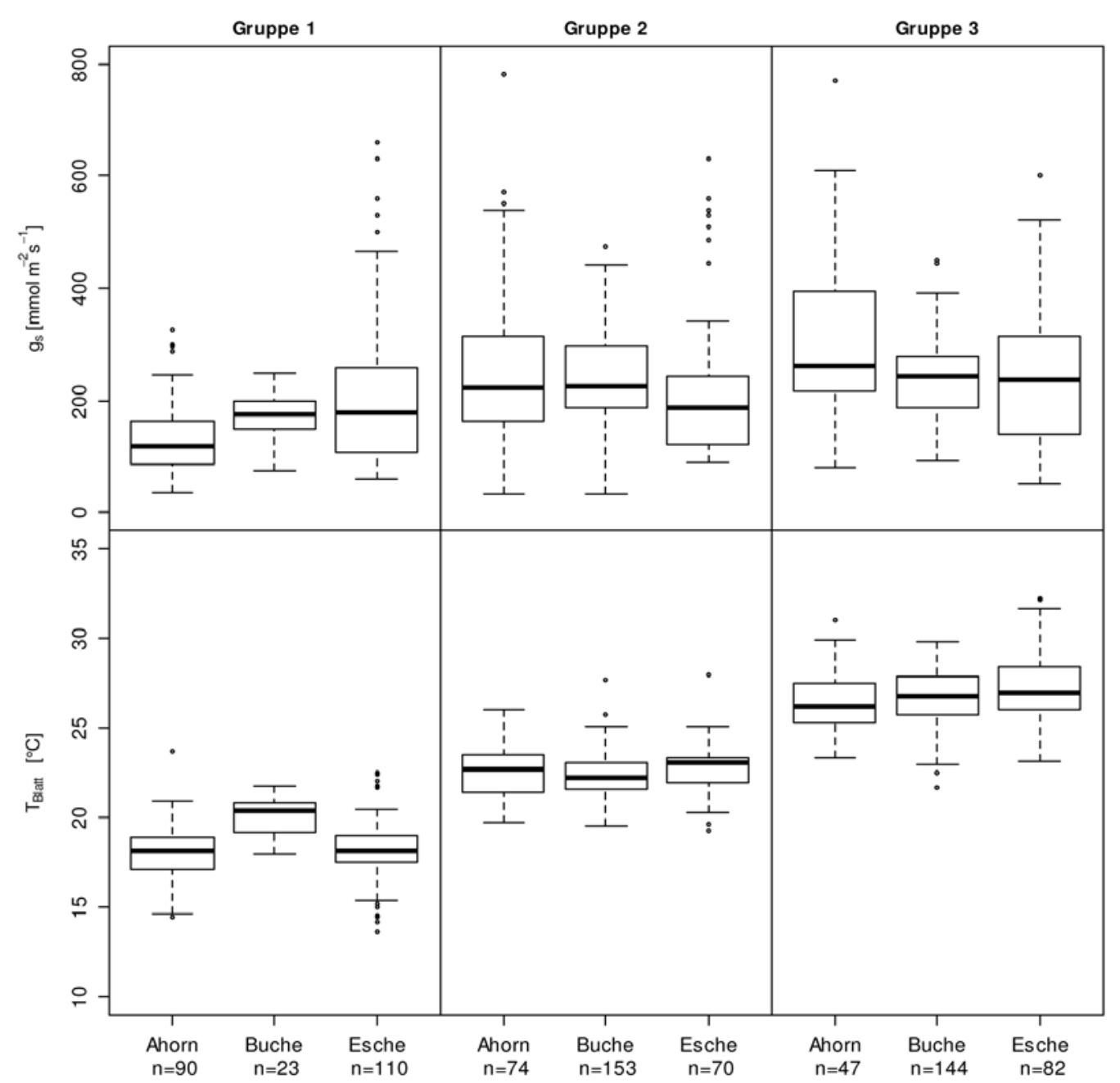

Figure 11. Stomatal conductance (gs) and leaf temperature (TBlatt) categorized into groups of air temperature: Tair $<20^{\circ} \mathrm{C}$, Tair $20-25^{\circ} \mathrm{C}$, Tair $>25^{\circ} \mathrm{C}$. (Source: Diers 2013)

Figure 11 shows the relationship between stomatal conductance and leaf temperature for each tree species categorized by air temperature. There is a small trend that suggests an increased stomatal conductance if the leaf temperature increases. For an air temperature between 20 to $25{ }^{\circ} \mathrm{C}$ and larger than $25{ }^{\circ} \mathrm{C}$, clear differences in leaf temperature among the tree species could not be detected. The intra-specific variability of the stomatal conductance is quite narrow, with the largest variability occurring in Fraxinus excelsior. 


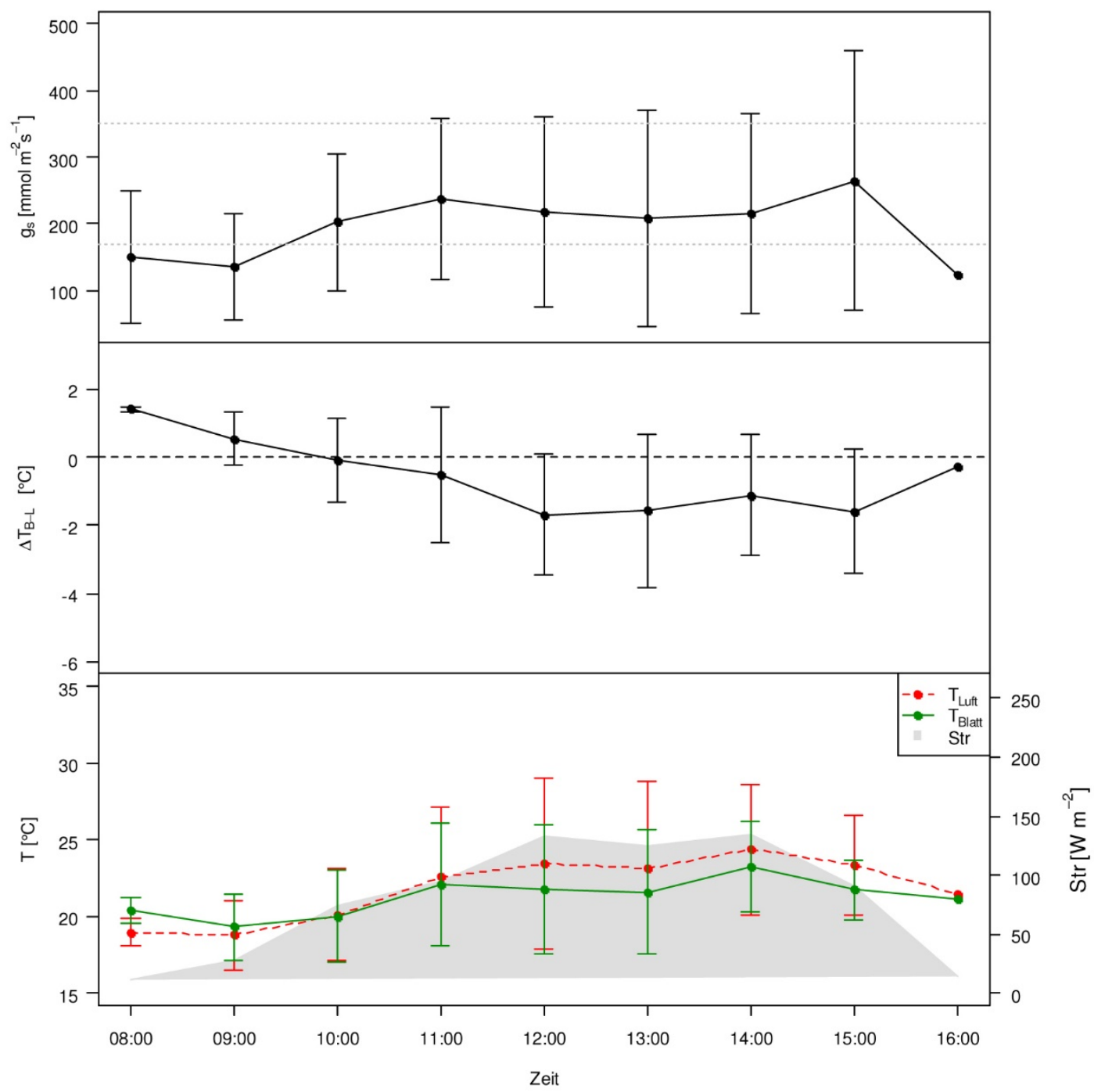

Figure 12. Mean daily temperature cycle between 8:00 am. and 4:00 pm of leaf (TBlatt) and air temperature(TLuft) in Acer pseudoplatanus. The grey area represents the global radiation (Str), the middle curve outlines the leaf-to-air difference ( $\Delta \mathrm{TB}-\mathrm{L}$ ). The top curve shows the stomatal conductance (gs).

The analyses of the Acer pseudoplatanus data measured over time as visualized in Figure 12 illustrate a typical curve for global radiation where the highest values are reached at midday. The influence of global radiation on the leaf as well as air temperature is illustrated by the same course of the curve. This relationship is similar for all the three tree species. Furthermore, we found a moderate but not significant relationship $(r=0.57, p=0.0513)$ between leaf temperature and stomatal conductance.

Early studies by Shull (1919), Eaton and Belden (1929), as well as Arthur and Stewart (1933) have shown that transpiration is of high importance for the regulation of leaf temperature. During the 1990s, it was confirmed (Jones, 1992; Willert et al., 1995) that transpiration assumes a prominent role in the leaf energy balance (cf. Chapter 8.4). Each of these studies used a different method to analyze the relationship, and, as a 
consequence, the results were sometimes clear, yet sometimes also ambiguous. Next to the influencing factors themselves, the method of data collection may have had an additional influence on the final result. This influence could be classified as a systematic or random error (cf. Chapter 5). Comparing both stomatal conductance and leaf temperature over time, the course of the curves is quite similar, which points to the tendency that, with a few exceptions only, a higher transpiration rate is linked to a decrease in leaf temperature.

In summary, the implementation of the greenhouse experiment was a crucial step towards a better understanding of leaf surface temperature and an improved interpretation of thermal imagery. The study revealed a small but measurable influence of transpiration for thermoregulation at least for a part of the measurements. The result suggests that higher transpiration seems to be linked to a lower leaf surface temperature. Although a number of influencing factors like relative humidity, wind speed, air temperature and water content per pot could be controlled, the complexity described above continues to be present. Even though the trees were planted inside the greenhouse, the uncontrollable weather conditions outside led to small variations in leaf surface temperature. This elucidates how sensitive to environmental changes the plants are. It is likely that these changes in the conditions outside the greenhouse can account for the variations in the results. Additionally, the analysis of the leaf surface temperature per species in the greenhouse was conducted on a much finer scale compared to the coarser resolution at the tower because of the distance of the camera. The result that there does exist a small difference supported our result from the tower site. Therefore, we can assume that there are tree-species specific characteristics which resulting in an individual canopy surface temperature.

Contrary to our expectation, each thermal image taken at the Hainich tower site looked differently and, depending on the surrounding conditions, tended to appear blurry or show traces of image noise. It was thus not possible to apply automatic classification or clustering approaches to the entire times series of images in order to extract the leaf pixels for subsequent comparisons and analyses. This topic is addressed in Manuscript IV that aims to statistically prove the very small difference in surface temperature over time between the tree species. In a future study, the successfully applied statistical method presented in Manuscript IV will be tested with the data set acquired in the greenhouse where the same thermal camera as at the tower site was used. 

Manuscript Abstracts 


\title{
10 Manuscript I (Annex A)
}

Thermal canopy photography in forestry - an alternative to optical cover photography

Nils Nölke, Philip Beckschäfer, Christoph Kleinn

Status: published 2014, iForest - Biogeosciences and Forestry, 8: 1-5

Contribution by N. Nölke: $90 \%$

- Collection of data

- Analysis and interpretation of data

- Draft and revision of the manuscript

\begin{abstract}
Hemispherical canopy photography is a widely used technique to observe crown-related forest variables. However, standardization of this technique remains challenging, as exposure and threshold settings continue to constitute the main sources of variation of such photographs. This paper, therefore, presents a new method to overcome standardization issues by using thermal canopy photography. With a thermal camera, images are produced which are not critically limited in their dynamic range so that photographic exposure becomes irrelevant. Moreover, the high temperature contrast between "sky” and "non-sky”, resulting from extreme low sky temperatures, facilitates the unambiguous selection of a threshold which separates "sky" from "non-sky” pixels. For our comparison, we have taken canopy images with a high-resolution thermal camera (VarioCam hr head [Infratec, Dresden, Germany]) and an optical camera (Nikon D70s). The correlation of canopy closure values derived from the image pairs was $r=0.98$. Our findings thus show that thermal canopy photography is a promising and simple to use alternative to optical canopy photography, because it limits possible sources of variability, since exposure settings and threshold definition cease to be an issue.
\end{abstract}




\title{
11 Manuscript II (Annex B)
}

On the geometry and allometry of big buttressed trees - a challenge for forest monitoring: new insights from 3D-modeling with terrestrial laser scanning

Nils Nölke, Lutz Fehrmann, I Nengah Surati Jaya, Tatang Tiryana, Dominik Seidel, Christoph Kleinn

Status: published 2015, iForest - Biogeosciences and Forestry, 8: 574-581

Contribution by N. Nölke: 80 \%

- Collection and processing of data

- Analysis and interpretation of data

- Draft and revision of the manuscript

\begin{abstract}
In many old-growth natural and close-to-natural forest types, notably in humid tropical forests, a relatively small number of very large trees contribute considerably to stand basal area and biomass. Often these big trees have distinct buttress roots and show irregular non-convex shapes. The methods used to measure or determine the diameter of buttressed trees have a large impact on the determination of volume and biomass and resulting estimates of aboveground carbon stocks in tropical forests. Usually diameter above buttress (DAB) is measured where the cylindrical bole of the tree starts, and this value is then used as an independent variable for biomass models. For the purpose of this article, we conducted a small methodological study that will contribute to improving determining individual tree volume and biomass by means of terrestrial laser scanning (TLS). We were interested in the geometry and allometry of the buttresses and in the change in buttress volume and cross-sectional area with height over tree. Our results suggest that the relationship between cross sectional areas at DAB height (ADAB) and the actual tree basal area measured at $1.3 \mathrm{~m}$ height is relatively strong $\left(\mathrm{R}^{2}=0.87\right)$ for a range of different buttress morphologies and tree dimensions. Furthermore, the change in stem cross sectional area with tree height is surprisingly similar and smooth. Our 3D-analysis of different buttressed trees therefore gives new insights into their very irregular geometry and our methodological approach can help to improve volume and biomass models for buttressed trees that are crucial contributors to carbon stocks in tropical forests by developing models that describe the relation between a diameter above buttress and the actual tree basal area in $1.3 \mathrm{~m}$ for different species or species groups.
\end{abstract}




\title{
12 Manuscript III (Annex C)
}

Changes in culm surface temperature with maturity of the bamboo species Guadua angustifolia Kunth

Nils Nölke, Juan Carlos Camargo García, Christoph Kleinn, Andrea Polle

Status: published 2015, Journal of Forest Research (early view): 1-7

Contribution by N. Nölke: $80 \%$

- Collection of data

- Analysis and interpretation of data

- Draft and revision of the manuscript

\begin{abstract}
Determining the age and culm maturity of commercial bamboo is essential to guarantee that the culms to be harvested are of high quality culms and feature the best physical and mechanical properties. The accurate estimation of guadua culm age is a challenge. The most common approach is based on visual interpretation of culm color and distribution of lichens. However, this assessment is prone to misinterpretation so that more objective approaches would help guadua management considerably. In this study, we used thermal images of bamboo culms of Guadua angustifolia Kunth and analyzed the relationship between culm surface temperature and maturity, driven by the hypothesis that young culms may exhibit lower surface temperatures than old ones. The culm surface temperature shows small but constant differences between the three age classes of one, two, and three years. Our findings indicate that surface temperature may be applied as an additional indicator to support the determination of maturity of guadua culms, in addition to the visual assessment of the culms.
\end{abstract}




\title{
13 Manuscript IV (Annex D)
}

\section{Comparing Canopy Leaf Temperature of Three Central European Tree} Species Based on Simultaneous Confidence Bands for Penalized Splines

Manuel Vonrüti, Aleaxander Spasojevic, Nils Nölke, Thomas Kneib, Christoph Kleinn

Status: Manuscript, in review since 13 January 2016 [Journal of Applied Statistics]

Contribution by N. Nölke: $50 \%$

- Conception and design of the work

- Collection and Pre-Processing of data

- Revision of the manuscript

\begin{abstract}
Temperature is an important physical factor that is known to affect strongly biodiversity and ecosystems and their functioning. However, it is still relatively little researched, possibly also because of the multitude of influencing factors and the complexity of the statistics involved. This study researches into differences between the surface temperature of three Central European broadleaf tree species. A better understanding of these differences may help to elucidate the role of microclimate for biodiversity. We consider a time series of high-resolution thermal images taken from a meteorological observation tower and calculate mean canopy leaf temperatures for beech, ash and maple (Fagus silvatica, Fraxinus excelsior and Acer pseudoplatanus). In a first step, comparable image areas are extracted for analyses from the thermal image sections of the crown of each tree species avoiding shadow areas, branches, etc. We used an automatic segmentation technique, the Otsu thresholding. Extracted canopy leaf temperature values were then processed and the resulting temperature profiles estimated by O'Sullivan penalized splines. For comparing the difference in canopy leaf temperature over time, we propose the construction of simultaneous confidence bands. The analyses show that there are significant though small - differences in canopy surface temperature between the three tree species.
\end{abstract}




\title{
14 Manuscript V (Annex E)
}

\section{Influence of four different digital elevation models on estimation of tree cover}

Hans Fuchs, Nils Nölke

Status: Manuscript, submission planned for March 2016 [Journal of Applied Remote Sensing] Contribution by N. Nölke: $50 \%$

- Processing of Pleaides images

- Analysis and interpretation of elevation data

- Draft and revision of the manuscript

\begin{abstract}
Relief plays a crucial role for land surface and atmospheric processes especially in mountainous terrain. Different attributes, such as elevation, slope, and aspect which are highly relevant for forest and environmental management can be extracted from digital elevation models (DEM). During the pre-processing of remote sensing images, DEMs play an important role in orthorectification and illumination correction. However, the degree of detail and the data quality differs among the available DEMs and thus directly influence the results of image processing. For this purpose, we focus on data quality and evaluate four different DEMs in Anhui province, China. The analysis shows a difference of up to $10 \%$ in tree cover between corrected and uncorrected images. Among the corrected ones, we found that the usage of SRTM30 results in an improved overall accuracy in comparison to the high-resolution DEM which is extracted from the Pleaides imagery.
\end{abstract}




\section{Synthesis: Integrating Remote Sensing Techniques into Forest Monitoring}

High-resolution thermal camera systems, terrestrial laser scanners, and high-resolution satellite imagery present three sources of data that have the potential to contribute to the advancement of forest monitoring. To adapt to ever changing and increasing information demands from different forest-related research communities and policy makers, research in forest monitoring also needs to be involved in how to integrate new variables into forest monitoring systems, either in the form of direct observations or indicator systems from which the target information is modelled. Further challenges in forest monitoring research include the improvement of measurement techniques and methods to reduce both costs and measurement errors.

\subsection{The Application of Infrared Thermal Imaging}

Temperature constitutes an important variable that controls the biological system and its processes, and also presents a characteristic of the global climate change. Besides thermal imaging technology, research has by and large focused rather on air temperature as a proxy or used thermosensors to measure surface temperature. Ritter et al. (2005) used this approach to punctually analyze the temperature of forest gaps. These sensors, measuring the kinetic temperature, however, are complicated to install rather on the forest floor or at e.g. the canopy foliage. In this thesis, thermal imaging is discussed as an easy-to-use method to measure the surface temperature on different scales, where the potential of integrating this technique into forest monitoring is analyzed.

Thermal imaging can enhance well-established techniques in forest monitoring. A new idea or application may increase the reliability and efficiency of the determination of the age of bamboo culms. Information about the maturity of bamboo culms is of utmost importance because it is only when the process of lignification is finished and the culm is strong that it can be used for construction. This is the ideal point in time for harvesting, but determining of the age of the culm still remains a challenge. As the findings of the study conducted in Colombia (Manuscript III) illustrate, thermal imagery can support researchers' determination of the maturity of bamboo culms and serve as an additional indicator beside visual assessment.

Secondly, thermal imaging may also improves canopy cover photography. Optical canopy photography is a well-established technique to estimate canopy cover; nevertheless, until now the results are influenced by a number of aspects, such as exposure, illumination conditions, and threshold definition. Thermal imaging, as Manuscript I shows, may substantially improve the measurement technique used to estimate canopy cover. These case studies illustrate that thermal imaging may overcome some of the problems of optical photography. Based on the resulting 
images, a standard protocol to estimate and compare canopy cover change could be devised that makes use of the large difference between sky and non-sky temperature. In the study, a strong correlation $\left(\mathrm{R}^{2}=0.96\right)$ of canopy closure values derived from thermal and optical image pairs could be observed. Accordingly, thermal imaging represents a feasible and accurate method. For similar case studies, we recommend the use of high-resolution thermal cameras, as we found the camera used (Infratec VarioCam hr head) suitable to obtain the maximum degree of detail from the canopy image.

Although the studies conducted enhance the knowledge of how infrared thermal imaging may benefit forest applications and show that integrating thermal camera systems into forest monitoring is without doubt a beneficial enterprise, the interpretation of thermal images continues to pose a challenge. Surface temperature is influenced on all different spatial and temporal scales from single leaf to canopy foliage and by time of the day. The results of our explorative studies (cf. Chapter 9) showed in accordance with existing literature (Gates, 1968), that the factors influencing leaf temperature most are the environmental conditions (sun position, incoming radiative energy, air temperature). In particular on leaf level there is an additional influence by the plant architecture (canopy density, shape, and leaf size). For an enhanced understanding and quantification of the influencing factors we recommend further research to investigate this relationship in more detail. Therefore one may use TLS or alike techniques to extract plant architecture variables in combination with a high resolution thermal camera.

Multi-temporal thermal imagery may be a promising data source in forest monitoring, but the analyses are still an ongoing challenge. When working with absolute temperature values extracted from thermal images taken at different points in time, the possibilities of analyzing changes in leaf or canopy temperature in detail are significantly reduced. Therefore, interpretation requires the calculation of the leaf-to-air difference in order to normalize the data. The fact that there are complex interactions at the leaf level, through light, wind, solar radiation, and air temperature which themselves interact with each other make the interpretation difficult. Among our studies (cf. Chapter 9.3; Manuscript IV), where we used high-resolution thermal imagery, auxiliary variables, like transpiration or stomatal conductance, and advanced statistical methods to test whether small differences in surface temperature can be observed in different tree species or not, could not be answered satisfactorily. We conclude that further research should go beyond the studies discussed here and try to investigate the single contribution of the influencing 
factors on surface temperature. A first step was done with the greenhouse experiment (cf. Chapter 9.3).

For a follow-up research project based on the findings of this thesis, one which is of major interest for the German forestry, we suggest studying the potential of thermal imagery in the early detection of trees infected by a bark beetle attack. This will be a novel approach, since detection will already be possible while the needles and leaves still appear green. Because of the blocked water transport, the transpiration rate changes and thus the surface temperature is expected to show an increase.

\subsection{Laser Scanning and Biomass of Big Trees}

Several aspects affect the quality of inventory data, during fieldwork it mainly depends on the skills of the field workers and the available measurement devices. The degree of accuracy is important if field data are linked with remote sensing data to estimate biomass. Seeing that big trees are important contributors to aboveground carbon content, a precise method of estimation is crucial to monitor forest carbon changes. Common measurement methods still result in an estimated biomass that is biased, in particular for big trees showing irregular non-convex shapes, and hence leaves researchers with a number of unresolved issues. We presented a new method to account for the complexity of buttressed trees (Manuscript II) using terrestrial laser scanning. Recent advancements in laser technology enabled us to use a light- weight and portable scanner. This scanner record as all of the TLS systems the structure of the tree with high precision and depending on the scan quality the point distance at $10 \mathrm{~m}$ distance differ between 3 to $12 \mathrm{~mm}$. In our study, a multiple scan approach was used to arrive at a high-resolution 3D representation of 12 selected buttressed trees. The number of scans depends the complexity of the shape. Our findings thus give new insights into the irregular geometry of buttressed trees and the methodological approach we employed will help to improve volume and biomass models for this type of tree. We detected a strong relationship $\left(\mathrm{R}^{2}=0.87\right)$ between cross-sectional areas at DAB height and the actual tree basal area measured at $1.3 \mathrm{~m}$ height. Thus, this relationship allows researchers to estimate the basal area at $1.3 \mathrm{~m}$ height based on the easily conducted measurement at DAB height.

We therefore conclude that the laser scanning approach presented here enhances the understanding of the difference of the actual and the estimated volume of large trees and may further improve the existing allometric models to finally result in a wellestimated AGB. This contributes to the ongoing research on tree biomass with a focus on the aboveground biomass variation due to large trees. This is an aspect of particular significance, as the study by Sill et al. (2013) shows that for example in South America 
big trees store on average $25.1 \%$ of the total AGB, but represent only $1.5 \%$ of the stems larger than $10 \mathrm{~cm}$. Furthermore, repeated scans of the same trees can be used to monitor not only changes in volume but also changes in the geometry of buttressed trees, where it is known that the geometry is related to important mechanical properties. Seidel (2011) studied the relationship of biomass and the number of data points, which belong to a single tree. He successfully estimated AGB for potted juvenile trees. Nevertheless, this approach requires measured biomass for a number of harvested trees. Calders et al. (2014) showed a nondestructive measurement of AGB from TLS data. The presented approach based on quantitative structure models and need no prior assumptions about tree structure. The latter approach seems to be quite promising and could be applied to our dataset as comparison to the presented manual approach (Manuscript II).

Until now, multiple scanning in dense forest, in particular in tropical forests, is impossible due to the large scan shadows caused by understory vegetation. Furthermore, laser scanning is prone to distortions in point cloud data, due to canopy movements caused by wind. The effect of shaking twigs and branches result in a scattering point cloud. To overcome the difficulties of the scan shadows, we expect an improvement with the availability of full-waveform terrestrial laser scanning which allows for the extraction of multiple returns per beam. We recommend first scanning trees in less dense forest and, secondly, scanning only as many trees per species which are required in order to establish further relationships between the variables that are relevant and feasible to measure in the field.

Parallel to the TLS application, there is another interesting development, namely terrestrial close range photogrammetry. This approach requires only a compact or even a smartphone camera. Based on several overlapping photos taken around the tree, the automatic SfM process (cf. Chapter 3.2.2) registers all photos and constructs a dense point cloud of the buttressed tree. This approach was successfully tested in November 2015 with two out of the 12 selected trees (cf. Manuscript II). The photogrammetric process shows some advantages compared to TLS, since low cost and portable cameras offer a high level of mobility inside the forest. This could be an advantage if understory vegetation occurs. Finally, this alternative approach will become a competitive tool for the $3 \mathrm{D}$ reconstruction of trees. 


\subsection{Illumination Correction and Tree Cover}

Researchers have been monitoring forest covers for many years using a variety of sensors. Since the launch of REDD, there has been even more focus on forest cover change to illustrate developing countries' performance in reducing forest degradation and deforestation. The transparent, consistent, and accurate reporting of the latter is required by the Measuring, Reporting, and Verification (MRV) system. In this context, remote sensing is a vital tool to estimate forest cover change. Furthermore, these data can be linked to several impact assessments. When using this technology, limitations in acquiring and analyzing data occur mainly due to seasonality effects or data artifacts, as well as for optical data in particular in clouds.

Currently, the main data source of global forest cover information is the global high-resolution map of tree cover, loss, and gain by Hansen et al. (2013). Here, the estimation of forest cover is based on a supervised classification approach using Landsat imagery. This also constitutes a widely-used source of remote sensing data within the scope of nationwide projects to detect areas of deforestation and degradation. The quality of the generated data, however, does not always fulfill the requirements of REDD+ because sensors such as Landsat are too coarse for an accurate deforestation monitoring. Therefore, an improved assessment of small-scale forest cover change is crucial which require satellites with resolution of 5 - $10 \mathrm{~m}$. In Manuscript V we found high-resolution RapidEye imagery more suitable for estimating forest cover on a minimum mapping unit of 0.5 ha; additionally, RapidEye, being an optical sensor, is sensitive to vegetation greenness, density, and fractional tree cover. Nevertheless, without a proper illumination correction, both for the global tree cover map and for RapidEye imagery, the estimation of tree cover will be biased, even more so in mountainous terrain. Our study elucidates that the change in tree cover varies up to $2 \%$ and may simply be by the different digital elevation models that range from high to coarse spatial resolution. This leads us to the assumption, that scale is a critical issue for removing topographic effects. Zhang et al. (2015) performed a scientific experiment where simulated satellite imagery with resolution of 30 to $500 \mathrm{~m}$ were corrected with DEMs of 5 to $500 \mathrm{~m}$ spatial resolution. They concluded that for illumination correction of $30 \mathrm{~m}$ resolution imagery, at least a DEM with $10 \mathrm{~m}$ resolution is necessary. If illumination correction is not performed at all, we found a difference in tree cover of up to $10 \%$ compared to the corrected imagery. Moreover, the study showed that sun-shaded steep slope terrain was often misclassified 
as coniferous forest due to the similarity of the spectral signature. Thus, imagery corrected with the free available SRTM30 DEM with a resolution of $30 \mathrm{~m}$ leads to a higher accuracy in the estimation of tree cover. High-resolution digital elevation models with a resolution of around $1 \mathrm{~m}$, however, do not further improve the estimation of forest tree cover within our study area. Hence, we strongly recommend the SRTM30 product when working with RapidEye and Landsat imagery. The application of the SRTM30 DEM for the illumination correction of very high-resolution imagery, such as Pleiades or WorldView 3, would recommend for a further study. Due to the large difference in spatial resolution, the result in the estimation of tree cover using this combination would be quite interesting. Additionally, the study conducted in Shitai County (Anhui Province, Southeast China) might be repeated in other locales to foster a better understanding of the influence of the sun elevation and azimuth on the one hand, and the variation in the performance of the illumination correction on the other hand.

\subsection{Conclusion}

Forest monitoring currently attracts great attention in the context of the international conventions UN-FCCC, UN-CBD, and UN-CCD well beyond the traditional applications in operational forest planning (forest operations inventories), as well as in forest management (forest management inventories) and for the formulation of forest policies (national forest inventories). Signatory states are also obliged to report the state of their forests on a regular basis and in many countries, new systems need to be installed because they have thus far lacked a systematic form of large area forest monitoring. Therefore, integrated field and remote sensing inventories have to be established to assess a multitude of different variables on a national level. When establishing forest monitoring systems, questions of operationally, cost and capacity are vital. In the realization phase, novel remote sensing approaches may lead to more efficient and more accurate forest monitoring. Such novel approaches are constantly under development due to technological advances and the need for new forest inventory variables. Additionally, these new techniques should also reduce the impact of the sources of residual variability. There are a multitude of possibilities to improve or develop new forest monitoring techniques in each of the steps of the forest monitoring process. Lu et al. (2014) show one example where a novel approach is implemented in the step of data analysis. They used a fusion of MODIS and Landsat images to enhance forest monitoring for REDD. Next to enhancements in the data processing workflow, novel or enhanced techniques may also be established in the step of data collection. Here, the novel techniques that are in the focus of this thesis include the usage of state-of-the-art instruments such as TLS, thermal cameras, and satellite imagery. 
On the one hand, a plethora of studies work on a large scale and produce global maps of biomass, tree cover or surface temperature. However, it is often unclear how accurate these maps are. Yet accuracy figures as an important issue if maps derived from remote sensing data are used for scientific purposes. This not only applies to global map products, but also to small scale maps derived from very high-resolution satellite imagery. The importance of this map accuracy is also outlined in Manuscript V where the accuracy of the tree cover map is used to identify the optimal DEM for the topographic correction.

Besides this global paradigm, it is crucial to also focus on small-scale challenges that occur during forest inventories. First of all, improvements in inventory techniques may pave the way for a more accurate way of calculating the emission factor and may thus help to overcome problems rooted in information gaps and/or the users' inexperience. Moreover, it is important to adjust the factor to each country to include localized and forest-type specific data. A variety of techniques and methods may be used in order to extract this information and are widely established in every NFI. Such methods provide estimates or measurements of tree and plot variables. Depending on the selected technique, however, restrictions and uncertainties may result in an inefficient usage, as Manuscript I illustrates when discussing the limitations of hemispherical photography.

This thesis has shown that through the integration of thermal remote sensing in different steps of the forest monitoring process, at least a small number of localized questions were addressed. Despite the positive and convincing results from our studies, the presented techniques are still in their inception phase and need to be evaluated. Despite the benefits of integrating thermal imaging as presented in the studies, limitations still exist: information about the surface temperature only often proves insufficient for an accurate interpretation. Therefore, a combined analysis with additional datasets, such as visual images, are required.

In developing countries, remote sensing based forest monitoring has become common, in particular, to monitor tropical forests. Since these forests cover large areas, field campaigns are time-consuming and cost-intensive. When integrating satellite technologies into forest monitoring, field data for modeling and validation is essential, but the accuracy of field measurements is not of satisfying quality, which is relevant for modeling or the validation of remote sensing data. The latter has a direct influence on the above-mentioned map accuracy. The sources of errors as discussed in Chapter 5, which arise while conducting the inventory, vary and may result in inaccurate field data. 
Irregular and large trees are a special case, because the measurement of diameter at breast height is not useful. In Manuscript II, terrestrial laser scanning was introduced as a technique that provides accurate data on the volume of these trees using a semi-automatic process. Based on the findings a wide establishment of TLS in tropical forest may result in an increasing accuracy of field measurements. Kato et al. (2014) present a very small and portable terrestrial laser scanner to derive tree parameters in tropical forests

In the future, monitoring programs will strive for well-structured and less costintensive monitoring techniques. A higher effectiveness in data collection, assessment, and reporting will require the integration of new technologies and techniques both for conducting ground measurements and analyzing remote sensing data. This combination will have a much higher importance in future and we hope that the techniques presented in this thesis ultimately have the potential to become valuable to support researchers as well as the field teams involved in the forest inventory to establish a more efficient forest monitoring program. 


\section{References}

Aldred, A.H., Bonnor, G.M., 1985. Application of airborne lasers to forest surveys. Patawa National Forestry Institut, Chalk River, Ont.

Alonso-Carne, J., Garcia-Martin, A., Estrada-Pena, A., 2013. Systematic errors in temperature estimates from MODIS data covering the western Palearctic and their impact on a parasite development model. Geospatial health 8 (1), 1-12.

Androli, R., 2014. Mangroves monitoring using VHR Pléiades data, Toulouse.

Ansari, A.Q., Loomis, W.E., 1959. Leaf Temperatures. American Journal of Botany 46 (10), 713-717.

Arthur, J., Stewart, W. Transpiration of tobacco plants in relation to radiant energy in the visible and infra-red. In: Contributions Boyce Thompson Institute, pp. 43-501.

Aschoff, T., Spiecker, H., 2004. Algorithms for the automatic detection of trees in laser scanner data. International Archives of Photogrammetry, Remote Sensing and Spatial Information Sciences 36 (Part 8), W2.

Asner, G.P., Powell, G.V.N., Mascaro, J., Knapp, D.E., Clark, J.K., Jacobson, J., KennedyBowdoin, T., Balaji, A., Paez-Acosta, G., Victoria, E., Secada, L., Valqui, M., Hughes, R.F., 2010. High-resolution forest carbon stocks and emissions in the Amazon. Proceedings of the National Academy of Sciences of the United States of America 107 (38), 16738-16742.

Barker, JR, Bollman, M., Ringold, P.L., Sackinger, J., Cline, S.P., 2002. Evaluation of metric precision for a riparian forest survey. Environmental Monitoring and Assessment 75 (1), 51-72.

Beguet, B., 2014. Quantification and mapping of forest structure from Pléiades image texture, Toulouse.

Bholanath, P., Cort, K., 2015. National Scale Monitoring Reporting and Verification of Deforestation and Forest Degradation in Guyana. ISPRS - International Archives of the Photogrammetry, Remote Sensing and Spatial Information Sciences XL-7/W3, 315-322.

Bickford, C.A., 1952. The sampling design used in the forest survey of the Northeast. Journal of Forestry 50 (4), 290-293.

Blackbridge, 2014. RapidEye Satellite Imagery. Supporting Global REDD+ Activities on a National, Regional, or Local Level, http://www.blackbridge.com/rapideye/upload/RE_REDD.pdf. (Accessed 5 December, 2015).

Buitrago, M.F., Groen, T.A., Hecker, C.A., Skidmore, A.K., 2016. Changes in thermal infrared spectra of plants caused by temperature and water stress. ISPRS Journal of Photogrammetry and Remote Sensing 111, 22-31.

Burkhart, H.E., Tomé, M., 2012. Modeling forest trees and stands. Springer, Dordrecht, New York.

Calders, K., Newnham, G., Burt, A., Murphy, S., Raumonen, P., Herold, M., Culvenor, D., Avitabile, V., Disney, M., Armston, J., Kaasalainen, M., McMahon, S., 2015. Nondestructive estimates of above-ground biomass using terrestrial laser scanning. Methods in Ecology and Evolution 6 (2), 198-208.

Cardelús, C.L., Chazdon, R.L., 2002. Distribution and abundance of vascular epiphytes in tropical wet forests. A multi-scale approach. 
Chave, J., Condit, R., Salomon Aguilar, Hernandez, A., Lao, S., Perez, R., 2004. Error Propagation and Scaling for Tropical Forest Biomass Estimates. Philosophical Transactions: Biological Sciences 359 (1443), 409-420.

Curtis, O.F., 1938. Wallace and Clum, "Leaf Temperatures": A Critical Analysis with Additional Data. American Journal of Botany 25 (10), 761-771.

Dash, P., Gottsche, F.M., Olesen, F.S., Fischer, H., 2002. Land surface temperature and emissivity estimation from passive sensor data: theory and practice-current trends. International Journal of Remote Sensing 23 (13), 2563-2594.

DeFries, R., 2008. Terrestrial Vegetation in the Coupled Human-Earth System: Contributions of Remote Sensing. Annual Review of Environment and Resources 33, 369-390.

Diers, M., 2014. Temperature and stomatal conductance of leaves of three deciduous tree species: a greenhouse case study (Master Thesis). Universität Göttingen

Eaton, F.M., Belden, G.O., 1929. Leaf temperatures of cotton and their relation to transpiration, varietal differences, and yields. US Department of Agriculture, Washington, DC.

Elzinga, C., Shearer, R.C., Elzinga, G., 2005. Observer variation in tree diameter measurements. Western Journal of Applied Forestry 20 (2), 134-137.

ESA, 2010. GMES Sentinel-2 Mission Requirements Document, http://esamultimedia.esa.int/docs/GMES/Sentinel-2_MRD.pdf. (Accessed 28 December, 2015).

FAO, 2001. Global Forest Resources Assessment 2000 - main report. FAO, Rome.

FAO, 2006. Better forestry, less poverty. A practitioner's guide. Food and Agriculture Organization of the United Nations, Rome.

FAO, 2008. Technical Review of FAO's Approach and Methods for National Forset monitoring and Assessment (NFMA), Rome.

FAO, 2013. Voluntary guidelines on national forest monitoring. Draft version for discussion of sections I and II, http://www.fao.org/forestry/3863108f58961a3495e61a2fa774eca65a792f.pdf. (Accessed 2 September, 2015).

FAO, 2014. FAO's State of the World's Forests 2014. Forestry Chronicle 90 (5), 564.

FAO, 2015. Global Forest Resources Assessment 2015. FAO, Rome.

Fitter, A.H., Fitter, R.S., 2002. Rapid changes in flowering time in British plants. Science 296 (5573), 1689-1691.

Fischer, M., Bossdorf, O., Gockel, S., Hänsel, F., Hemp, A., Hessenmöller, D., Korte, G., Nieschulze, J., Pfeiffer, S., Prati, D., Renner, S., Schöning, I., Schumacher, U., Wells, K., Buscot, F., Kalko, E.K.V., Linsenmair, K.E., Schulze, E.D., Weisser, W.W. 2010. Implementing large-scale and long-term functional biodiversity research: The Biodiversity Exploratories. Basic and Applied Ecology 11 (6), 473-485.

Flannigan, M.D., Haar, T.H.V., 1986. Forest fire monitoring using NOAA satellite AVHRR. Canadian Journal of Forest Research 16 (5), 975-982.

FLIR, 2016. Thermal Imaging for Moisture \& Restoration, http://www.flir.com/instruments/building/display/?id=49421. (Accessed 8 January, 2016).

Fuchs, M., 1990. Infrared measurement of canopy temperature and detection of plant water stress. Theoretical and Applied Climatology 42 (4), 253-261.

Gates, D.M., 1968. Transpiration and Leaf Temperature. Annual Review of Plant Physiology 19, 211-238.

Gelpke, N., 2015. Sustainable use of our oceans - making ideas work. maribus, Hamburg. 
Gurevitch, J., Scheiner, S.M., Fox, G.A., 2006. The ecology of plants, 2. ed. Sinauer Assoc, Sunderland, Mass.

Hansen, M.C., Potapov, P.V., Moore, R., Hancher, M., Turubanova, S.A., Tyukavina, A., Thau, D., Stehman, S.V., Goetz, S.J., Loveland, T.R., Kommareddy, A., Egorov, A., Chini, L., Justice, C.O., Townshend, J.R.G., 2013. High-resolution global maps of 21st-century forest cover change. Science (New York, N.Y.) 342 (6160), 850-853.

Hatfield, J., Burke, J., 1991. Energy exchange and leaf temperature behavior of three plant species. Environmental and Experimental Botany 31 (3), 295-302.

Heinzel, J., Koch, B., 2011. Exploring full-waveform LiDAR parameters for tree species classification. International Journal of Applied Earth Observation and Geoinformation 13 (1), 152-160.

Herold, M., Skutsch, M., 2011. Monitoring, reporting and verification for national REDD+ programmes: two proposals. Environmental Research Letters 6 (1), 14002.

Hojas-Gascon, L., Belward, A., Eva, H., Ceccherini, G., Hagolle, O., Garcia, J., Cerutti, P., 2015. Potential improvement for forest cover and forest degradation mapping with the forthcoming Sentinel-2 program. ISPRS - International Archives of the Photogrammetry, Remote Sensing and Spatial Information Sciences XL-7/W3, 417-423.

Holmgren, J., 2004. Prediction of tree height, basal area and stem volume in forest stands using airborne laser scanning. Scandinavian Journal of Forest Research 19 (6), 543-553.

Huy, B., 2009. Methodology for research on CO2 sequestration in Natural Forests to join the program of Reducing emissions from deforestation and degradation (REDD). National Journal on Agriculture and Rural Development (1), 85-91.

Ishimura, A., Shimizu, Y., Rahimzadeh-Bajgiran, P., Omasa, K., 2011. Remote sensing of Japanese beech forest decline using an improved Temperature Vegetation Dryness Index (iTVDI). iForest - Biogeosciences and Forestry 4, 195-199.

Jentsch, A., Kreyling, J., Boettcher-Treschkow, J., Beierkuhnlein, C., 2009. Beyond gradual warming: extreme weather events alter flower phenology of European grassland and heath species. Global Change Biology 15 (4), 837-849.

Jiménez-Muñoz, J.C., Mattar, C., Sobrino, J.A., Malhi, Y., 2015. Digital thermal monitoring of the Amazon forest: an intercomparison of satellite and reanalysis products. International Journal of Digital Earth, 1-22.

Jones, H.G., 1999. Use of thermography for quantitative studies of spatial and temporal variation of stomatal conductance over leaf surfaces. Plant, Cell and Environment 22 (9), 1043-1055.

Jones, H.G., 1992. Plants and microclimate : a quantitative approach to environmental plant physiology, 2nd ed. Cambridge Univ. Press, Cambridge [u.a.].

Jones, H.G., Rotenberg, E., 2001. Energy, Radiation and Temperature Regulation in Plants. In: eLS. John Wiley \& Sons, Ltd.

Kalliovirta, J., Laasasenaho, J., Kangas, A., 2005. Evaluation of the Laser-relascope. Forest Ecology and Management 204 (2-3), 181-194.

Kankare, V., Holopainen, M., Vastaranta, M., Puttonen, E., Yu, X., Hyyppä, J., Vaaja, M., Hyyppä, H., Alho, P., 2013. Individual tree biomass estimation using terrestrial laser scanning. ISPRS Journal of Photogrammetry and Remote Sensing, 64-75.

Kato, A., Kajiwara, K., Honda, Y., Watanabe, M., Enoki, T., Yamaguchi, Y., Kobayashi, T. Efficient field data collection of tropical forest using terrestrial laser scanner. IGARSS 2014 - 2014 IEEE International Geoscience and Remote Sensing Symposium, pp. 816819. 
Kleinn, C., 2015. Lecture Notes for the Module “Monitoring of Forest Resources”, 5th ed., Göttingen.

Kuyah, S., Muthuri, C., Jamnadass, R., Mwangi, P., Neufeldt, H., Dietz, J., 2012. Crown area allometries for estimation of aboveground tree biomass in agricultural landscapes of western Kenya. Agroforestry systems 86 (2), 267-277.

Lambers, H., Chapin, F. Stuart, III, Pons, T., 2008. Photosynthesis. In: Plant Physiological Ecology. Springer New York, pp. 11-99.

Larcher, W., 2001. Ökophysiologie der Pflanzen. Leben, Leistung und Streßbewältigung der Pflanzen in ihrer Umwelt ; 77 Tabellen, 8 Boxen, 6., neubearb. Aufl. Ulmer, Stuttgart.

Leinonen, I., Grant, O.M., Tagliavia, C.P.P., Chaves, M.M., Jones, H.G., 2006. Estimating stomatal conductance with thermal imagery. Plant, Cell \& Environment 29 (8), 1508-1518.

Leuning, R., Grace, J., Monteith, J.L., Milford, J.R., Unsworth, M.H., Fowler, D., 1989. Leaf Energy Balances. Developments and Applications [and Discussion]. Philosophical Transactions of the Royal Society B: Biological Sciences 324 (1223), 191-206.

Leuzinger, S., Koerner, C., 2007. Tree species diversity affects canopy leaf temperatures in a mature temperate forest. Agricultural and Forest Meteorology 146, 29-37.

Li, Z., Chen, J., Baltsavias, E., 2008. Advances in Photogrammetry, Remote Sensing and Spatial Information Sciences; 2008 ISPRS Congress Book. 2008 ISPRS Congress Book. CRC Press, London.

Lillesand, T.M., Kiefer, R.W., Chipman, J.W., 2008. Remote sensing and image interpretation, 6th ed. John Wiley \& Sons, Hoboken, NJ.

Lösch, R., 2003. Wasserhaushalt der Pflanzen, 2., unveränd. Aufl. Quelle und Meyer, Wiebelsheim.

Lovett, G.M., Burns, D.A., Driscoll, C.T., Jenkins, J.C., Mitchell, M.J., Rustad, L., Shanley, J.B., Likens, G.E., Haeuber, R., 2007. Who needs environmental monitoring? Frontiers in Ecology and the Environment 5 (5), 253-260.

Lu, D., 2006. The potential and challenge of remote sensing-based biomass estimation. International Journal of Remote Sensing 27 (7), 1297-1328.

Luttrell, C., 2011. Lessons for REDD+ from measures to control illegal logging in Indonesia. Center for International Forestry Research; Niedersächsische Staats- und Universitätsbibliothek, Bogor, Göttingen.

Magnussen, S., Boudewyn, P., 1998. Derivations of stand heights from airborne laser scanner data with canopy-based quantile estimators. Canadian Journal of Forest Research 28 (7), 1016-1031.

McRoberts, R.E., Westfall, J.A., 2014. Effects of uncertainty in model predictions of individual tree volume on large area volume estimates. Forest Science 60 (1), 34-42.

Mitchard, E.T., Saatchi, S.S., Baccini, A., Asner, G.P., Goetz, S.J., Harris, N.L., Brown, S. 2013. Uncertainty in the spatial distribution of tropical forest biomass: a comparison of pan-tropical maps. Carbon balance and management 8(1), 1.

Myers, B.J., 1982. Guide to the identification of some tropical rainforest species from largescale colour aerial photographs. Australian Forestry 45 (1), 28-41.

Naesset, E., 1997. Determination of mean tree height of forest stands using airborne laser scanner data. ISPRS Journal of Photogrammetry and Remote Sensing 52 (2), 49-56.

Naesset, E., Gobakken, T., Holmgren, J., Hyyppa, H., Hyyppa, J., Maltamo, M., Nilsson, M., Olsson, H., Persson, A., Soderman, U., 2004. Laser scanning of forest resources: The Nordic experience. Scandinavian Journal of Forest Research 19 (6), 482-499. 
Næsset, E., 2002. Predicting forest stand characteristics with airborne scanning laser using a practical two-stage procedure and field data. Remote Sensing of Environment 80 (1), 8899.

Nelson, R., Krabill, W., Maclean, G., 1984. DeterminigForest Canopy Characteristics using Airborne Laser Data. Remote Sensing of Environment 15 (3), 201-212.

De Sy, V., 2012. Forest monitoring should integrate biodiversity and socioeconomic data, say experts, http://blog.cifor.org/13018/forest-monitoring-should-integrate-biodiversity-andsocioeconomic-data-say-experts. (Accessed 25 September, 2015).

Norman, J.M., Becker, F., 1995. Terminology in thermal infrared remote sensing of natural surfaces. Thermal Remote Sensing of the Energy and Water Balance over Vegetation. Agricultural and Forest Meteorology 77 (3-4), 153-166.

Oehmichen, K., 2006. Satellitengestütze Waldflächenkartierung für die Bundeswaldinventur. Dissertation, Hamburg.

Ørka, H.O., Næsset, E., Bollandsås, O.M., 2009. Classifying species of individual trees by intensity and structure features derived from airborne laser scanner data. Remote Sensing of Environment 113 (6), 1163-1174.

Pfeil, W., 1858. Die Forsttaxation in ihrem ganzen Umfange, [4., umgearb. Ausg.], 3., abermals sehr verb. Aufl. Baumgärtner, Leipzig.

Raschke, K., 1956. Mikrometeorologisch gemessene Energieumsätze eines Alocasiablattes. Theoretical and applied climatology 7 (1956), 240-268.

Raumonen, P., Kaasalainen, M., Åkerblom, M., Kaasalainen, S., Kaartinen, H., Vastaranta, M., Holopainen, M., Disney, M., Lewis, P., 2013. Fast Automatic Precision Tree Models from Terrestrial Laser Scanner Data. Remote Sensing 5 (2), 491-520.

Reitberger, J., Krzystek, P., Stilla, U., 2008. Analysis of full waveform LIDAR data for the classification of deciduous and coniferous trees. International Journal of Remote Sensing 29 (5), 1407-1431.

Ritter, E., Dalsgaard, L., Einhorn, K.S., 2005. Light, temperature and soil moisture regimes following gap formation in a semi-natural beech-dominated forest in Denmark. Forest Ecology and Management 206 (1-3), 15-33.

Romijn, E., Herold, M., Kooistra, L., Murdiyarso, D., Verchot, L., 2012. Assessing capacities of non-Annex I countries for national forest monitoring in the context of REDD+. Environmental Science \& Policy 19, 33-48.

Rubio, E., Caselles, V., Badenas, C., 1997. Emissivity measurements of several soils and vegetation types in the 8-14, $\mu \mathrm{m}$ Wave band: Analysis of two field methods. Remote Sensing of Environment 59 (3), 490-521.

Saatchi, S.S., Harris, N.L., Brown, S., Lefsky, M., Mitchard, E.T.A., Salas, W., Zutta, B.R., Buermann, W., Lewis, S.L., Hagen, S., Petrova, S., White, L., Silman, M., Morel, A., 2011. Benchmark map of forest carbon stocks in tropical regions across three continents. Proceedings of the National Academy of Sciences of the United States of America 108 (24), 9899-9904.

Savvides, A., Ieperen, W.I., Dieleman, J.A., Marcelis, L.F.M., 2013. Meristem temperature substantially deviates from air temperature even in moderate environments. Plant, Cell \& Environment 36 (11), 1950-1960.

Scherrer, D., Bader, M.K.-F., Körner, C., 2011. Drought-sensitivity ranking of deciduous tree species based on thermal imaging of forest canopies. Agricultural and Forest Meteorology 151 (12), 1632-1640. 
Schreuder, H.T., Wood, G.B., Gregoire, T.G., 1993. Sampling methods for multiresource forest inventory. Wiley, New York.

Seidel, D., Beyer, F., Hertel, D., Fleck, S., Leuschner, C., 2011. 3D-laser scanning: A nondestructive method for studying above-ground biomass and growth of juvenile trees. Agricultural and Forest Meteorology 151 (10), 1305-1311.

Shull, C.A., 1919. Transpiration as energy dispersal. School Science and Mathematics 19 (1), $1-6$.

Simonse, M., Aschoff, T., Spiecker, H., Thies, M. (Eds.), 2003. Automatic determination of forest inventory parameters using terrestrial laserscanning.

Solodukhin, V.I., 1976. Metody izucheniia vertikal'nykh secheniĭ drevostoev. Metodicheskie rekomendatsii. Gosudarstvennyı̌ komitet lesnogo khoziaĭstva Soveta Ministrov SSSR, Leningradskiı̆ nauchno-issledovatel'skiŭ Institut lesnogo khoziăstva, Leningrad.

Stoll, M., Jones, H.G., 2007. Thermal imaging as a viable tool for monitoring plant stress. Journal International des Sciences de la Vigne et du Vin 41 (2), 77.

Tobin, B., Nieuwenhuis, M., 2007. Biomass expansion factors for Sitka spruce (Picea sitchensis (Bong.) Carr.) in Ireland. European Journal of Forest Research 126 (2), 189-196.

Tomppo, E., Haakana, M., Katila, M., Peräsaari, J., 2008. Multi-source national forest inventory. Methods and applications, 1. Ed. Springer Netherland, Berlin.

Townshend, J.R., Justice, C.O., Kalb, V., 1987. Characterization and classification of South American land cover types using satellite data. International Journal of Remote Sensing 8 (8), 1189-1207.

Tronin, A.A., Hayakawa, M., Molchanov, O.A., 2002. Thermal IR satellite data application for earthquake research in Japan and China. Journal of Geodynamics 33 (4), 519-534.

Unterseher, M., Reiher, A., Otto, P., Schnittler, M., 2008. Pilze im Kronenraum lebender Bäume - 5 Jahre mykologische Biodiversitätsforschung am Leipziger Auwald Kran. Zeitschrift fuer Mykologie (74), 203-220.

Waggoner, P.E. Forest Inventories: Discrepancies and Uncertainties, http://www.rff.org/documents/RFF-DP-09-29.pdf.

Whittell, T., Duncombe, J., 1768. Tables of solid measure, for finding, by inspection, the quantity of any tree, from six inches to eighty feet in length, and from six inches to three feet in diameter. [printed for the patentees of the dendrometer [i.e. Thomas Whittell and John Duncombe], London.

Willert, D.J. von, Matyssek, R., Herppich, W., 1995. Experimental plant ecology: fundamentals and applications. Experimentelle Pflanzenökologie: Grundlagen und Anwendungen.

Winjum, J.K., Brown, S., Schlamadinger, B., 1998. Forest harvests and wood products: sources and sinks of atmospheric carbon dioxide. Forest Science 44 (2), 272-284.

Wulder, M.A., Bater, C.W., Coops, N.C., Hilker, T., White, J.C., 2008. The role of LiDAR in sustainable forest management. Forestry Chronicle 84 (6), 807-826.

Yanli Zhang, Guangjian Yan, Yulong Bai, 2015. Sensitivity of Topographic Correction to the DEM Spatial Scale. IEEE Geoscience and Remote Sensing Letters 12 (1), 53-57.

Yuan, W., Yu, Y., Yue, Y., Wang, J., Zhang, F., Dang, X., 2015. Use of infrared thermal imaging to diagnose health of Ammopiptanthus mongolicus in northwestern China. Journal of Forestry Research 26 (3), 605-612. 
Annex A

Manuscript I 


\section{Thermal canopy photography in forestry - an alternative to optical cover photography}

\author{
Nils Nölke, Philip Beckschäfer, Christoph Kleinn
}

Hemispherical canopy photography is a widely used technique to observe crown-related forest variables. However, standardization of this technique remains challenging, as exposure and threshold settings continue to constitute the main sources of variation of such photographs. This paper presents a new method to overcome standardization issues by using thermal canopy photography. Using a thermal camera, images are produced which are not critically limited in their dynamic range so that photographic exposure becomes irrelevant. Moreover, the high temperature contrast between "sky" and "non-sky", resulting from extreme low sky temperatures, facilitates the unambiguous selection of a threshold which separates "sky" from "non-sky" pixels. For a comparison, we have taken canopy images with a high-resolution thermal camera (VarioCam hr head - Infratec, Dresden, Germany) and an optical camera (Nikon D70s). The correlation of canopy closure values derived from the image pairs was $r=0.98$. Our findings thus show that thermal canopy photography is a promising and simple to use alternative to optical canopy photography, because it limits possible sources of variability, since exposure settings and threshold definition cease to be an issue.

Keywords: Hemispherical Photographs, Exposure, Thresholding, Thermal Images, Canopy Structure

\section{Introduction}

Information on gap fraction, leaf area, and other structural variables of forest canopies are required parameters in a wide range of studies, but their "measurement" is evidently difficult. Cover photography (Macfarlane et al. 2007a, 2007b) and hemispherical photography in particular are terrestrial remotesensing techniques widely employed to produce upward facing images of sections of the forest canopy (Hale \& Edwards 2002). The term "hemispherical" here refers to the approach of taking wide-angle photographs. These photographs, frequently taken with a fisheye lens, form the basis for subsequent analyses with gap fraction (or its complement canopy closure) being the most frequently derived target variable (Jonckheere et al. 2005). Moreover, canopy related attributes like, e.g., near-ground solar radiation (Zou et al. 2007), leaf area index (Zhang et al. 2005), and microclimate below canopy

(Van Pelt \& Franklin 2000) are modeled from hemispherical photographs.

Yet before they may be analyzed, raw photographs need to be pre-processed, i.e., converted into binary images comprising just "sky" and "non-sky" pixels. Here, a crucial step is the selection of a radiometric threshold value that correctly separates "sky" from "non-sky" in the photograph, a process referred to as "thresholding". Thresholding has been identified as a source of inconsistencies by several studies that aim at identifying an "optimal threshold" either through automatic (Nobis \& Hunziker 2005, Macfarlane 2011) or manual approaches (Frazer et al. 2001). When preparing a threshold, it is important to take the canopy photographs with a photographic exposure setting that allows for a clear separation of the classes "sky" and "non-sky" (Rich 1990). However, the definition of a standardized optimal exposure is challenging because various condi-

$\checkmark$ Chair of Forest Inventory and Remote Sensing, Georg-August-Universität Göttingen, Büsgenweg 5, D-37077 Göttingen (Germany)

(a) Nils Nölke (nnoelke@gwdg.de)

Received: Sep 17, 2013 - Accepted: Mar 13, 2014

Citation: Nölke N, Beckschäfer P, Kleinn C, 2015. Thermal canopy photography in forestry an alternative to optical cover photography. iForest 8: 1-5 [online 2014-05-07] URL:

http: / / www.sisef.it/iforest/contents/?id=ifor1129-007

Communicated by: Francesco Ripullone tions, including cloudiness and illumination geometry may interfere. The effects of photographic exposure on optical hemispherical photography can be immense and have been discussed intensively (Chen et al. 1991, Wagner 1994, 1998, Macfarlane et al. 2000, Zhang et al. 2005, Beckschäfer et al. 2013). For neither of the processing steps - exposure and threshold definition - standard protocols do yet exist which are consistently applied throughout the scientific community. As a consequence, comparability between and within studies is hampered. Furthermore, gamma correction is another critical preprocessing step (Chianucci \& Cutini 2012) that can affect estimates based on hemispherical photography (Leblanc et al. 2005) and mainly influences the lighter midtones of an optical photograph which are linked to canopy transmittance.

While hemispherical and cover photography of forest canopy has been implemented and researched most frequently by using optical cameras that work in the visible spectral domain, we suggest a novel approach using a thermal camera which records the emission of radiation instead of a blend of direct, scattered, reflected, and transmitted radiation in the visible range of the spectrum. We hypothesize that recent technological advances in thermal photography might allow to overcome the challenges mentioned in standardizing terrestrial forest canopy photographs.

All objects that have a temperature above absolute zero $\left(-273^{\circ} \mathrm{C}\right)$ emit radiation in the wavelength range of 7-14 $\mu \mathrm{m}$ (thermal infrared). Thermal cameras are sensitive in this spectral range, record thermal infrared radiation, and translate it into temperature values. Thermal images may be employed for research into any temperature-related features including plant physiological processes like stomatal conductance (Matsumoto et al. 2005) or the comparison of crown temperatures between urban tree species (Leuzinger et al. 2010). Contrary to the thermal radiation emitted by plant tissue which is close to the ambient air temperature, there is only a small amount of thermal radiation emitted by the upper atmosphere. A thermal camera pointed to clear sky will measure a temperature of around $-30{ }^{\circ} \mathrm{C}$ independent from the ambient air temperature. This large difference in temperature between the sky as background and the tree canopy in the foreground promises to be an excellent basis to unambiguously distinguish "sky" pixels from "non-sky" pixels in a terrestrial canopy photograph taken with a thermal camera. Under cloudy conditions the temperature difference will decrease because the amount of emitted radiation from low-lying clouds is higher but the measured cloud temperature is below zero degree nevertheless.

Moreover, the dynamic range of a thermal 
camera is large: it covers a range from -40 to $120{ }^{\circ} \mathrm{C}$ and is thus considerably larger than that occurring in a forest canopy thermal photograph. In contrast, optical cameras have a limited dynamic range (in the order of magnitude of 6 to $8 \mathrm{f}$-stops), which frequently causes an over-exposure of vegetation parts due to inadequate exposure settings (Wagner 1998, Zhang et al. 2005, Beckschäfer et al. 2013).

In this study we compare canopy closure estimates obtained from canopy photographs taken with an optical camera with those derived from images taken with a thermal camera. We introduce thermal photography as a possibility for the standardization of terrestrial forest canopy photography.

\section{Materials and methods}

\section{Study site}

Canopy photographs were taken at 12 locations within the Forest Botanical Garden at Göttingen University (WGS84: 51 ${ }^{\circ} 3^{\prime} 28.08^{\prime \prime}$
$\mathrm{N}, 9^{\circ} 57^{\prime} 44.28^{\prime \prime}$ E). Optical and thermal photographs were taken at the same locations immediately one after another. The selection of the 12 locations was such that a range of canopy openness situations was covered as we expect it to be typical in deciduous forests. As we were focusing on pure methodological differences, we did not apply a probabilistic sampling scheme as it would be recommended for, e.g., assessing light conditions in a forest (Leblanc et al. 2005, Macfarlane et al. 2007b).
(A)

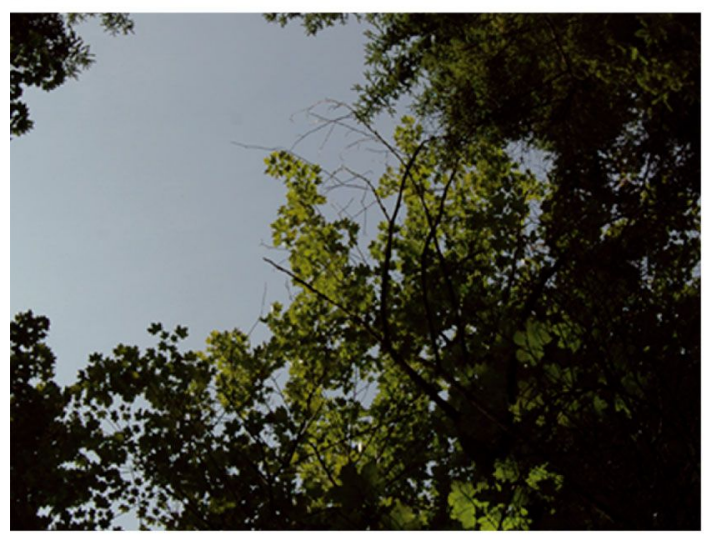

(C)

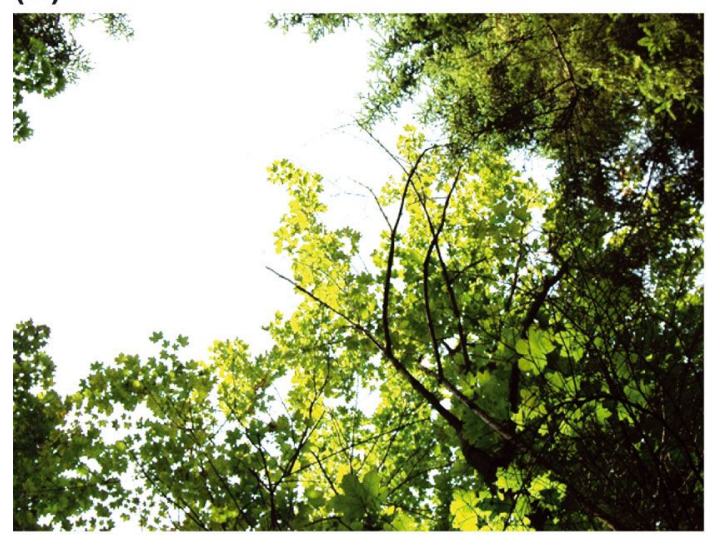

(E)

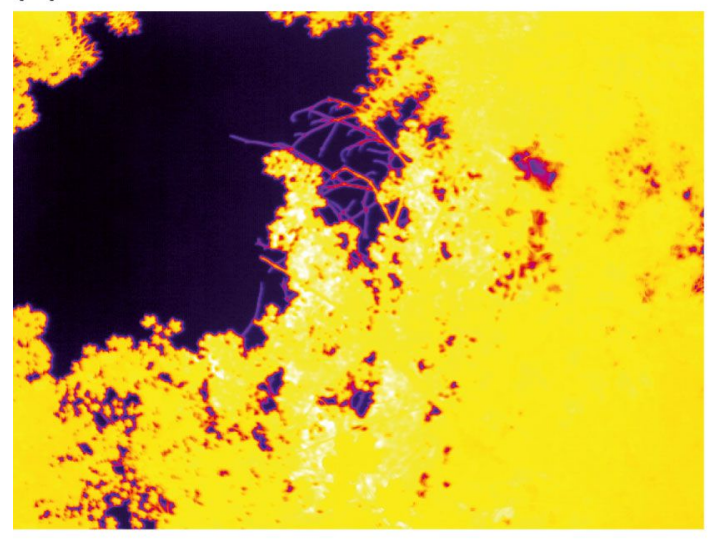

(B)

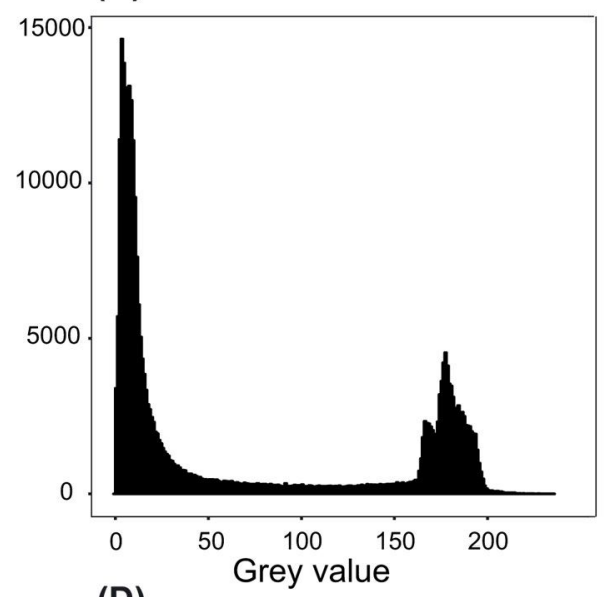

(D)

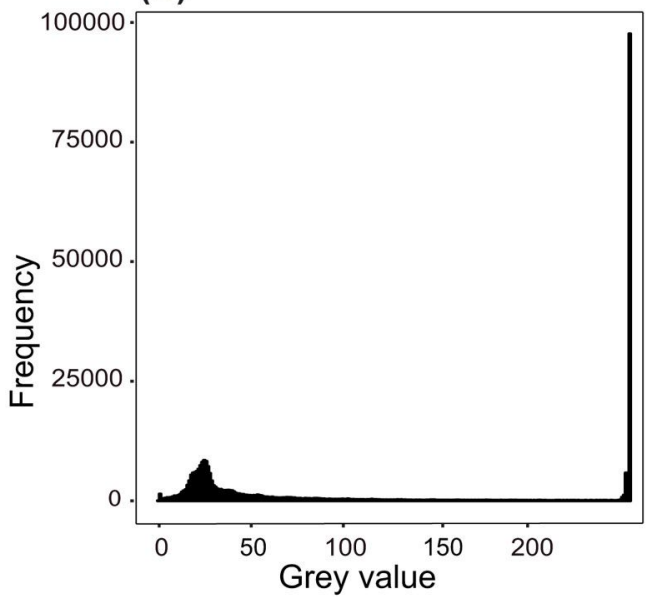

(F)

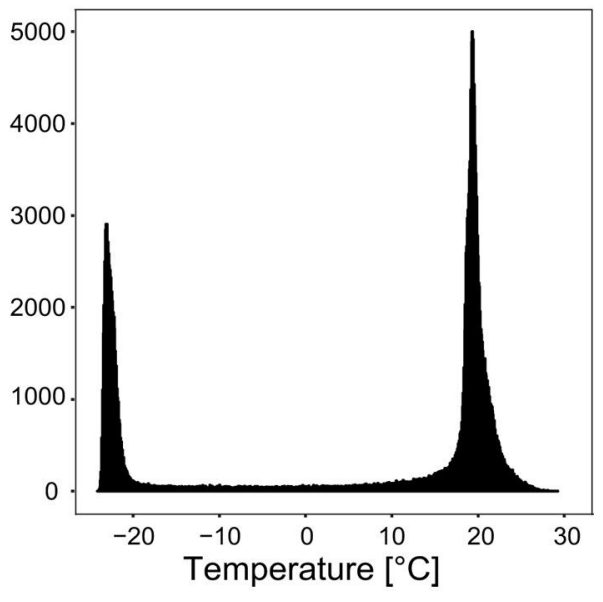

Fig. 1 - (A) Optical photograph (histogram-exposed, aperture F8.0, shutter speed $1 / 250)$ and (B) its grey value histogram. (C) Autoexposed optical photograph and (D) its grey value histogram. (E) Thermal image taken at the same location as (A) and (B), where black indicates sky and yellow represents vegetation; and (F) the corresponding temperature value histogram. The two peaks indicate sky and vegetation pixels. The peaks are best pronounced in the thermal image. 
Estimation of canopy attributes from thermal photography

Thermal images were taken with a VarioCAM hr head 720 (Infratec, Dresden, Germany) that has a resolution of $640 \times 480$ pixels and a spectral range of 7.5-14 $\mu \mathrm{m}$. The camera was equipped with a $30 \mathrm{~mm}$ lens with a field-of-view of $30^{\circ} \times 23^{\circ}$ and was mounted on a tripod at $1.3 \mathrm{~m}$ height. It was orientated to magnetic north using a compass and leveled to exactly face the vertical using a bubble-level. Images were stored in a raw format with a dynamic range of 16 bit in a temperature range between -40 to $+120{ }^{\circ} \mathrm{C}$. Photographs were taken between 8 and 10 a.m. on $26 / 07 / 2013$ where the day temperatures ranged between 18 and $23{ }^{\circ} \mathrm{C}$. We assumed a constant emissivity of 0.98 as an average for forest vegetation (Rubio et al. 1997).

For data processing the software packages Irbis 3 Plus (InfraTec, Dresden, Germany) and "R" (R Core Team 2013) with the EBImage package (Sklyar et al. 2007) were used. We converted each thermal raw image into an ASCII-file of temperature values per pixel. To separate "sky" and "non-sky" pixels we applied a global threshold of $0{ }^{\circ} \mathrm{C}$. Each pixel below $0{ }^{\circ} \mathrm{C}$ was classified as "sky", while pixels above $0{ }^{\circ} \mathrm{C}$ were classified as "non-sky". Canopy closure estimates, computed as unweighed gap fraction (Englund et al. 2000), were derived by counting the "non-sky" pixels per image.

\section{Estimation of canopy attributes from optical photography}

A NIKON D70s single lens reflex camera equipped with a standard 17-35 mm 1:2.8-4 lens (Tamron SP AF Aspherical DI LD - IF) was used for the acquisition of optical photographs. For the comparison of the field-ofview, we took one photograph with a $180^{\circ}$ fisheye lens (Sigma AF 2.8/4.5 DC). Like the thermal camera, the optical camera was mounted on a tripod at $1.3 \mathrm{~m}$ height and leveled to face exactly the vertical using a bubble-level. The top of the camera (position of the flash socket) was orientated to the magnetic north using a compass (Beaudet \& Messier 2002). The photographs were taken without direct sunlight entering the lens (Rich 1989) in the early morning. The basic camera settings mode "P" (Programmed Auto), ISO $=200$, and matrix metering were used; the focal length was fixed to $17 \mathrm{~mm}$. At each location a photograph was taken following the protocol for histogram exposure (Beckschäfer et al. 2013). Further, an autoexposed photograph was taken.

Each photograph was manually aligned with the slightly smaller thermal images and cropped to the same extent using Adobe Photoshop ${ }^{\circledR}$ (Adobe Systems Corporation, San Jose, CA, USA). The section of the photograph covering the same scene as the

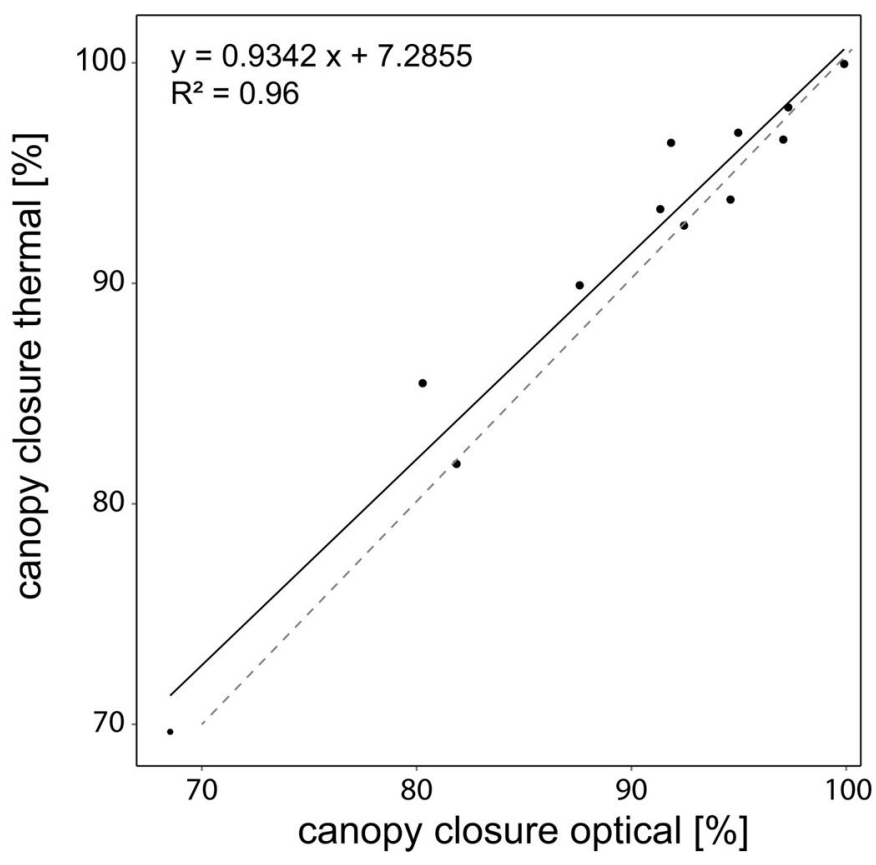

Fig. 2 - Canopy closure values based on optical photographs against canopy closure estimates based on thermal images. The dashed line is the 1:1 line and the solid line is the linear regression.

thermal image was resampled to the resolution of the thermal camera. To the blue color plane of the 8-bit photograph an automated global thresholding was applied to avoid variations in the threshold setting caused by the manual interpretation of the photographs (Jonckheere et al. 2004). Following Beckschäfer et al. (2014), the "minimum thresholding algorithm" (Prewitt \& Medelsohn 1966) implemented in ImageJ (Schneider et al. 2012) was used.

\section{Results}

Due to the narrow field-of-view of the thermal camera only a small part of the canopy is depicted in the photograph if compared to the area covered in a photograph taken with a $180^{\circ}$ fisheye lens.

Thermal images (Fig. 1e and Fig. 1f) taken in the forest cover a wide range of temperature values from cold sky $\left(-30^{\circ} \mathrm{C}\right)$ to warm vegetation $\left(+20{ }^{\circ} \mathrm{C}\right)$. In the temperature histogram (Fig. 1f), two distinct peaks can be clearly identified. The peak occurring at -23 ${ }^{\circ} \mathrm{C}$ represents "sky" pixels, with the majority of sky pixels showing a temperature in the range of -25 to $-18{ }^{\circ} \mathrm{C}$; this variation, of course, is also due to the composition of the atmosphere. The second peak at $+20{ }^{\circ} \mathrm{C}$ represents "non-sky", i.e., vegetation pixels with temperature values ranging from 15 to $28^{\circ} \mathrm{C}$. Between the two peaks the frequency values are very low. These intermediate temperature values are caused by mixed pixels covering vegetation and sky.

A visual comparison of Fig. 1a, Fig. 1c, and Fig. 1e shows that the thermal camera also clearly depicts small features like branches or individual leaves in the image. Thus, the thermal image allows a very clear dis- tinction between sky and vegetation and no over-exposure occurs. In comparison, the auto-exposed image taken with the optical camera (Fig. 1c) shows a considerable loss of information due to overexposure: the corresponding histogram shows that half of the pixels are white (Fig. 1d).

Canopy closure values for the same image sections of thermal photography and optical photography showed a relatively strong relation $\left(\mathrm{R}^{2}=0.96\right.$ - Fig. 2); the mean absolute difference was $1.6 \%$ and the regression line did not significantly deviate from the 1:1 line. Additionally, the slope indicated that the canopy closure of the thermal image increased by 0.9342 if the optical canopy closure increased by 1 .

\section{Discussion and Conclusion}

Our study clearly demonstrates the potential of terrestrial thermal canopy photography to overcome the challenges of standardization in conventional optical canopy photography, while resulting in the same canopy closure observations. The major advantage of thermal canopy photography is that a standardized protocol can be formulated easily, because no exposure setting or gamma correction is needed and the process of determining a threshold is straightforward and insensitive to thresholding algorithm issues. In thermal photographs, a threshold to separate "sky" from "non-sky" pixels may be unambiguously defined due to the high contrast between sky and vegetation pixels in the temperature histogram. This facilitates the retrieval of reproducible results and increases the comparability of results among studies.

Extreme temperature contrasts occur du- 
ring dry weather with clear sky (or low cloud cover). Although this is the ideal weather condition for image acquisition, nearly all weather conditions excluding rain will potentially allow for equally suitable images.

Thermal camera systems use uncooled microbolometer focal plane arrays (FPA) with a limited resolution of $640 \times 480$ pixels $(0.3$ megapixel) detecting the long wave radiation emitted by an object. Currently such thermal camera systems are referred to as high-resolution. Nevertheless, compared to the resolution of optical cameras (12-24 megapixel) their resolution is quite low. Thermal camera systems are not sensitive to visible light where the sun radiates the most energy and are therefore not affected by short-term variability in direct and diffuse solar radiation. Hence, cutting off the wavelengths lower than $8000 \mathrm{~nm}$ decreases the energy of the sun that reaches the detector and finally results in very low temperature values for the "sky" pixels. It is this physical principle that constitutes a strong advantage as images can be taken at any time of the day, compared to optical photographs which need to be taken during early morning or late evening hours Changing sky conditions can represent challenging issues for optical cover photography (i.e., shifting from clear sky to patchy cloud sky conditions). The application of thermal cameras may ultimately overcome the problem of changing sky conditions, and therefore, greatly increase the flexibility of work organization.

Optical cameras, in contrast, use high-resolution APS-C sensors (3008 x 2000 pixels) which are sensitive to the full visible spectrum of light, but as the dynamic range of such a sensor is smaller than the dynamic range of the scene to be photographed, overexposure, associated with a loss of information, frequently occurs in optical photographs.

Currently, a disadvantage of thermal photography is that only narrow field-of-view lenses are available for thermal cameras; full hemispherical or fisheye lenses are not yet on the market. Therefore, to date, an ideally suitable application for thermal cameras is cover photography as introduced by Macfarlane et al. (2007a, 2007b) which is a single view-angle method using a narrow field-ofview lens. This method has advantages over hemispherical photography (Pekin \& Macfarlane 2009), e.g., more accurate gap retrieval (Ryu et al. 2010, Chianucci \& Cutini 2013), and is much closer to the thermal photography approach. To obtain nearly the same canopy image compared to a standard $35 \mathrm{~mm}$ lens for digital single lens reflex cameras, we recommend using a high-resolution thermal camera with a wide-angle 12.5 $\mathrm{mm}$ lens and field-of-view of $65^{\circ} \times 51^{\circ}$. An obstacle for the use of thermal camera systems in forest research might be the much higher price of the equipment (US\$ 25000) compared to a standard optical DSLR cameras (US\$ 1000). Nonetheless, our results and theoretical considerations suggest that thermal cameras equipped with hemispherical lenses may well overcome the critical standardization issues which currently constitute a challenge in optical terrestrial canopy photography.

\section{Acknowledgements}

This study is an outcome of the research project KL894/14 "Enhancing the understanding of canopy biodiversity: estimating forest canopy surface temperature by airborne laser scanning, thermal infrared scanning, and 3D radiation modeling" funded by DFG, the German Research Foundation as a contributing project to the DFG Priority Program "Exploratories for large-scale and long-term functional biodiversity research". We thank the managers of the three exploratories, Swen Renner, Sonja Gockel, Kerstin Wiesner, and Martin Gorke for their work in maintaining the plot and project infrastructure; Simone Pfeiffer and Christiane Fischer for giving support through the central office, Michael Owonibi for managing the central data base, and Markus Fischer, Eduard Linsenmair, Dominik Hessenmöller, Jens Nieschulze, Daniel Prati, Ingo Schöning, François Buscot, Ernst-Detlef Schulze, Wolfgang W. Weisser and the late Elisabeth Kalko for their role in setting up the Biodiversity Exploratories project.

\section{References}

Beaudet M, Messier C (2002). Variation in canopy openness and light transmission following selection cutting in northern hardwood stands: an assessment based on hemispherical photographs. Agricultural and Forest Meteorology 110: 217228. - doi: 10.1016/S0168-1923(01)00289-1

Beckschäfer P, Seidel D, Kleinn C, Xu J (2013).

On the exposure of hemispherical photographs in forests. iForest 6: 228-237. - doi: 10.3832/ifor09 57-006

Beckschäfer P, Fehrmann L, Harrison RD, Xu J, Kleinn C (2014). Mapping Leaf Area Index in subtropical upland ecosystems using RapidEye imagery and the randomForest algorithm. IForest 7: 1-11. - doi: 10.3832/ifor0968-006

Chen J, Black T, Adams R (1991). Evaluation of hemispherical photography for determining plant area index and geometry of a forest stand. Agricultural and Forest Meteorology 56: 129-143. doi: 10.1016/0168-1923(91)90108-3

Chianucci F, Cutini A (2012). Digital hemispherical photography for estimating forest canopy properties: current controversies and opportunities. iForest 5 (6): 290-295. - doi: 10.3832/ifor 0775-005

Chianucci F, Cutini A (2013). Estimation of canopy properties in deciduous forests with digital hemispherical and cover photography. Agricultural and Forest Meteorology 168: 130-139. - doi: 10.1016/j.agrformet.2012.09.002 Englund SR, O'Brien JJ, Clark DB (2000). Evaluation of digital and film hemispherical photography and spherical densitometry for measuring forest light environments. Canadian Journal of Forest Research 30 (12): 1999-2005. - doi: 10.11 39/x00-116

Frazer G, Fournier R, Trofymow J, Hall R (2001). A comparison of digital and film fisheye photography for analysis of forest canopy structure and gap light transmission. Agricultural and Forest Meteorology 109: 249-263. - doi: 10.1016/ S0168-1923(01)00274-X

Hale SE, Edwards C (2002). Comparison of film and digital hemispherical photography across a wide range of canopy densities. Agricultural and Forest Meteorology 112: 51-56. - doi: 10.1016/ S0168-1923(02)00042-4

Jonckheere I, Fleck S, Nackaerts K, Muys B, Coppin P, Weiss M, Baret F (2004). Review of methods for in situ leaf area index determination: Part I. Theories, sensors and hemispherical photography. Agricultural and Forest Meteorology 121: 19-35. - doi: 10.1016/j.agrformet.2003.08 027

Jonckheere I, Nackaerts K, Muys B, Coppin P (2005). Assessment of automatic gap fraction estimation of forests from digital hemispherical photography. Agricultural and Forest Meteorology 132: 96-114. - doi: 10.1016/j.agrformet.20 05.06.003

Leblanc SG, Chen JM, Fernandes R, Deering DW, Conley A (2005). Methodology comparison for canopy structure parameters extraction from digital hemispherical photography in boreal forests. Agricultural and Forest Meteorology 129: 187-207. - doi: 10.1016/j.agrformet.2004. 09.006

Leuzinger S, Vogt R, Körner C (2010). Tree surface temperature in an urban environment. Agricultural and Forest Meteorology 150: 56-62. doi: 10.1016/j.agrformet.2009.08.006

Macfarlane C, Coote M, White D, Adams M (2000). Photographic exposure affects indirect estimation of leaf area in plantations of Eucalyptus globulus Labill. Agricultural and Forest Meteorology 100: 155-168. - doi: 10.1016/S016 8-1923(99)00139-2

Macfarlane C, Grigg A, Evangelista C (2007a). Estimating forest leaf area using cover and fullframe fisheye photography: thinking inside the circle. Agricultural and Forest Meteorology 146: 1-12. - doi: 10.1016/j.agrformet.2007.05.001

Macfarlane C, Hoffman M, Eamus D, Kerp N, Higginson S, McMurtrie R, Adams MA (2007b). Estimation of leaf area index in eucalypt forest using digital photography. Agricultural and Forest Meteorology 143: 176-188. - doi: 10.1016/j.agrformet.2006.10.013

Macfarlane C (2011). Classification method of mixed pixels does not affect canopy metrics from digital images of forest overstorey. Agricultural and Forest Meteorology 151: 833-840. - doi: 10.1016/j.agrformet.2011.01.019

Matsumoto K, Ohta T, Tanaka T (2005). Dependence of stomatal conductance on leaf chloro- 
phyll concentration and meteorological variables. Agricultural and Forest Meteorology 132: 44-57. - doi: 10.1016/j.agrformet.2005.07.001

Nobis M, Hunziker U (2005). Automatic thresholding for hemispherical canopy-photographs based on edge detection. Agricultural and Forest Meteorology 128: 243-250. - doi: 10.1016/j.agrformet.2004.10.002

Pekin B, Macfarlane C (2009). Measurement of crown cover and leaf area index using digital cover photography and its application to remote sensing. Remote Sensing 1: 1298-1320. - doi: 10.3390/rs 1041298

Prewitt JMS, Medelsohn ML (1966). The analysis of cell images. Annals of the New York Academy of Sciences 128: 1035-1053. - doi: 10.1111/j. 1749-6632.1965.tb11715.x

R Core Team (2013). R: a language and environment for statistical computing. R Foundation for Statistical Computing, Vienna, Austria. [online] URL: http://www.R-project.org/

Rich P (1989). A manual for analysis of hemispherical canopy photography. Technical Report, Los Alamos National Lab, Los Alamos, NM, USA, pp. 82.

Rich P (1990). Characterizing plant canopies with hemispherical photographs. Remote Sensing Reviews 5: 13-29. - doi: 10.1080/02757259009532 119

Rubio E, Caselles V, Badenas C (1997). Emissivity measurements of several soils and vegetation types in the $8-14 \mu \mathrm{m}$ wave band: analysis of two field methods. Remote Sensing of Environment 59: 490-521. - doi: 10.1016/S0034-4257 (96)00123-X

Ryu Y, Sonnentag O, Nilson T, Vargas R, Kobayashi H, Wenk R, Baldocchi DD (2010). How to quantify tree leaf area index in an open savanna ecosystem: a multi-instrument and multi-model approach. Agricultural and Forest Meteorology 150 (1): 63-76. - doi: 10.1016/j.agrformet.2009. 08.007

Schneider CA, Rasband WS, Eliceiri KW (2012). NIH Image to ImageJ: 25 years of image analysis. Nature Methods 9: 671-675. - doi: 10.1038/ nmeth.2089

Sklyar O, Huber W, Smith M (2007). EBImage: Image processing and image analysis toolkit for R. R package version 2, web site. [online] URL: http://bioconductor.wustl.edu/bioc/html/EBImag e.html

Van Pelt R, Franklin JF (2000). Influence of cano- py structure on the understory environment in tall, old-growth, conifer forests. Canadian Journal of Forest Research 30 (8): 1231-1245. - doi: 10.1139/x00-050

Wagner S (1994). Strahlungsschätzung in Wäldern durch hemisphrische Fotos. Methode und Anwendung. [Estimation of the radiation in forests by hemispheric photos. Methods and applications]. PhD thesis, University of Göttingen, Göttingen, Germany, pp. 166. [in German] Wagner S (1998). Calibration of grey values of hemispherical photographs for image analysis. Agricultural and Forest Meteorology 90: 103117. - doi: 10.1016/S0168-1923(97)00073-7

Zhang Y, Chen J, Miller J (2005). Determining digital hemispherical photograph exposure for leaf area index estimation. Agricultural and Forest Meteorology 133: 166-181. - doi: 10.1016/j.agrformet.2005.09.009

Zou CB, Barron-Gafford GA, Breshears DD (2007). Effects of topography and woody plant canopy cover on near-ground solar radiation: Relevant energy inputs for ecohydrology and hydropedology. Geophysical Research Letters 34 (24): L24S21 . - doi: 10.1029/2007GL031484 
Annex B

Manuscript II 


\section{On the geometry and allometry of big- buttressed trees - a challenge for forest monitoring: new insights from 3D-modeling with terrestrial laser scanning}

\author{
Nils Nölke ${ }^{(1)}$, Lutz Fehrmann ${ }^{(1)}$, I Nengah Surati Jaya ${ }^{(2)}$, \\ Tatang Tiryana $^{(2)}$, Dominik Seidel ${ }^{(1)}$, Christoph Kleinn ${ }^{(1)}$
}

In many old-growth natural and close-to-natural forest types, notably in humid tropical forests, a relatively small number of very tall trees contribute considerably to stand basal area and biomass. Such trees often show distinct buttress roots with irregular non-convex shapes. Buttresses are complex structures in the lowest stem section, where most tree biomass is located. The methods used to assess the diameter of buttressed trees have a large impact on the determination of volume and biomass, as well as on the resulting estimates of the aboveground carbon stock in tropical forests. As the measurement of diameter at breast height $(D B H$ at $1.3 \mathrm{~m})$ is not feasible in such conditions, the diameter above buttress $(D A B)$, where the cylindrical bole of the tree begins, is usually measured and included as an independent variable in biomass models. We conducted a methodological study aimed at determining the volume and biomass of individual buttressed trees belonging to several tropical species by the application of terrestrial laser scanning (TLS). The geometry and allometry of the buttresses, as well as the change with height along the stem in buttress volume and cross-sectional area were analyzed. Our results suggest that the relationship between cross-sectional areas at $D A B$ height $\left(A_{D A B}\right)$ and the actual tree basal area measured at $1.3 \mathrm{~m}$ height is relatively strong $\left(R^{2}=0.87\right)$ across a range of different species, buttress morphologies and tree dimensions. Furthermore, the change in stem cross-sectional area with tree height was surprisingly similar and smooth. Despite the small number of trees sampled, the methodological approach used in this study provided new insights on the very irregular geometry of buttressed trees. Our results may help improving the volume and biomass models for buttressed trees, that are crucial contributors to carbon stocks in tropical forests.

Keywords: Biomass, Morphology, Volume, Form Factor

\section{Introduction}

One of the most meaningful attributes used to describe forests both as a resource and as an ecosystem is biomass density per unit area. Nondestructive measurements of tree biomass are not possible - at least if the term "measurement" is used in its generic sense. Therefore, models are established based on

destructively sampled trees to estimate total biomass. Tree variables commonly used for such models are the diameter at breast height ( $D B H$, measured at $1.3 \mathrm{~m}$ height) or $D B H$ in combination with total tree height. These allometric relationships (from the ancient Greek word " $\alpha \lambda \lambda \circ \varsigma$ " = "other") are commonly modeled as power functions (Niklas

$\square$ (1) Chair of Forest Inventory and Remote Sensing, Universität Göttingen, Büsgenweg 5, D-37075 Göttingen (Germany); (2) Division of Forestry Planning, Department of Forest Management, Faculty of Forestry, Bogor Agricultural University (Indonesia)

@ Nils Nölke (nnoelke@gwdg.de)

Received: Sep 19, 2014 - Accepted: Dec 22, 2014

Citation: Nölke N, Fehrmann L, Surati Jaya IN, Tiryana T, Seidel D, Kleinn C, 2015. On the geometry and allometry of big-buttressed trees - a challenge for forest monitoring: new insights from 3D-modeling with terrestrial laser scanning. iForest (early view): e1-e8 [online 2015-03-02] URL: http://www.sisef.it/iforest/contents/?id=ifor1449-007

Communicated by: Matteo Garbarino
1994, West et al. 1999a, Zianis \& Mencuccini 2004, Pilli et al. 2006, Fehrmann \& Kleinn 2006) of the form $M=a D b$, where $M$ is the mass of dry matter, $D$ is the diameter, $b$ is the allometric scaling factor and $a$ is a coefficient determining the allometric intercept (Parresol 1999). The general model formulation also complies with assumptions of process models in plant allometry that are based on considerations on the hydraulic architecture and structural design of vascular plants and derive a particular scaling exponent of 8/3 (West et al. 1997, 1999a, 1999b, Enquist 2002, Niklas 2004, 2013). Total tree biomass is expected to scale proportionally to the conducting tissue that determines the metabolic rate.

The predicted biomass value, however, is not to be understood as a "measurement", but rather as "model-based estimation", carrying not only measurement errors (introduced by the measurement of the input variables to the model used) but also model errors (Clark \& Kellner 2012). In many old-growth natural and close-to-natural forest types, in particular tropical forests, the relatively few very large trees fix a large amount of carbon (Stephenson et al. 2014) and contribute a considerable share to the stand basal area and total biomass: "Large trees drive forest aboveground biomass variation in moist lowland forests across the tropics" (Slik et al. 2010).

In tropical forests the largest proportion of buttressed trees is usually among the emergent trees in the upper crown layer. These huge trees frequently show very irregular non-convex shapes (Chapman et al. 1998, Mehedi et al. 2012, Cushman et al. 2014). Clark (2002) reports for a Costarican lowland rain forest that about $52 \%$ of the stands' above ground woody biomass was constituted by trees whose diameter needed to be measured above stem irregularities. A study in southwest China shows that the percentage of buttressed trees is highest in the larger diameter classes (He et al. 2013). Buttresses are complex features that are regarded as an adaptation to poor tropical soils, enabling trees to form a flat root system in the upper, nutrient richer soil layers while maintaining their mechanical stability and anchorage (Richards 1952, Richter 1984, Ennos 1993, Crook et al. 1997, Newbery et al. 2009, Niklas 2013). Usually Dipterocarpaceae, Ligumninosae and Sterculiaceae show a greater tendency to produce buttresses than other tree species. Physiologically, buttress roots are the result of secondary xylem formed on the upper side of lateral roots. In very large trees the buttresses may extend to heights of more than $9 \mathrm{~m}$. Early studies have already shown that the size and profile of buttresses vary considerably between species, while within species the de- 
velopment and morphology of buttressing often appears to follow a fairly fixed character (Richards 1952, Smith 1972, He et al. 2013).

The methods used to measure the diameter of buttressed trees have a large impact on the determination of the volume and biomass, and consequently on the resulting estimates on aboveground carbon stocks in tropical forests (Clark \& Clark 2000). Measuring the $D B H$ of these trees is practically impossible and actually counterproductive, because a proper interpretation of such a measurement is not possible as of yet (Ngomanda et al 2012). Commonly, a diameter above buttress $(D A B)$ is measured where the cylindrical bole of the tree starts (Clark \& Clark 2000 Clark 2002, Basuki et al. 2009, Metcalf et al 2009). However, ignoring the buttressed part of the stem when determining total tree biomass and carbon stocks (e.g., by applying biomass models that are calibrated based on $D B H$ measurements) will lead to a considerable under-estimation (Nogueira et al. 2006 Cushman et al. 2014). This is a dilemma as there are no operational allometric models for buttressed trees, even though they are known to be one of the most important contributors to total biomass in many forests (Phillips et al. 2002, Henry et al. 2010) Even if buttressed trees are included in some general allometries (like e.g., Chave et al 2005), unbiased predictions could only be expected if the model is applied to a forest that has a similar proportion of buttressed trees as the calibration dataset.

Hence the challenging shape of buttressed trees has long attracted the attention of fores researchers and ecologists and their morphology has been investigated by different techniques. The measurement of the crosssectional area for buttressed parts of the trunk with conventional techniques is difficult (Ngomanda et al. 2012) and precise volume estimates of the buttressed stem section for larger trees are rare and often based on destructive techniques (Nogueira et al 2006)

Terrestrial laser scanning (TLS), on the other hand, offers new possibilities to tackle the issue of buttress shape by providing a contactless and non-destructive approach to derive 3-dimensional point clouds of the stem surface that can be used as a basis to establish operational allometric models for buttressed trees. The application of terrestrial "close-range remote sensing" is not entirely new. For example, Dean (2003) presented a study where terrestrial photography was applied to assess the stem taper of buttressed trees. Moreover, a study on modeling irregularly shaped trees with TLS and photogrammetry was recently conducted in Central Africa (Bauwens 2013).

The overall goal of this study is to contribute to improving buttressed tree mensuration, in particular in the context of determining individual tree volume and biomass. We were interested in tree geometry and allometry of buttress variables and how buttress volume can be determined from variables that can realistically be measured in the field during standard forest monitoring projects. If multiplied with mean wood density the buttress volume can also be used to predict the biomass of respective stem sections. Further, in order to apply existing allometric biomass models that are based on $D B H$ or tree basal area at $1.3 \mathrm{~m}$ above the ground, our study evaluates whether these input variables could be modeled from $D A B$ measurements. For this study we scanned 12 huge buttressed trees of different species in the Botanical Garden of Bogor, Indonesia and analyzed the geometry of the buttresses, specifically investigating the change of the stem cross-sectional area and compactness over tree height for individual trees, as well as the common allometry of the buttresses over different species. Despite the relatively small number of sample trees does not allow general conclusions about buttress morphology in different species, our study does give valuable indications about the suitability of the methodological approach

\section{Material and methods}

\section{Study site}

Data were collected in the Bogor Botanical

Tab. 1 - List of the tree species sampled in this study.

\begin{tabular}{cllc}
\hline Tree (\#) & Species & Family & Height $(\mathbf{m})$ \\
\hline 1 & Koompassia excelsa & Fabaceae & 43.3 \\
2 & Ficus robusta & Moraceae & 39.9 \\
3 & Celtis rigescens & Cannabaceae & 48.3 \\
4 & Ficus albipila & Moraceae & 53.7 \\
5 & Shorea leprosula & Dipterocarpaceae & 51.7 \\
6 & Sterculia urceolata & Sterculiaceae & 34.0 \\
7 & Sterculia urceolata & Sterculiaceae & 39.1 \\
8 & Sterculia foetida & Sterculiaceae & 39.1 \\
9 & Ceiba pentandra & Bombacaceae & 32.6 \\
10 & Bombax ceiba & Bombacaceae & 34.1 \\
11 & Bombax valetonii & Bombacaceae & 30.3 \\
12 & Bombax valetonii & Bombacaceae & 30.1 \\
\hline
\end{tabular}

Garden (Kebun Raya Bogor) located in the city of Bogor, $60 \mathrm{~km}$ south of Jakarta, Indonesia (WGS 84: 6 $6^{\circ} 35^{\prime} 51^{\prime \prime} \mathrm{S}, 106^{\circ} 47^{\prime} 54^{\prime \prime}$ E). The Botanical Garden, founded in 1817 , has a total area of 87 hectares and contains a wide diversity of flora and fauna, approximately 15000 plant and tree species including huge buttressed trees. Due to the great variety of buttressed trees and the good visibility of their stems, the study site offers ideal conditions for prelimininary methodological studies.

We selected 12 different isolated buttressed trees spanning a variety of species, buttress heights and buttress geometric complexity (Tab. 1) and that were well visible by the terrestrial laser scans, since buttresses were not covered by climbers or other vegetation.

\section{Terrestrial laser scanning}

A phase-based terrestrial laser scanner (Zoller and Fröhlich Imager 5010c, Zoller and Fröhlich GmbH, Wangen i.A., Germany) was used to obtain three-dimensional point clouds. The single-scan resolution is defined by an angular step width of $0.036^{\circ}$ and a field-of-view of $360^{\circ}$ horizontally and $320^{\circ}$ vertically, resulting in up to 44 million measurements per scan. The wavelength of the emitted light beam is $1500 \mathrm{~nm}$. Scan settings were selected to provide a good balance of scan time and resolution; the time-consuming HDR image capture option was not used. A multiscan method was applied to retrieve a complete high-density point cloud of the bole and buttresses. In order to eliminate scan shadows up to 8 single scans from different positions were merged by placing artificial targets around the tree to co-register the single point clouds using ZF Laser Control 8.2 (Zoller and Fröhlich GmbH, Wangen i.A. Germany) with a maximum registration error of less than $6 \mathrm{~mm}$. The laser returns of single trees were extracted manually using Cyclone (Vers. 6, Leica Geosytems, Heerbrugg, Switzerland) and exported as .xyz file for further processing in $\mathrm{R}$ ( $\mathrm{R}$ Core Team 2013).

\section{Point cloud processing}

We used the Poisson Surface Reconstruction method (Kazhdan et al. 2006) for solid modeling based on the algorithm provided by the software MeshLab (Version 1.3.2). The meshes were applied to the whole trunk, but visual quality checks reveal that the resulting surface models do not describe the actual stem form very well, especially for very irregular trees. For an automated polygonal outline delineation of cross sections in different tree heights we applied the basic alpha shapes (Edelsbrunner \& Mücke 1994) based on the Delaunay triangulation to each polygon. However, this approach failed, especially in cases of high complex tree geometries, due to variation in point density. 
In order to determine accurate outlines of the non-convex cross sections at different heights for those trees that show more complex buttress morphology, we separated the point clouds in continuous thin layers ("discs") of $5 \mathrm{~cm}$ height, according to $z$ values to the upper end of buttresses. Above buttresses the distance between layers was increased to $50 \mathrm{~cm}$ up to the first strong branches. The lowermost disc was defined as the first cross-section that is free of ground elements (soil). The height of this disc was also used as reference for the determination of $D B H$ height $(1.3 \mathrm{~m})$.

Each layer of the point cloud was projected to a plane by removing the height information and a non-convex polygonal outline was delineated manually in standard GIS software (ARCGIS 10). Area, perimeter and shape metrics were calculated for each height from the outline delineated polygon. Further, we computed the convex hull and calculated its perimeter (Fig. 1). The latter is equal to a girth measured by tape around the buttresses at a specific height.

\section{Estimation of buttress volume}

From the delineated cross sections, the volume of each disc was calculated using the Smalian's formula (eqn. 1):

$$
v=\frac{A_{l}+A_{u}}{2} \cdot l
$$

where $A_{1}$ and $A_{\mathrm{u}}$ are the cross-sectional areas at the lower and upper side of each disk and $l$ is its height $(5 \mathrm{~cm}$ or $50 \mathrm{~cm}$, in our case). The single layer volumes were then accumulated over tree height, so that the actual volume up to each height interval is available.

\section{Characterization of buttress shape}

For each cross section we calculated the actual perimeter $P$ of the polygon, the crosssectional area $A$ and their ratio $(P / A)$. Moreover, we computed different metrics characterizing the shape of the cross sections. The isoperimetric quotient $Q$ is a measure of compactness and describes the ratio of the actual cross-sectional area $A$ and that of the circle of same perimeter $P$ (eqn. 2):

$$
Q=\frac{4 \pi A}{P^{2}}
$$

The end of buttresses refers to the height at which the isoperimetric index becomes $\geq$ 0.95 , indicating that the shape of the cross section is close to a circle (Fig. 2A). DAB was derived as diameter of a coextensive circle at $50 \mathrm{~cm}$ distance above the last buttress, which differed little from the average of two perpendicular direct measurements in the point clouds. There is no consistent definition of the height at which $D A B$ is measured (and neither a consistent definition of what is meant by the "top" of buttress); distances above the highest buttress of $0 \mathrm{~cm}$ (Ngo-

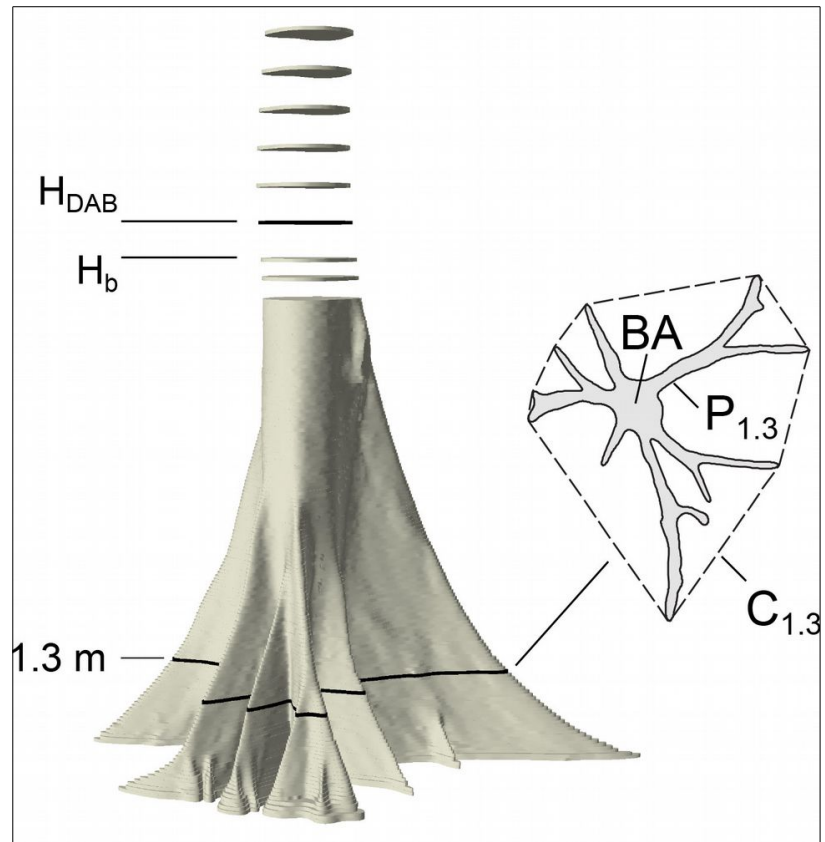

Fig. 1 - Graphical representation of the measurements taken on each sample tree analyzed. $H_{\mathrm{b}}$ is the maximum height of buttresses, $H_{\mathrm{DAB}}$ is the height of the diameter above buttresses $\left(H_{\mathrm{b}}+50 \mathrm{~cm}\right), A$ is the actual cross-sectional area (here at breast height), $P_{1.3}$ is the actual non-convex perimeter of the cross section at breast height and $C_{1.3}$ is the perimeter of the convex hull (dashed line).

manda et al. 2012, Saner et al. 2012), $20 \mathrm{~cm}$ (Mindawati et al. 2004), $30 \mathrm{~cm}$ (Basuki et al. 2009 citing FAO 2004), and $50 \mathrm{~cm}$ (Newbery et al. 2009) appear to be most common. However, the differences in diameter between these positions at the stem are mini$\mathrm{mal}$ in our data set. The perimeter of the convex hull in breast height $C_{1.3}$ is the girth measured above the buttresses at $1.3 \mathrm{~m}$ above the ground. The cross-sectional area at breast height is the tree basal area $(B A)$.

Based on the $D A B$ and its height we derived a buttress form factor $f_{\mathrm{b}}$ that describes the relation between the actual buttress volume $\left(V_{\mathrm{b}}\right)$ and the volume of a cylinder with a diameter equal to $D A B$ and a length equal to the $D A B$ measurement height $H_{\mathrm{DAB}}$ as follows (eqn. 3):

$$
f_{b}=\frac{V_{b}}{\frac{\pi}{4} D A B^{2} H_{D A B}}
$$

This form factor can be interpreted as an "indicator" for the potential under-estima-
A

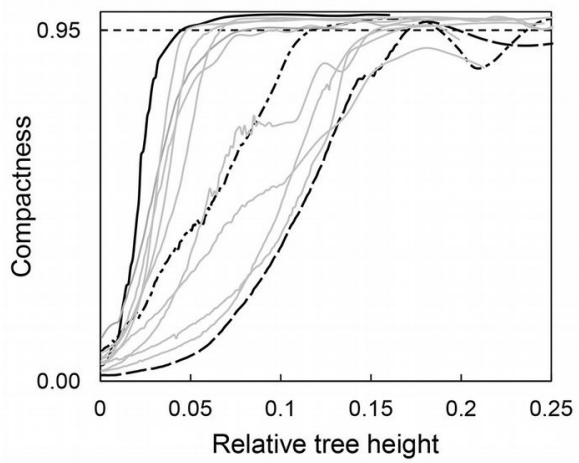

tion of the volume of the lower stem section in case that $D A B$ is used in the context of volume modeling.

In order to search for any relations among buttress variables that are of practical relevance, we fitted functions to describe the relation between the actual tree basal area, the cross-sectional area in $D A B$ height and the $C_{1.3}$. Acknowledging the small sample size, we did not focus on the best fit to the twelve data points, but we chose functions that make sense on first principles and that could extend over the full possible range of data. Power functions were fitted by linear regression on log-transformed data.

\section{Results}

In this study, the selected trees had very different dimensions and buttress morphologies, which was also reflected in the variables extracted. Tab. 2 thus gives an overview of the main characteristics of the 12 sample trees. The highest volume of the buttressed stem section was found for tree \#4 (Ficus al-

B

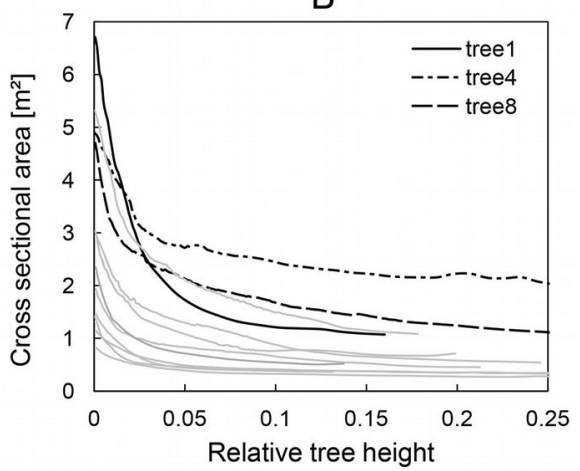

Fig. 2 - (A) Development of the isoperimetric quotient $(Q)$ over the relative tree height. (B) Development of the cross-sectional area over the relative tree height. 
Tab. 2 - Buttress characteristics obtained for each sampled tree. (BA): basal area; $\left(C_{1.3}\right)$ girth at $1.3 \mathrm{~m} ;\left(H_{\mathrm{DAB}}\right)$ : height of $D A B$ measurement; $(D A B)$ : diameter above buttress, $\left(V_{\mathrm{b}}\right)$ : buttress volume; $\left(f_{\mathrm{b}}\right)$ : buttress form factor.

\begin{tabular}{ccccccc}
\hline Tree & $\left.\boldsymbol{B} \boldsymbol{A} \mathbf{( m}^{\mathbf{2}}\right)$ & $\boldsymbol{C}_{\mathbf{1 . 3}}(\mathbf{m})$ & $\boldsymbol{H}_{\mathbf{D A B}}(\mathbf{m})$ & $\boldsymbol{D} \boldsymbol{A} \boldsymbol{B}(\mathbf{c m})$ & $\boldsymbol{V}_{\mathbf{b}}\left(\mathbf{m}^{\mathbf{3}}\right)$ & $\boldsymbol{f}_{\mathbf{b}}$ \\
\hline 1 & 2.41 & 5.84 & 2.43 & 1.40 & 7.45 & 1.99 \\
2 & 1.49 & 8.78 & 7.07 & 0.88 & 7.97 & 1.85 \\
3 & 0.52 & 3.40 & 5.08 & 0.72 & 2.67 & 1.29 \\
4 & 3.15 & 10.18 & 7.18 & 1.66 & 20.50 & 1.32 \\
5 & 2.73 & 12.68 & 9.08 & 1.18 & 17.41 & 1.75 \\
6 & 0.88 & 6.17 & 7.23 & 0.81 & 5.10 & 1.37 \\
7 & 1.27 & 8.06 & 6.78 & 0.95 & 6.97 & 1.45 \\
8 & 2.35 & 13.38 & 7.03 & 1.32 & 13.67 & 1.42 \\
9 & 0.77 & 3.53 & 2.98 & 0.85 & 2.65 & 1.57 \\
10 & 0.43 & 3.27 & 2.63 & 0.67 & 1.24 & 1.34 \\
11 & 0.46 & 2.50 & 1.98 & 0.72 & 1.33 & 1.65 \\
12 & 0.52 & 2.83 & 2.98 & 0.73 & 1.72 & 1.38 \\
\hline
\end{tabular}

bipila) with $20.2 \mathrm{~m}^{3}$ up to a height of $7.18 \mathrm{~m}$ (and $38.2 \mathrm{~m}^{3}$ up to $15.5 \mathrm{~m}$ height). The total height of buttresses showed large variations. Some of the species analyzed were characterized by very tall buttresses of more than 8 m (e.g., Sterculia urceolata or Ficus robusta), while others tend to develop long lateral buttresses though quite low upwards (e.g., Koompassia excelsa or Bombax valetonii). Fig. 3 shows a perspective view of the delineated cross sections. Here the polygons are extruded to their original height of $5 \mathrm{~cm}$, giving an overview of the different buttress morphologies detected for the selected trees.

Fig. 4 shows how the cross sections change along the lowest $5-\mathrm{m}$ stem section for some sample trees: the geometries vary considerably, so that for many trees the stem could not be distinguished at the lowest cross sections.

Comparing the lower profiles of the depicted trees, the different morphology of lateral buttresses becomes obvious. While the horizontal projection of the laterals for tree \#4 (Ficus albipila) was characterized by a trapezoid form that narrows with increasing distance, the buttresses of tree \#8 (Sterculia foetida) were extremely thin.

In contrast to the different buttress morphologies of sample trees and their irregular cross sections, the development of the stem cross-sectional area over tree height was surprisingly similar and smooth. Fig. 2 shows the compactness (A, left) and the development of the cross-sectional area over the relative tree height $(\mathrm{B}$, right).

\section{Buttress allometry}

Despite the different morphology of buttressing across the tree species analyzed, the buttress form factor we derived for every individual tree showed a surprisingly small variability (Tab. 2). The mean form factor derived from the sample trees was $f_{\mathrm{b}}=1.53$ with a standard deviation of 0.23 . A simple generalized form factor may be applied to assess the volume of the buttressed lower stem section $V_{\mathrm{b}}$. Such calculation is based on two measurements, the $D A B$ and its height $H_{\text {DAB }}$ (eqn. 4):

$$
V_{b}=\frac{\pi}{4} D A B^{2} H_{D A B} f_{b}
$$

Another relation of practical relevance is that between the perimeter of the convex hull at $1.3 \mathrm{~m}$ height and the actual cross-sectional area. The former can be tape-measured as girth over the buttresses at breast height,

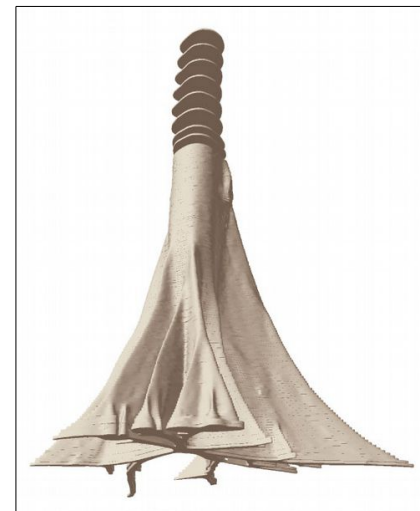

Tree 8 (Sterculia foetida)

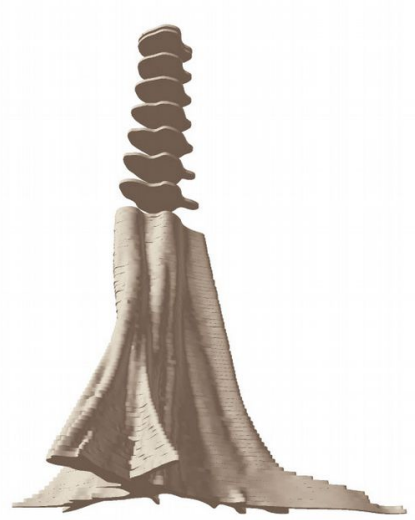

Tree 6 (Sterculia urceolata)
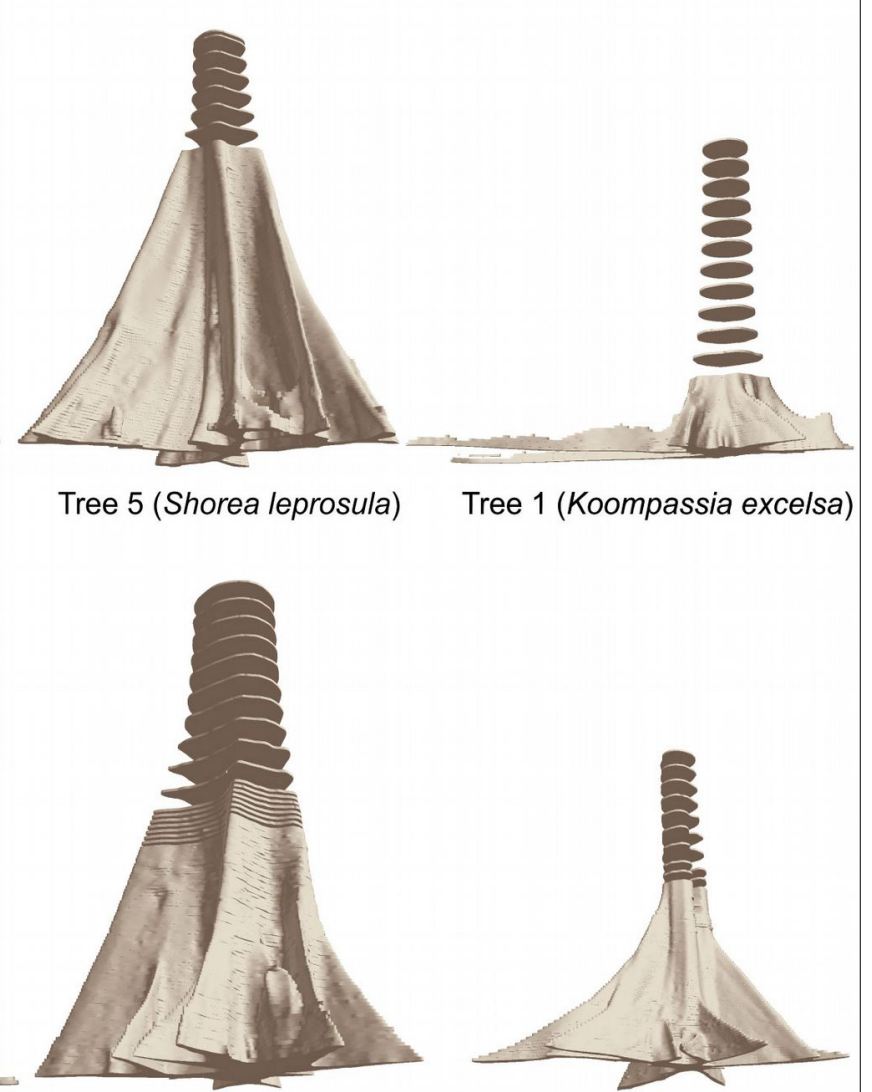

Tree 4 (Ficus albipila)
Fig. 3 - Examples of different buttress morphology of the sample trees (trees not in scale). 
Fig. 4 - Cross sections at different heights of tree \#1 (Koompassia excels), tree \#2 (Ficus robusta), tree \#4 (Ficus albipila), tree \#5 (Shorea leprosula), tree \#7 (Sterculia urceolata) and tree \#8 (Sterculia foetida). The dashed line at $1.3 \mathrm{~m}$ height represents the outline of the convex hull that could be tapemeasured as girth "around" butressess.

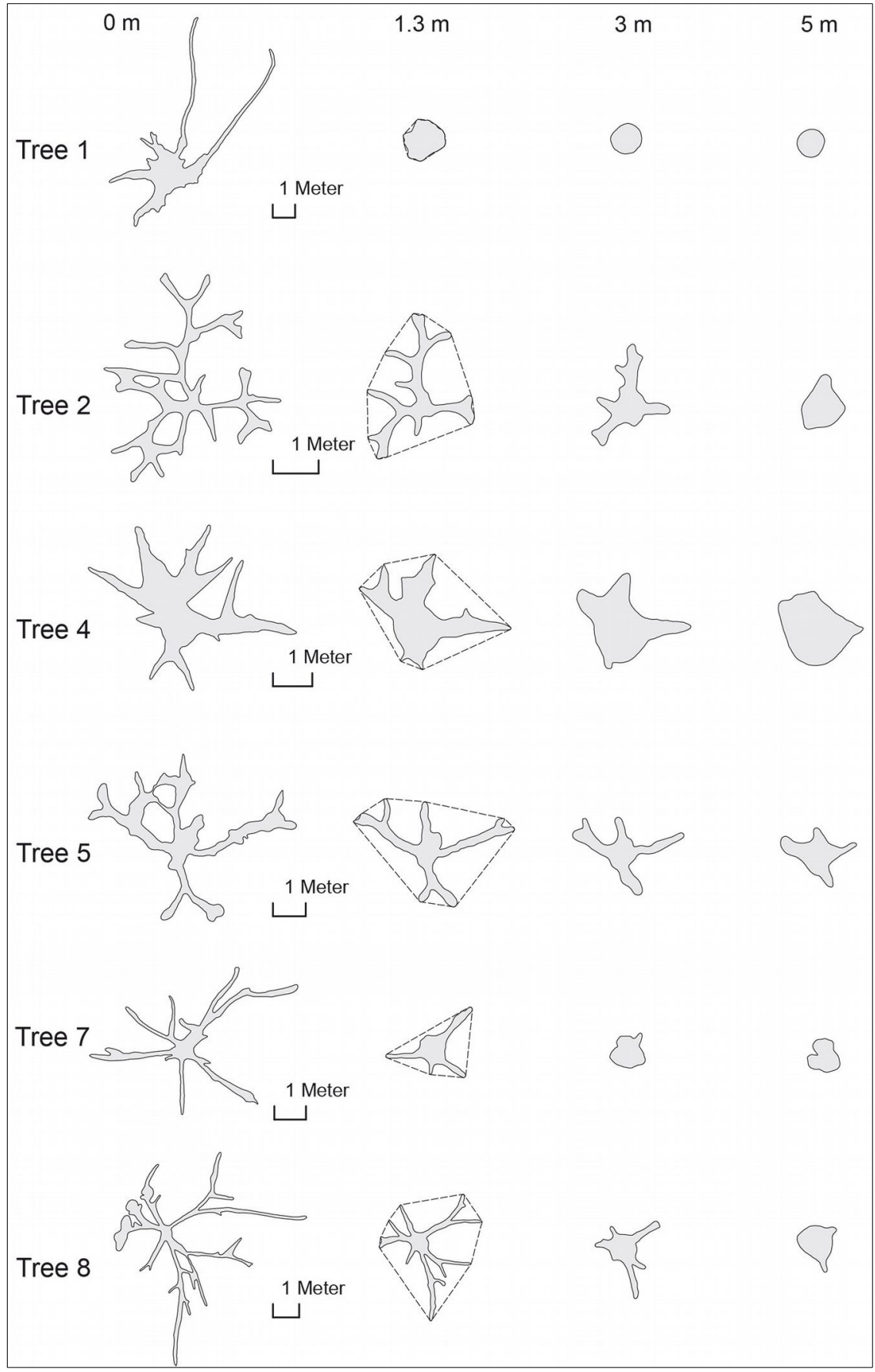

A

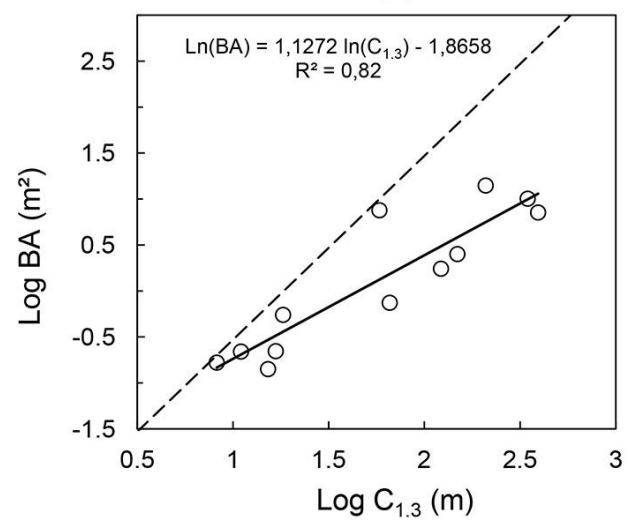

B

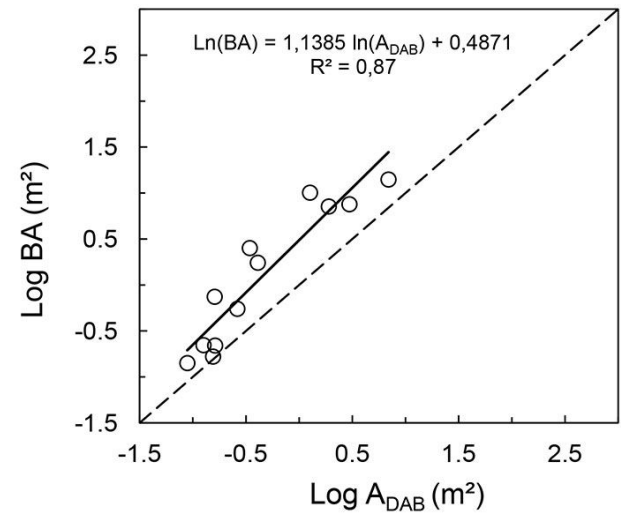

Fig. 5 - (A) Relationship between the perimeters of the convex hull measured

"around" buttresses at $1.3 \mathrm{~m}$ height $\left(C_{1.3}\right)$ and the actual basal area of the respective tree; (B) relationship between cross-sectional area at $D A B$ height and basal area at $1.3 \mathrm{~m}$ height. 
while the latter is the actual basal area of the tree. The relationship between the cross-sectional area above the buttress and the basal area at $1.3 \mathrm{~m}$ height $(B A)$ is crucial for practical applications, as it allows for the predic tion of the stand basal area of buttressed trees. The relatively strong relationships found in this study between the above parameters are displayed in Fig. 5. These results are consistent with the findings by Ngomanda et al. (2012), who measured the buttress perimeter with a wire. As there is visual evidence of heteroscedasticity, linear models were fit to the log-transformed variables. The plot of $B A$ versus $A_{\mathrm{DAB}}$ includes a $1: 1$ line, while the dashed line in the plot of $B A$ versus $C_{1.3}$ shows the relationship for a perfect circle.

\section{Discussion}

The estimation of forest biomass has received much attention over the past years. In spite of the increasing number of global forest biomass maps available, many basic questions on the determination of single tree biomass, volume or carbon still remain to be solved.

Large trees carry the largest variability in volume and biomass - in particular in tropical lowland rain forests - and exhibit considerable stem irregularities, most notably buttresses. Measuring the volume, biomass or carbon for these trees is evidently difficult and constitutes a considerable source of error when estimating forest above ground biomass and carbon stocks. In this study, we used a terrestrial laser scanner to scan 12 buttressed trees of different species in the Botanical Garden of Bogor, Indonesia in order to analyze the geometry and allometry of these highly irregular stems. Although the 3D analyses carried out on buttresses revealed new insights into their very irregular geometry, our small sample size does not allow the derivation of generalized allometric relationships for different tree species or dimensions. However, the methodological ap proach described in our study may easily be extended to a more comprehensive data sample, including larger numbers of trees per species, covering a wider range of diameters, and including trees grown-up within forest stands.

The changes in actual cross sections along the buttressed part of sampled trees follow highly variable patterns. For trees characterized by very high but slim buttresses, the diameter of the central solid stem is decreasing with increasing the cross-sectional area of buttresses (see e.g., tree \#2 and \#8 in Fig. 4). For other trees analyzed, like tree \#4 (Ficus albipila), \#9 (Ceiba pentandra) or \#1 (Koompassia excelsa), the solid stem (even if reduced in diameter) reaches down to the ground, contributing significantly to the lowest cross-sectional area.
We may conclude that the geometry of the buttress cross sections towards the tree base is much more complex than expected. To our knowledge, the geometric feature of cross sections of buttressed trees has not been described yet in this details. Indeed, our results contradict the assumption that a distinct stem becomes thinner towards the ground, laterally supported by buttresses (Mattheck 1998). In some cases, the concept of a distinct stem appears to dissolve towards the ground. This also means that the measurement protocol described by Picard et al. (2012, p. 68 and Fig. 4.6) for the calculation of buttress volume is not generally applicable, but holds for "simply buttressed" trees only.

Despite the small sample size analyzed, our results suggest that the relation between the cross-sectional area in $D A B$ height and the actual tree basal area measured at $1.3 \mathrm{~m}$ height is relatively strong $\left(\mathrm{R}^{2}=0.87\right)$ for a range of buttress morphologies and tree dimensions, regardless of the very different geometries observed in the cross-sectional areas. By means of relationships between $D A B$ and basal area, it would be possible to model the actual basal area of tropical forests including the buttressed trees. As the basal area is one of the most important variables in forestry, being highly correlated to total stand volume and biomass, knowledge about this variable would allow deriving models for fast volume approximations. For the analysis of the buttress allometry, we chose a general allometric model that allows the interpretation based on first principles and that could extend over the full possible range of data. The fitted power of the relationships between $C_{1.3}, A_{\mathrm{DAB}}$ and tree basal area was close to one, suggesting a nearly isometric scaling. However, the relation between the log-transformed tree basal area and crosssectional area at $D A B$ height showed a slightly non-linear trend, thus better results were obtained using a logarithmic function $\left(B A=1.5545 \cdot \ln \left(A_{\mathrm{DAB}}\right)+1.9434, \mathrm{R}^{2}=0.93\right)$.

The mean form factor of 1.53 we derived from the sampled trees gives an indication of the potential under-estimation of volume and biomass for the lower buttressed stem section. The buttressed lower stem section contains $153 \%$ of the volume of the cylindrical volume calculated based on the $D A B$.

The relation between $C_{1.3}$ and basal area showed a nearly linear trend. Besides the actual tree size, it should be noted that the $C_{1.3}$ is very much influenced by the number and direction of main buttresses that span the convex hull. In this study, trees having a low number of main buttresses tend to extend farther from the stem axis than those with more main buttresses.

Allometric relationships are commonly used for the biomass estimation of individual trees. According to Ngomanda et al. (2012), we expect that such allometric relationships can be derived with reasonable model accuracy also for irregularly shaped large trees, either using a buttress form factor (as introduced here) or by using the diameter above buttress and/or the length of the convex hull at $1.3 \mathrm{~m}$ height as input variables. However, any measurement taken from such trees in the field is difficult to obtain. Therefore, it is certainly worthwhile to look into potential measurement errors when developing allometric functions based on variables that are difficult to be measured.

Even if multiple scanning positions were necessary to avoid scan shadows, the applied TLS approach was easy to implement under the given conditions in a botanical garden. A single tree could be scanned in less than 35 min, including the time for scanner repositioning. The duration of a single scan with normal quality and high-angle resolution is 3:22 min. Pre-processing, co-registration and cleaning of the laser point clouds is office work, taking about half a day for highlycomplex tree geometries. The manual delineation of cross-sectional areas in $5 \mathrm{~cm}$ height intervals was the most time-expensive activity. However, considering that destructive sampling is not a viable alternative to research into the allometry of big-buttressed trees in a similar level of detail, the proposed method proves to be a useful and non-destructive approach that allows for a range of meaningful measurements.

In a dense tropical rain forest, however, the understory vegetation and lianas may hamper fast and easy scanning, especially if the multi-scan method is used. Under these conditions, data collection and pre-processing could be more complicated and time-consuming. Our approach of manual delineation of the cross sections turned out to be robust as compared with the existing algorithms for automated identification of non-convex shapes. The proposed method might help to convert diameters measured at different heights to a single standard reference height, not only in context of model application but also for model building. This allows estimating a stand basal area at a defined reference height for forest stands including buttressed trees.

Further research should be addressed to the relationships among variables that are relevant and feasible to measure in the field, e.g., the relation between $D A B$ and the tree basal area. The patterns observed in this study suggest that general allometric relations may exist for buttressed trees, though a confirmation based on a larger sample size is required.

\section{Acknowledgements}

This study was made possible through financial support from the German Academic Exchange Service (DAAD) which has been 
granted through the Higher Education Program HEP between the Agricultural University of Bogor IPB and the Faculty of Forest Sciences and Forest Ecology and SETSAF at Georg-August-Universität Göttingen. The study contributes to project B05 of the DFG funded CRC990 "Efforts". Data was collected in the context of a TLS course delivered at the Bogor Agricultural University IPB by Dominik Seidel and Nils Nölke. We thank our Bachelor students Michael Weber and Markus Klingemann for help in data collection and preparation. We are grateful to the Faculty of Forest Sciences and Forest Ecology in Göttingen for granting financial support. We thank PT. Datascrip and Zoller + Fröhlich GmbH in Jakarta for making available the laser scanner for our project We are also grateful to Didik Widyatmoko of LIPI for granting the permission to implement our study in the Bogor Botanical Garden.

\section{References}

Basuki TM, Van Laake PE, Skidmore AK, Hussin YA (2009). Allometric equations for estimating the above-ground biomass in tropical lowland Dipterocarp forests. Forest Ecology and Management 257: 1684-1694. - doi: 10.1016/j.foreco. 2009.01.027

Bauwens S (2013). Le LiDAR-t et la photogrammétrie pour modéliser des troncs irréguliers [Modeling irregular shaped tree with Terrestrial LiDAR and photogrammetry]. In: Proceedings of the International Conference "Utilisation du système LiDAR terrestre en écologie forestière (4ème édition)". Marseille (France) 8 Oct 2013. On-line presentation, pp. 24. [online] URL: http://hdl.handle.net/2268/159158

Chapman CA, Kaufman L, Chapman LJ (1998). Buttress formation and directional stress experienced during critical phases of tree development. Journal of Tropical Ecology 14: 341-349. - doi: 10.1017/S0266467498000261

Chave J, Andalo C, Brown S, Cairns MA, Chambers JQ, Eamus D, Folster H, Fromard F, Higuchi N, Kira T, Lescure JP, Ogawa BWNH, Puig H, Riera B, Yamakura T (2005). Tree allometry and improved estimation of carbon stocks and balance in tropical forests. Oecologia 145:87-99. - doi: 10.1007/s00442-005-0100-x

Clark DB, Clark DA (2000). Landscape-scale variation in forest structure and biomass in a tropical rain forest. Forest Ecology and Management 137: 185-198. - doi: 10.1016/S0378-1127 (99)00327-8

Clark DA (2002). Are tropical forests an important carbon sink? Reanalysis of the long-term plot data. Ecological Applications 12: 3-7. - doi: 10.1890/1051-0761(2002)012[0003:ATFAIC]2. $0 . \mathrm{CO} ; 2$

Clark DB, Kellner JR (2012). Tropical forest biomass estimation and the fallacy of misplaced concreteness. Journal of Vegetation Science 23: 1191-1196. - doi: 10.1111/j.1654-1103.2012.01 471.x
Crook MJ, Ennos AR, Banks JR (1997). The function of buttress roots: a comparative study of the anchorage systems of buttressed (Aglaia and Nephelium ramboutan species) and non-buttressed (Mallotus wrayi) tropical trees. Journal of Experimental Botany 48: 1703-1716. - doi: $10.1093 / \mathrm{jxb} / 48.9 .1703$

Cushman KC, Muller-Landau HC, Condit RS, Hubbell P (2014). Improving estimates of biomass change in buttressed trees using tree taper models. Methods in Ecology and Evolution 5 (6): 573-582. - doi: 10.1111/2041-210X.12187 Dean C (2003). Calculation of wood volume and stem taper using terrestrial single-image closerange photogrammetry and contemporary software tools. Silva Fennica 37 (3): 359-380. - doi: 10.14214/sf.495

Edelsbrunner H, Mücke EP (1994). Three-dimensional alpha shapes. ACM Transactions on Graphics 13 (1): 43-72. doi: 10.1145/174462.1566 35

Ennos AR (1993). The scaling of root anchorage. Journal of Theoretical Biology 161: 61-75. - doi: 10.1006/jtbi.1993.1040

Enquist BJ (2002). Universal scaling in tree and vascular plant allometry: toward a general quantitative theory linking plant form and function from cells to ecosystems. Tree Physiology 22: 1045-1064. - doi: 10.1093/treephys/22.15-16.10 45

Fehrmann L, Kleinn C (2006). General considerations about the use of allometric equations for biomass estimation on the example of Norway spruce in central Europe. Forest Ecology and Management 236: 412-421. - doi: 10.1016/j.for eco.2006.09.026

FAO (2004). National forest inventory: field manual template. Food and Agricukture Organization of the United Nations, Rome, Italy, pp. 84. [online] URL: http://www.fao.org/docrep/008/ae57 8e/ae578e00.htm

He Z, Tang Y, Deng X, Cao M (2013). Buttress trees in a 20 -hectare tropical dipterocarp rainforest in Xishuangbanna, SW China. Journal of Plant Ecology 6: 187-192. - doi: 10.1093/jpe/rtt 052

Henry M, Besnard A, Asante WA, Eshun J, AduBredu S, Valentini R, Bernoux M, Saint-André L (2010). Wood density, phytomass variations within and among trees, and allometric equations in a tropical rainforest of Africa. Forest Ecology and Management 260: 1375-1388. - doi: 10.1016/j.foreco.2010.07.040

Kazhdan M, Bolitho M, Hoppe H (2006). Poisson surface reconstruction. In: Proceedings of the "Eurographics Symposium on Geometry Processing" (Polthier K, Sheffer A eds). Cagliari (Italy) 26-28 Jun 2006, pp. 61-70. [online] URL: http://faculty.cs.tamu.edu/schaefer/teaching/689 Fall2006/poissonrecon.pdf

Mattheck C (1998). Design in nature: learning from trees. Springer Science \& Business Media, Springer-Verlag, Berlin, Germany, pp. 276. [online] URL: http://books.google.com/books?id=X $\mathrm{NZ} 3$ G7gMwC

Mehedi AH, Kundu C, Chowdhury Q (2012). Pat- terns of tree buttressing at Lawachara National Park, Bangladesh. Journal of Forest Research 23 (3): 461-466. - doi: 10.1007/s11676-012-0285-x Metcalf CJE, Clark JS, Clark DA (2009). Tree growth inference and prediction when the point of measurement changes: modelling around buttresses in tropical forests. Journal of Tropical Ecology 25: 1-2. - doi: 10.1017/S0266467408 005646

Mindawati N, Hendromono HM, Toma T, Morikawa Y, Ngaloken GA (2004). Tree trunk volume of Shorea species: case study in Darmaga and Haurbentes research forest in West Java, Indonesia. Journal of Forestry Research 1 (1) 17-24. [online] URL: http://ejournal.forda-mof. org/ejournal-litbang/index.php/IJFR/article/view/ 483

Newbery DM, Schwan S, Chuyong GB, Van der Burgt XM (2009). Buttress form of the central African rain forest tree Microberlinia bisulcata, and its possible role in nutrient acquisition. Trees 23: 219-234. - doi: 10.1007/s00468-008-0270-3 Ngomanda A, Mavouroulou QM, Obiang NLE, Iponga DM, Mavoungou JF, Lépengué N, Picard N, Mbatchi B (2012). Derivation of diameter measurements for buttressed trees, an example from Gabon. Journal of Tropical Ecology 28: 299-302. - doi: 10.1017/S0266467412000144 Niklas KJ (1994). Plant allometry: the scaling of plant form and process. University of Chicago Press, Chicago, IL, USA, pp. 395. [online] URL: http://books.google.com/books?id=Wiy3fL_ofTEC

Niklas KJ (2004). Plant allometry: is there a grand unifying theorem? Biological Reviews 79: 871889. - doi: 10.1017/S1464793104006499

Niklas KJ (2013). Biophysical and size-dependent perspectives on plant evolution. Journal of Experimental Botany 64: 4817-4827. - doi: 10.1093/jxb/ers379

Nogueira EM, Nelson BW, Fearnside PM (2006). Volume and biomass of trees in central Amazonia: influence of irregularly shaped and hollow trunks. Forest Ecology and Management 227: 14-21. - doi: 10.1016/j.foreco.2006.02.004 Parresol BR (1999). Assessing tree and stand biomass: a review with examples and critical comparisons. Forest Science 45 (4): 573-593. [online] URL: http://www.ingentaconnect.com/ content/saf/fs/1999/00000045/00000004/art0001 4

Phillips OL, Malhi Y, Vincety B, Baker T, Lewis SL, Higuchi N, Laurance WF, Nunez Vargas P, Vasquez Martinez R, Laurance S, Ferreira LV, Stern M, Brown S, Grace J (2002). Changes in growth of tropical forests: evaluating potential biases. Ecological Applications 12: 576-587. doi: 10.1890/1051-0761(2002)012[0576:CIGOT F]2.0.CO;2

Picard N, Saint-André L, Henry M (2012). Manual for building tree volume and biomass allometric equations: from field measurement to prediction. Food and Agricultural Organization of the United Nations, Rome, Italy, and Centre de Coopération Internationale en Recherche Agronomique pour le Développement, Montpellier, 
France, pp. 215.

Pilli R, Anfodillo T, Carrer M (2006). Towards a functional and simplified allometry for estimating forest biomass. Forest Ecology and Management 237: 583-593. - doi: 10.1016/j.foreco.2006. 10.004

R Core Team (2013). R: a language and environment for statistical computing. $\mathrm{R}$ foundation for statistical computing, Vienna, Austria. [online] URL: http://www.r-project.org/

Richards PW (1952). The tropical rain forest Cambridge University Press, Cambridge, UK, pp. 450.

Richter W (1984). A structural approach to the function of buttresses of Quararibea asterolepis. Ecology 65 (5): 1429-1435. - doi: 10.2307/19 39123

Saner P, Loh YY, Ong RC, Hector A (2012). Carbon stocks and fluxes in tropical lowland dipterocarp rainforests in Sabah, Malaysian Borneo. PloS One 7 (1): e29642. - doi: 10.1371/journal. pone.0029642

Slik JWF, Aiba SI, Brearley FQ, Cannon CH, Forshed O, Kitayama K, Nagamasu H, Nilus R, Payne J, Paoli G, Poulsen AD, Raes N, Sheil D, Sidiyasa K, Suzuki E, Van Valkenburg JLCH (2010). Environmental correlates of tree biomass, basal area, wood specific gravity and stem density gradients in Borneo's tropical forests. Global Ecology and Biogeography 19: 50-60. doi: 10.1111/j.1466-8238.2009.00489.x

Smith AP (1972). Buttressing of tropical trees: a descriptive model and new hypotheis. American Naturalist 106: 32-46. - doi: 10.1086/282749

Stephenson NL, Das AJ, Condit R, Russo SE, Baker PJ, Beckman NG, Coomes DA, Lines ER, Morris WK, Ruger N, Alvarez E, Blundo C, Bunyavejchewin S, Chuyong G, Davies SJ, Duque A, Ewango CN, Flores O, Franklin JF, Grau HR, Hao Z, Harmon ME, Hubbell SP, Kenfack D, Lin Y, Makana J, Malizia A, Malizia LR, Pabst RJ, Pongpattananurak N, Su S, Sun I,
Tan S, Thomas D, Van Mantgem PJ, Wang X, Wiser SK, Zavala MA (2014). Rate of tree carbon accumulation increases continuously with tree size. Nature 507 (7490): 90-93. - doi: 10.1038/nature12914

West GB, Brown JH, Enquist BJ (1997). A general model for the origin of allometry scaling laws in biology. Science 276: 122-126. - doi: 10.11 26/science.276.5309.122

West GB, Brown JH, Enquist BJ (1999a). The fourth dimension of live: fractal geometry and allometric scaling of organisms. Science 284: 167169. - doi: 10.1126/science.284.5420.1677

West GB, Brown JH, Enquist BJ (1999b). A general model for the structure and allometry of plant vascular systems. Nature 400: 664-667. - doi: $10.1038 / 23251$

Zianis D, Mencuccini M (2004). On simplifying allometric analyses of forest biomass. Forest Ecology and Management 187: 311-332. - doi: 10.1016/j.foreco.2003.07.007 
Annex C

Manuscript III 


\title{
Changes in culm surface temperature with maturity of the bamboo species Guadua angustifolia
}

\author{
Nils Nölke ${ }^{1}$ Juan Carlos Camargo García ${ }^{2}$ Christoph Kleinn ${ }^{1} \cdot$ Andrea Polle $^{3}$
}

Received: 16 December 2014/ Accepted: 29 January 2015

(C) Northeast Forestry University and Springer-Verlag Berlin Heidelberg 2015

\begin{abstract}
We used thermal images of bamboo culms of Guadua angustifolia Kunth to analyze the relationship between culm surface temperature and maturity, driven by the hypothesis that young culms may exhibit lower surface temperatures than old ones. The culm surface temperature shows small but constant differences between three age classes of 1,2 , and 3 years. Our findings indicate that surface temperature may be applied as an additional indicator to support the determination of maturity of guadua culms besides the visual assessment of the culms.
\end{abstract}

Keywords Bamboo culms - Thermal images - Bamboo wood quality

Project funding: This work was both financially supported by "Nuevas metodologías para la evaluación y monitoreo de carbono e indicadores de biodiversidad en sistemas silvopastoriles y bosques de guadua en paisajes de la zona cafetera de Colombia" and "Innovación tecnológica para la optimización de procesos y la estandarización de productos en empresas rurales con base en Guadua: una contribución para el fortalecimiento de la competitividad de la cadena productiva de la Guadua en el eje cafetero de Colombia" by Colciencias.

The online version is available at http://www.springerlink.com

Corresponding editor: Yu Lei

Nils Nölke

nnoelke@gwdg.de

1 Chair of Forest Inventory and Remote Sensing, Universität Göttingen, Büsgenweg 5, 37077 Göttingen, Germany

2 Faculty of Environmental Sciences, Technological University of Pereira, La Julita, Pereira, Colombia

3 Department of Forest Botany and Tree Physiology, Universität Göttingen, Büsgenweg 2, 37077 Göttingen, Germany

\section{Introduction}

All objects that have a temperature above absolute zero $\left(-273^{\circ} \mathrm{C}\right)$ emit energy as radiation in the wavelength range of $7-14 \mu \mathrm{m}$, the so-called thermal infrared spectral range. The radiation emitted by a surface depends on the surface material. One part of incoming energy (sunlight) is reflected and the other part is absorbed. This ratio is expressed by the term 'emissivity' which describes the efficiency with which an object radiates infrared energy compared to the theoretical radiation predicted by Planck's law. Natural objects have emissivity values between 0 and 1.0 , where a value of 1.0 only applies to the theoretical blackbody. The amount of infrared radiation emitted by an object is determined by its temperature and emissivity. Thermal cameras record thermal infrared radiation and translate it into surface temperature values. The resulting thermal images may be employed for research into any temperature-related features including also plant physiological processes like stomatal conductance (Matsumoto et al. 2005) or crown temperatures of urban tree species (Leuzinger et al. 2010).

Lobovikov et al. (2007) estimated that bamboo covers about $36,777,000$ ha around the world of which approximately $65 \%$ are in Asia, $28 \%$ in Latin America, and $7 \%$ in Africa. Distributed from the tropics to temperate areas, around 1450 bamboo species are known and described. In the coffee region of Colombia, an inventory study by Kleinn and Morales (2006) estimated the area of forests dominated by Guadua angustifolia (guadua) at about 28,000 ha. In that region 95 bamboo species (Londoño 1990) have been recorded. About 50 species of bamboo worldwide are cultivated (Hunter 2003) and constitute a source of raw material substituting trees for many uses. 
Guadua angustifolia is a woody bamboo species naturally distributed along the north of South America and parts of Central America (Panama and Costa Rica), and has been introduced to Mexico, Guatemala, and Honduras (Londoño 1998). Due to its favorable physical (strength and density) and dendrometric properties (such as an average culm diameter in $9-13 \mathrm{~cm}$ and culm lengths of $15-30 \mathrm{~m}$ ), this species is widely utilized for construction purposes (Takeuchi et al. 2009; Correal and Arbelaez 2010). Guadua culms are harvested when they have reached maturity, i.e. when the physical and chemical properties of the wood are optimal and the resistance against fungi and insects best. Culms that are harvested pre- or overmaturely are much less durable. Culm maturity is commonly reached at the age of five to seven years (Camargo and Suarez 2014; Camargo and Rodriguez 2010).

To provide good culm quality it is important for managers of guadua forests to assess the culm age before harvesting. Traditionally, external culm features, such as color or presence of lichen and fungi on its surface, are used to the determination of culm maturity. The assessment of maturity is very much a matter of experience of the individual guadua manager. However, ecological conditions may significantly influence the culm appearance and frequently lead to wrong decisions regarding adequate time points for the bamboo harvest (Camargo and Rodriguez 2010). Research has been conducted on the development of techniques to determine culm maturity and has indeed resulted in improved decisions on culm selection (Camargo and Rodriguez 2010; Duque et al. 2010). First, labeling culms when they are just emerging provides precise information on their maturity (Camargo and Rodriguez 2010). However, the time required, the associated costs, and the fact that shoots can appear at any time of the year limit the applicability of this approach. Second, researchers have employed devices capable of perceiving wave sounds along the culm and studied the relationships between the natural frequency of these waves and the maturity of the culms (Duque et al. 2010). Nevertheless, the related costs make this an inaccessible technology for farmers and foresters. Consequently, rapid and straightforward approaches are still to be identified. We tested the relationship between culm maturity and the temperature of the culm surface may inform such an approach.

Our purpose is to support guadua management by improving the assessment of culm maturity through the evaluation of the surface temperature of $G$. angustifolia culms. This research is based on the hypothesis that the physiological processes occurring as culms mature may lead to differences in properties of the culm surface which manifest themselves not only in coverage by lichens and fungi, but also in surface temperature.

\section{Materials and methods}

\section{Study site}

The data for our study were collected on permanent plots of an area of $100 \mathrm{~m}^{2}$ each, which were established in a natural guadua bamboo forest with a total of 7 ha located in the botanical garden of the Universidad Tecnologica de Pereira UTP, in Pereira, Colombia. The elevation of this area is around $1450 \mathrm{~m}$ above sea level, with a mean total rainfall of $2600 \mathrm{~mm}$ per year and an average temperature of $20^{\circ} \mathrm{C}$. Within the botanical garden the guadua bamboo forest is subject to research and it is also actively managed so that the rapid spread of the culms and the excessive abundance of dry culms are controlled. In order to document the age of the individual culms on selected permanent observation plots, all culms were marked with differently colored tapes once they emerged from the ground so that the age of these culms is known for subsequent research; this marking was started 4 years ago so that for our study, we could use culms of a known age of up to 3.5 years.

\section{Culm variables}

A number of culm variables including, diameter at $1.3 \mathrm{~m}$ height, total length, and the length of internodes where temperature measurements were taken were recorded. In addition, we determined the position of neighboring culms by measuring azimuth and distance from the target culm which yields information about the culm density in the immediate surroundings of each target culm. We hypothesize that culm density may be one factor influencing culm surface temperature of the target culm, because every surrounding culm emits long wave radiation and this small amount of energy is absorbed by the target culm. Based on culm position maps, we constructed Thiessen polygons that define "areas of influence" around each target culm. The area of the polygon in which the target culm is located, is then taken as an indicator for culm density.

\section{Determining surface temperature}

To determine culm surface temperature, 360 thermal images were taken using a state-of-the-art thermal camera (FLIR E60bx, FLIR Systems GmbH, Frankfurt, Germany). The thermal camera has a resolution of $320 \times 240$ pixels and records electromagnetic radiation in the spectral range of 7.5-14 $\mu \mathrm{m}$. In this range the emitted long wave radiation of the culm is measured at defined positions, converted into temperature, and recorded as a raster image in which each pixel carries the temperature value in degrees Celsius. Simultaneously with the thermal image, the camera takes a 
picture in the visible spectral range. This true color photograph has a higher spatial resolution of $640 \times 480$ pixel so that it can be used to create a sharper thermal infrared image showing the contours of culm, nodes, and internodes. Photographs were taken between 5:00 and 7:00 pm on 04/08/2014 and 05/08/2014 with five repetitions within each time slot. This time slot proved to be most suitable for taking thermal photographs, because at this time of the day the camera could record only emission (after 5:00 pm the incoming the solar radiation was at $0 \mathrm{~W} / \mathrm{m}^{2}$ ) and was thus not influenced by solar irradiance which would have resulted in an increased surface temperature. On both measurement days the temperatures ranged between $21^{\circ} \mathrm{C}$ and $26{ }^{\circ} \mathrm{C}$. For the thermal images we assumed a constant emissivity of 0.98 which, in the absence of specific values, is frequently taken as an average for forest vegetation (Rubio et al. 1997). For each culm (four per maturity stage), we took thermal images from a horizontal distance of $1 \mathrm{~m}$ of three internodes: the fourth, sixth, and eighth internode from below. The decision to take specifically these internodes was a practical one, since these internodes are positioned around $1.3 \mathrm{~m}$ height at the culm, which is a standard height in many bamboo related inventory studies (Camargo 2006; Camargo and Suarez 2014). Moreover, thermal photographs were taken at different heights to test whether there is a short-distance temperature trend along the culm height or as a function of the length of the internode.

For data processing the software packages FLIR Tools (FLIR Systems GmbH, Frankfurt, Germany) and 'R' ('R' Core Team 2004) were used. We used clearly defined rectangular image sections (Fig. 1) on each internode to calculate the mean surface temperature. These image sections varied in height and width according to the diameter and the length of the internode. To reduce the distortive influence of the cylindrical geometry on the measured surface temperature we centered the image at the nearest point of the culm and defined the width of the image to be $60 \%$ of the culm diameter there. Within the $60 \%$ image section the emitted radiation is uniform because the major amount of thermal energy radiates towards the thermal camera leading to stable measurements.

\section{Environmental variables}

Air temperature and relative humidity close to each culm were measured at $1 \mathrm{~m}$ distance using a precise digital psychrometer (Mannix SAM990DW). This device is accurate to $\pm 1{ }^{\circ} \mathrm{C}$ in temperature and $\pm 3 \%$ in relative humidity. A climate station (WGS84: $4.792080 \mathrm{~N}-$ $75.689589 \mathrm{E}$, altitude: $1435 \mathrm{~m}$ ) on the top of the faculty building close to the botanical garden provided us with long-term data of the air temperature and humidity logged at a 5 min interval which we use here as "above bamboo canopy" temperature.

\section{Results}

The thermal images taken at the botanical garden vary within a relatively narrow, but consistent range of temperature values for each internode within approximately $2{ }^{\circ} \mathrm{C}$ (Fig. 1a-f). The temperature pattern of the internodes varies with the surface, where homogenous green-colored internodes have the most homogenous temperature pattern (Fig. 1e, h). Internodes with lichens (Fig. 1d, g) or yellowcolored parts (Fig. 1f, i) exhibit a more heterogeneous temperature pattern.

The environmental conditions during the measurement phase varied between 20 and $26^{\circ} \mathrm{C}$ and a mean relative humidity between 75 and $85 \%$. The air temperature outside the bamboo forest was about $1-2{ }^{\circ} \mathrm{C}$ lower than the temperature within the bamboo forest, with a constant decreased during the night (Fig. 2a). The relative humidity outside the forest on the first night was about $9 \%$ higher than within the bamboo stand, with a maximum of $82.0 \%$. During the second night the difference was $1.7 \%$ and with ongoing time the humidity inside the bamboo forest was above the outside humidity.

Figure $2 c, d$ shows the difference between culm surface temperatures of age class two and three and the difference of age class one and three. The youngest culms, marked in 2013, show the largest surface temperature difference of $0.48{ }^{\circ} \mathrm{C}$ on $04 / 08 / 2014$ at $5: 00 \mathrm{pm}$ and $0.28{ }^{\circ} \mathrm{C}$ on $05 / 08 /$ 2014 at $6: 00 \mathrm{pm}$ compared to the references culms from 2011. The culms marked in 2012 have a maximum difference of $0.17{ }^{\circ} \mathrm{C}$ on $04 / 08 / 2014$ at $7 \mathrm{pm}$ and $0.23{ }^{\circ} \mathrm{C}$ on $05 / 08 / 2014$ at $6: 30 \mathrm{pm}$. The mean temperature curve (Fig. 3) shows that with the setting sun $(5: 00 \mathrm{pm})$ we recorded larger differences in surface temperature until 5:30 pm. Under complete darkness from 6:00 pm, the surface temperatures further decreased, where the differences between the culm surfaces at different ages remained about the same. Throughout the entire measurement period we observe a small but constant temperature difference between the different culm ages.

At 0.1 significance level the result of the paired sample Wilcoxon signed rank test showed that the surface temperature of culms about 3 years of age $(P=0.0625)$ and 2 years of age $(P=0.0625)$ differed significantly from 1 year old culms. The inter-culm variability of both the length of the internode and the surface temperature show a similar trend. The length of the internode increases from the fourth to the sixth internode on average by $5.68 \%$ and from the fourth to eighth there is an average increase of $16.35 \%$. The surface temperature increases around 


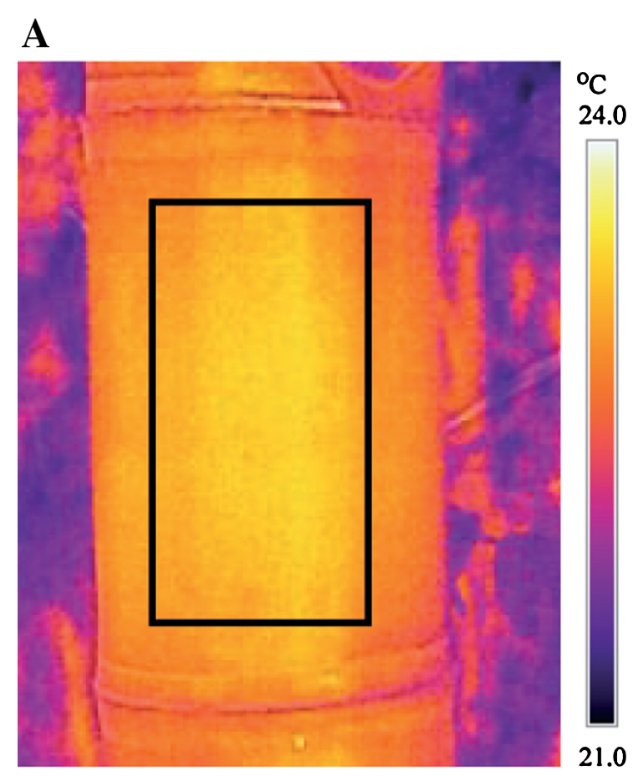

B

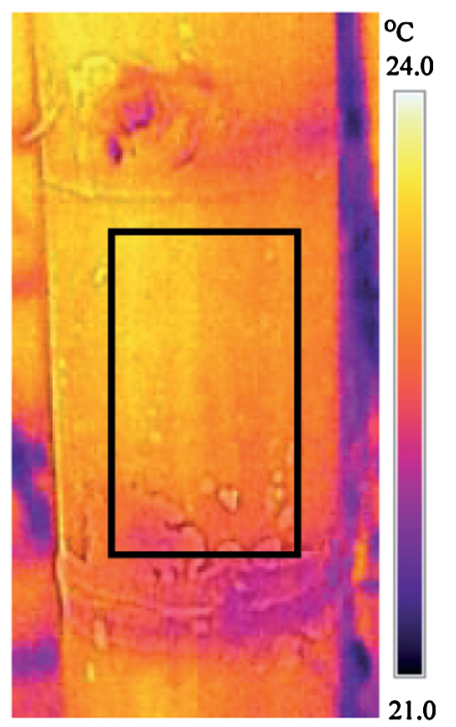

D

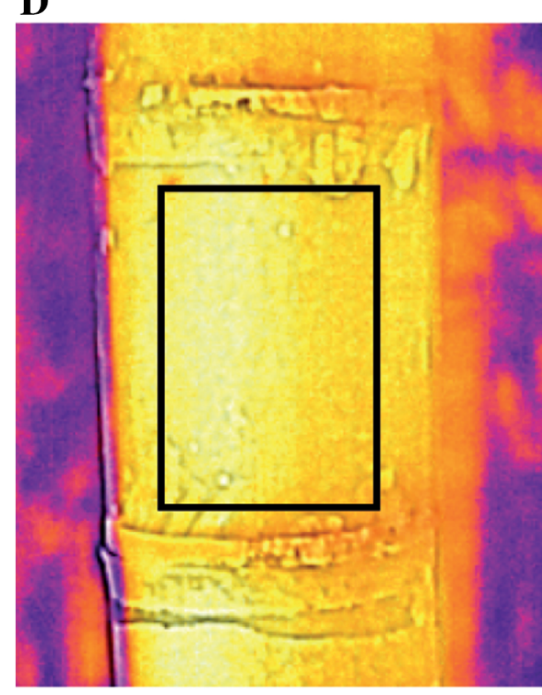

G

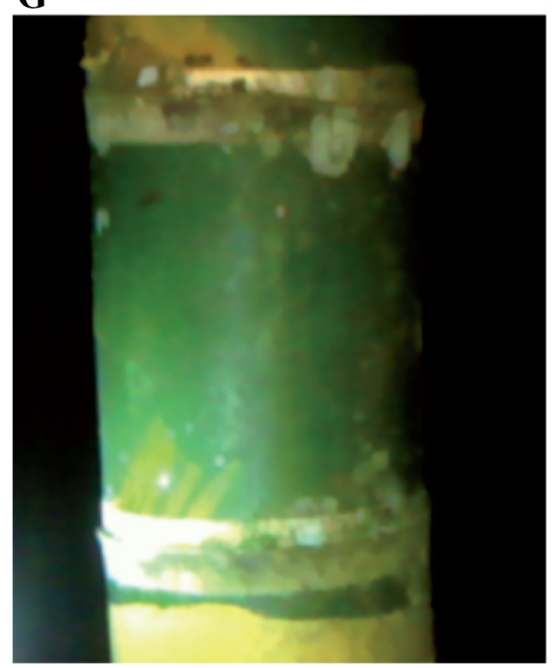

E ${ }^{\circ} \mathrm{C}$
24.0

21.0

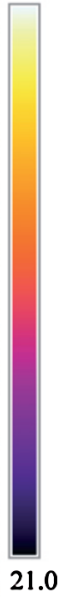

H

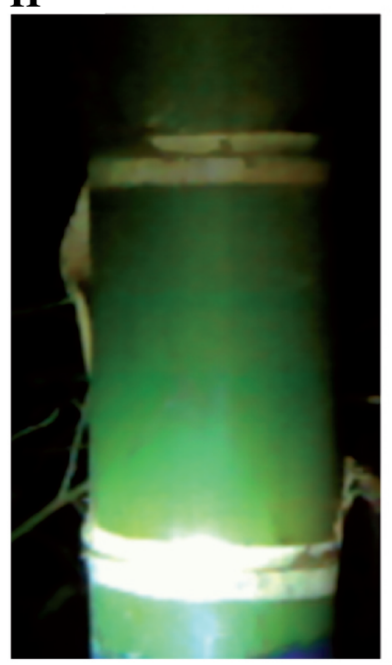

\section{C}

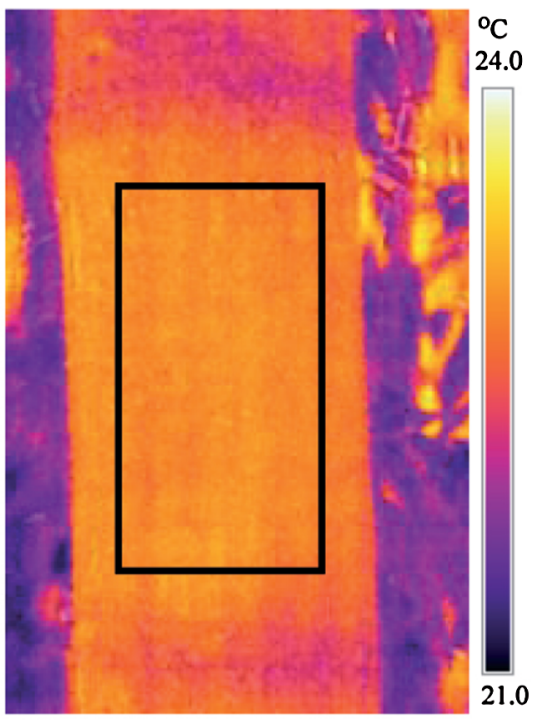

F

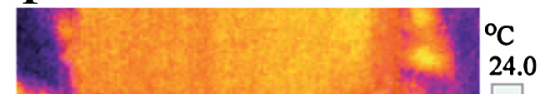

24.0

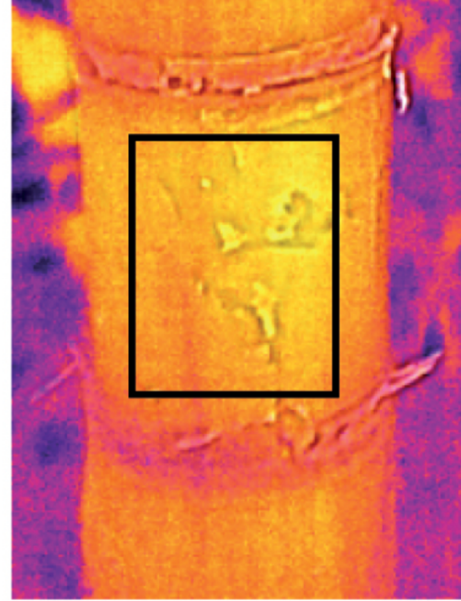

24.0

I

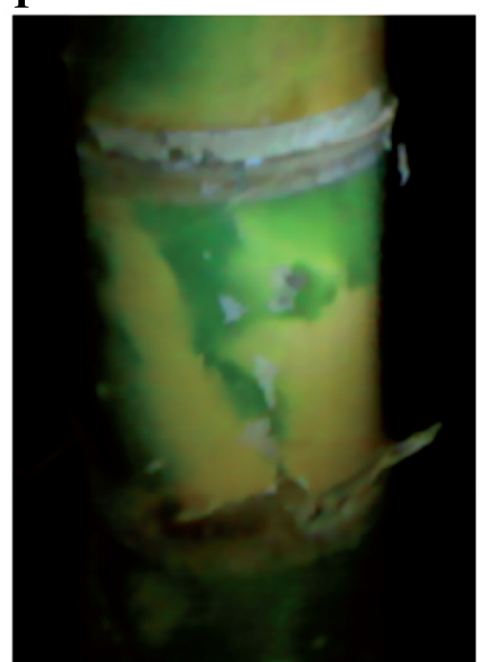


4Fig. 1 a-c Thermal (above) and visual image (below) of culm ages of 3 years $(\mathbf{d}, \mathbf{g}), 2$ years $(\mathbf{e}, \mathbf{h})$ and 1 year $(\mathbf{f}, \mathbf{i})$. All images were taken at same internode height. The black rectangles in the upper row illustrate the area in which the mean surface temperature was calculated

$0.21{ }^{\circ} \mathrm{C}$ from fourth to sixth and around $0.41{ }^{\circ} \mathrm{C}$ from the fourth to eighth internode.

\section{Discussion and conclusion}

The higher surface temperature of the older culms may be associated with culm anatomy, since, according to Liese (1985), the vascular bundles at the peripheral zone of the culm are smaller and more numerous, which may cause a more expressed cooling effect. In the vertical direction, the amount of fibers as well as vessels and phloem increases from the bottom to the top, while cells of parenchyma are scarcer. Therefore, when xylem sap occur in greater abundance close to the bottom section of the culm, they may have a cooling effect; in contrast, in the upper section the abundance of fibers restricts the presence of xylem sap. The types of cells that are predominant in higher parts of the culms may well explain the slightly higher temperature at higher internodes, as most of them are associated with

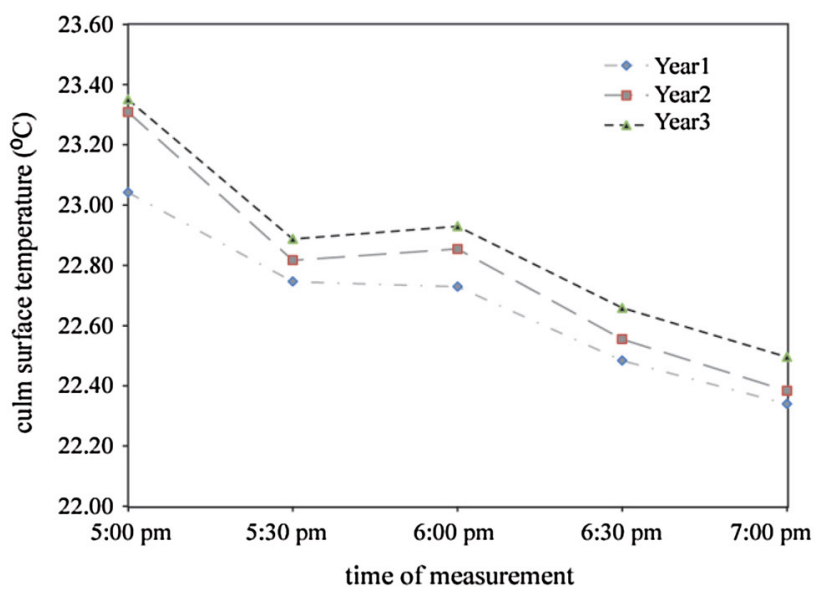

Fig. 3 Mean temperature curves over time for the three age classes

the transportation of xylem sap and with high percentages of fibers. The percentage of vascular bundles at the outer part of the culms can vary between bamboo species, yet the concentration is higher at the outer than in the middle and the inner parts (Mustafa et al. 2011). Thus, the higher concentration of structures associated with the transportation of xylem sap is more important close to the culm surface and likely related to changes in temperature.
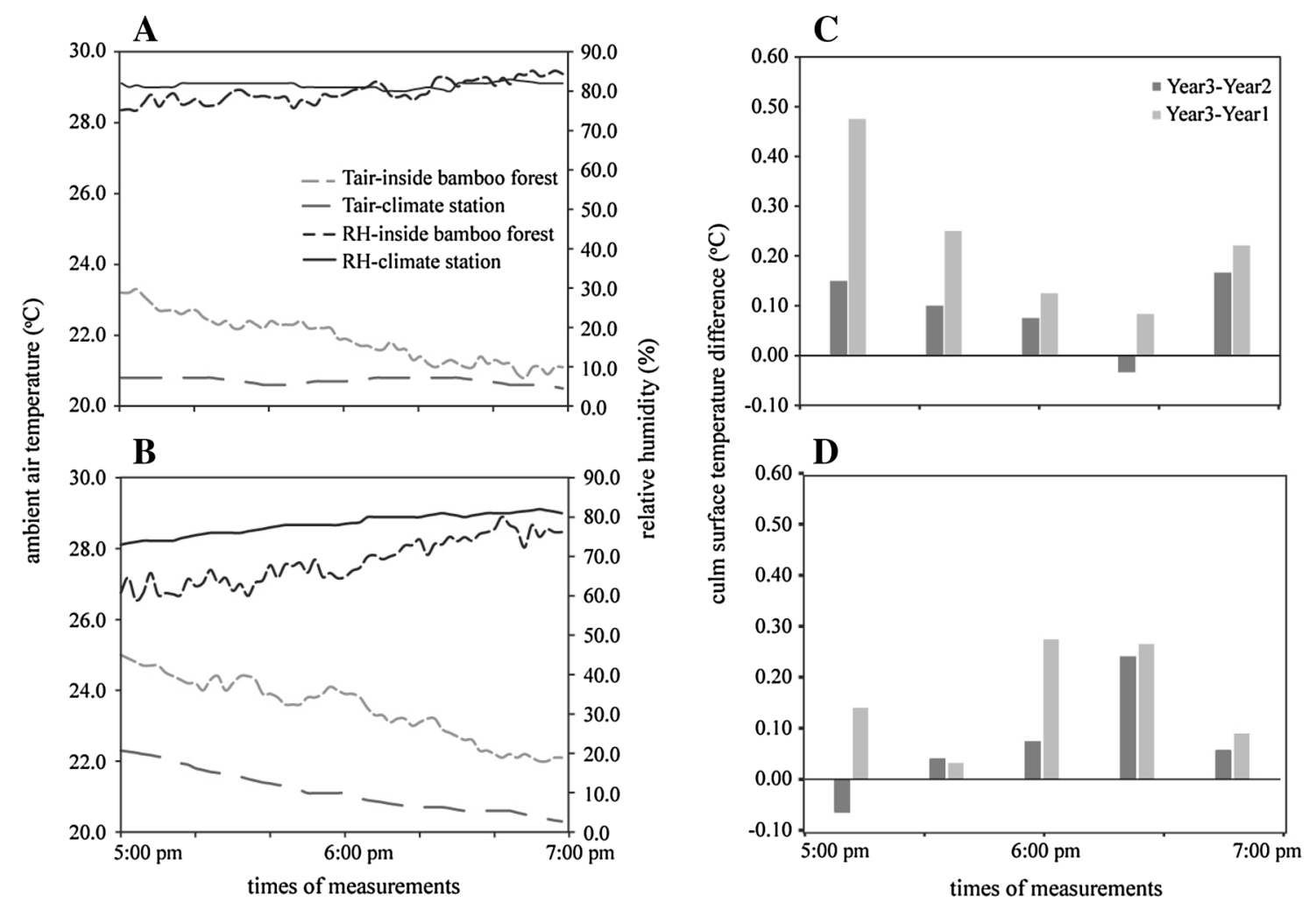

Fig. 2 Air temperature, relative humidity within and above the canopy and the differences in culm surface temperature during the measurements. Measurements were taken on (a, c) 04/08/2014 and (b, d) 05/08/2014, both between 5:00 and 7:00 pm 
Therefore, we recommend more extensive research to prove this hypothesis.

According to Gonzalez et al. (2008) younger culms have a higher moisture content, while in older culms, vessels and sieve tubes lose their conductivity due to depositions of gum-like substances, which may cause the death of the aged culms (Liese 1985). Therefore, older culms have limitations in water transportation because vessels and sieve tubes are obstructed and the space for water transportation is reduced; therefore moisture content decreases leading to a reduced cooling effect of the water flow resulting in higher temperatures. Furthermore, a study by Wakchaure and Kute (2012) showed that the moisture content tends to decrease from bottom to the top of the culm. These findings suggest that the flows of xylem sap along the culm may have an influence on the surface temperature at the time of measurement (evening). As the sap flow during the day is almost insignificant and the main hydraulic events occur between 11:00 pm until 9:00 am with a peak between 4:00 am and 5:00 am (Zachary 2009), the concentration of xylem sap during our measurement time interval between 5 and $7 \mathrm{pm}$ might be still higher at top, but insufficient to reduce the temperature. Beyond that, the leaf area which is usually higher in younger culms might also contribute to explaining the higher moisture content found within these culms, since transpiration tends to be higher and more water needs to be transported along the culms.

If the emissivity is not taken into account, the surface temperature of an object may appear to be emitting more radiation than it actually does. This can give an incorrect temperature of the culm surface. In our study, we chose an emissivity value of 0.98 which is an average value commonly taken for trees (Rubio et al. 1997). Specific emissivity values for the culm of guadua bamboo appear not to be available. Indeed, the changes of structure and color of the culm surface with maturity may have an influence on the emissivity and may result in more significant differences in culm surface temperature with maturity when more accurate and age-dependent emissivity values are available.

It is difficult to determine the emissivity of an object because it is a measure of the surface emittance which can change during the day. Therefore, we used an emissivity table which includes approximations or averages of different surface materials and objects.

Thermal cameras, such as the one used in this study, begin at a price range of $\$ 1000$ and may thus constitute more affordable tools for farmers and foresters. Our results support the hypothesis that differences in culm surface temperature as a function of maturity may exist for guadua bamboo. At the time of our study, the age of the oldest and marked culm at our study area is 3 years. The temperature differences we found in our sample are modest, but significant. The ranges in culm surface temperature are explained by culm age and internode length. The area of influence of the sample culm depending on the number and distance of the surrounding culms. The hypothesis that a high density may influence the surface temperature of the sample could not be proven, because we could not quantize the amount of radiated energy from surrounding culms. Nevertheless, due to the physical principals of thermal infrared imaging (Vollmer and Möllmann 2010), we expect that there is an influence by the culm density. Further bamboo culm characteristics (internode wall thickness, cell wall structure, and moisture content) may influence the final surface temperature. Their measurement would be necessary to better understand what causes the difference in culm surface temperature. Additionally, in the future study the difference would need to be confirmed with a larger number of culms and with age-marked culms that have reached the maturity age.

Acknowledgements We want to thank to the projects "Nuevas metodologías para la evaluación y monitoreo de carbono e indicadores de biodiversidad en sistemas silvopastoriles y bosques de guadua en paisajes de la zona cafetera de Colombia" and "Innovación tecnológica para la optimización de procesos y la estandarización de productos en empresas rurales con base en Guadua: una contribución para el fortalecimiento de la competitividad de la cadena productiva de la Guadua en el eje cafetero de Colombia" both funded by Colciencias. Great thanks are also going to DAAD, the German Academic Exchange Service, for supporting the university partnership between Pereira and Göttingen in the course of which this research had been implemented.

\section{References}

Camargo JC. 2006. Growth and productivity of the bamboo species Guadua angustifolia Kunth in the Coffee Region of Colombia. $\mathrm{PhD}$. Thesis. Göttingen, Universität. Cuvillier, Göttingen

Camargo JC, Rodriguez JA (2010) Determinación en campo de la madurez de los culmos de Guadua angustifolia Kunth en el Eje Cafetero de Colombia. Revista Recursos Naturales y Ambiente 61:95-103

Camargo JC, Suarez JD (2014) Compression resistance and shear strength of Guadua angustiolia culms after drilling of the node diaphragm. Colomb For 17(1):117-124

Correal JF, Arbeláez J (2010) Influence of age and height position on Colombian Guadua angustifolia bamboo mechanical properties. Maderas 12(2):105-113

Duque AF, Lara A, Quintero HF, Castañeda E, Monroy M (2010) Medición indirecta de la madurez del culmo de guadua por medio de las vibraciones mecánicas. Revista Recursos Naturales y Ambiente 61:26-37

González HA, Montoya JA, Bedoya JR (2008) Comportamiento de muestras de Guadua angustifolia kunth con diafragma y sin diafragma sometidas a esfuerzo de compresión. Scientia et Technica 38:449-454

Hunter IR (2003) Bamboo resources, uses and trade: the future? J Bamboo Rattan 2(4):319

Kleinn C, Morales D (2006) An inventory of Guadua (Guadua angustifolia) bamboo in the Coffee Region of Colombia. Eur J For Res 125(4):361-368 
Leuzinger S, Vogt R, Körner C (2010) Tree surface temperature in an urban environment. Agric For Meteorol 150:56-62

Liese W (1985) Anatomy and properties of bamboo. Recent research on bamboos. In: Proceedings of the international bamboo workshop, Hangzhou, pp 196-208. 6-14 Oct 1985

Lobovikov M, Ball L, Guardia M, Russo L (2007) World bamboo resources: a thematic study prepared in the framework of the Global Forest Resources Assessment 2005. Food \& Agriculture Org, Rome

Londoño X (1990) Aspectos sobre la distribución y ecología de los bambúes de Colombia (Poaceae: Bambusoideae). Caldasia 16(77):139-153

Londoño X (1998) Evaluation of bamboo resources in Latin Latin America. A summary of the final report of project No. 96-830001-4. International Network for Bamboo and Rattan. Instituto Vallecaucano de Investigaciones Científicas, Cali

Matsumoto K, Ohta T, Tanaka T (2005) Dependence of stomatal conductance on leaf chlorophyll concentration and meteorological variables. Agric For Meteorol 132:44-57

Mustafa MT, Wahab R, Sudin M, Sulaiman O, Kamal NAM, Khalid I (2011) Anatomical and microstructures features of tropical bamboo Gigantochloa brang, G. levis, G. scotechinii and G. wrayi. Int J For Soil Eros 1(1):25-35

R Core Team (2004) R: a language and environment for statistical computing. $\mathrm{R}$ foundation for statistical computing, Vienna, Austria

Rubio E, Caselles V, Badenas C (1997) Emissivity measurements of several soils and vegetation types in the $8-14, \mu \mathrm{m}$ wave band: analysis of two field methods. Remote Sens Environ 59:490 521. doi:10.1016/S0034-4257(96)00123-X

Takeuchi C, Lamus F, Malaver D, Herrera JC, River JF (2009) Study of the behaviour. In: The 8th world bamboo congress proceedings. World Bamboo Organization, Plymouth, pp 42-58

Vollmer M, Möllmann KP (2010) Infrared thermal imaging, fundamentals, research and applications. Wiley-VCH, Berlin, p 594

Wakchaure MR, Kute SY (2012) Effect of moisture content on physical and mechanical properties of bamboo. Asian J Civ Eng (Build Hous) 13(6):53-763

Zachary M (2009) Sap flows dynamics of a tropical woody bamboo: deductions of physiology and hydraulics within Guadua angustifolia, Thesis. Washington University in St. Louis 
Annex D

Manuscript IV 


\title{
Comparing Canopy Leaf Temperature of Three Central European Tree Species Based on Simultaneous Confidence Bands for Penalized Splines
}

\author{
Manuel Vonrütia*, Aleksandar Spasojevic ${ }^{\mathrm{a}}$, Nils Nölke ${ }^{\mathrm{b}}$, Thomas Kneib ${ }^{\mathrm{a}}$, Christoph Kleinn ${ }^{\mathrm{b}}$ \\ ${ }^{a}$ Chair of Statistics, Georg-August University, Göttingen, Germany ${ }^{b}$ Chair of Forest Inventory \\ and Remote Sensing, Georg-August University, Göttingen, Germany
}

\begin{abstract}
Temperature is an important physical factor that is known to affect strongly biodiversity and ecosystems and their functioning. However, it is still relatively little researched, possibly also because of the multitude of influencing factors and the complexity of the statistics involved. This study researches into differences between the surface temperature of three Central European broadleaf tree species. A better understanding of these differences may help to elucidate the role of microclimate for biodiversity. We consider a time series of high-resolution thermal images taken from a meteorological observation tower and calculate mean canopy leaf temperatures for beech, ash and maple (Fagus silvatica, Fraxinus excelsior and Acer pseudoplatanus). In a first step, comparable image areas are extracted for analyses from the thermal image sections of the crown of each tree species avoiding shadow areas, branches, etc. We used an automatic segmentation technique, the Otsu thresholding. Extracted canopy leaf temperature values were then processed and the resulting temperature profiles estimated by O'Sullivan penalized splines. For comparing the difference in canopy leaf temperature over time, we propose the construction of simultaneous confidence bands. The analyses show that there are significant ? though small - differences in canopy surface temperature between the three tree species.
\end{abstract}

Keywords: Otsu Thresholding; thermal picture; leaf canopy temperature; penalized splines

\section{Introduction}

Forest canopies with their complex horizontal and vertical structures are home to a high biodiversity, notably of insects [7]. Tree crowns carry the majority of leaf biomass where many plant physiological processes take place. Temperature is among the important environmental factors for these physiological processes and in particular leaf temperature has been referenced as a central factor for functional plant ecology resulting from interactions between different environmental and physiological factors. Matsumoto (2005) [9] for example, showed that leaf temperature affects stomatal conductance. This relationship was used before by Jones (1999) [2] to develop methods to estimate stomatal conductance from measurements of leaf temperature. The process of transpiration is known to directly influence leaf temperature because of its cooling effect. In fact, through a variety of physiological processes, temperature eventually affects all aspects of plant growth [15], either directly or indirectly. Temperature does also exert influence on faunistic diversity. Diversity, abundance and distribution of insects, for example, is related to the ambient temperature range and as a consequence also the distribution of other animals feeding

\footnotetext{
${ }^{*}$ Corresponding author. Email: manu.vonrueti@swissonline.ch
} 
on insects. Ambient temperature itself is affected by many abiotic environmental factors including moisture content of soil, distribution and intensity of illumination, and topographic and geological conditions, and also by biotic factors including plant cover, density and structure.

Altogether, temperature is one out of various physical factors affecting plant growth and ecosystem development and it is among those factors for which field research is extremely complex and not so abundant. One of early studies in that context showed a difference in mean canopy leaf temperature between coniferous and broad-leaved trees and was conducted by Leuzinger (2007) [6]. He also discussed the complexity of such studies where the crown surface temperature is both influenced by the meteorological conditions and by the crown and leaf structure.

In this paper we follow Leuzinger's work (2007) [6] in the field of bioclimatology and search for potential differences between the canopy surface temperatures of three broadleaved tree species. However, in contrast to previous studies, a time series of thermal imagery over different days was taken from a climate tower and this paper turns to statistical approaches of segmentation for the distinction of differently illuminated canopy regions. Then, the comparison of canopy temperature is made per illumination class where the temperature profiles are estimated by O'Sullivan penalized splines. For comparing the difference in canopy leaf temperature profiles for the different species, we suggest simultaneous confidence bands for penalized splines.

\section{Material and Methods}

\section{$2.1 \quad$ Study Area}

The study area is part of a German long-term collaborative research project on biodiversity-functioning, the DFG-funded infrastructure priority project "Exploratories for large-scale and long-term functional biodiversity research" (funded by the German Research Foundation, DFG, see Fischer et al. (2010) [8]. The study was conducted in one of the three exploratories around the eddy covariance tower in the Nationalpark HainichDün in Thuringia, Central Germany. Since 1935, it was used as a military base and since then parts of the forest area are unmanaged and without major disturbance. The Hainich National Park was established in 1997 and includes the largest continuous beech forest in Germany. Around $90 \%$ of the forest area are not used for wood production. Close to the climate tower, there is an uneven-aged unmanaged forest with a maximum tree height between 31 and $34 \mathrm{~m}$ and a diverse canopy structure dominated by European beech (Fagus sylvatica), European ash (Fraxinus excelsior) and sycamore maple (Acer pseudoplatanus). The location of the tower site is in a subcontinental climate with a mean precipitation between 500 and $800 \mathrm{~mm}$ per year, and a mean temperature between 6.5 and $8.0^{\circ} \mathrm{C}$. The climate is typical for a humid temperate zone and is described in detail by Knohl (2003) [3].

\subsection{High-Resolution Thermal Images}

Thermal images were taken with a state-of-the-art camera (VarioCam hr head, Infratec, Dresden, Germany) with a resolution of $640 \times 480$ pixel and a spectral range of 7.5 $-14 \mathrm{~m}$. The camera was mounted on the climate tower at a height of $45.4 \mathrm{~m}$ with an azimuth of 100 degrees. Images were taken on two different periods. Period 1 started at 28.08.2012 and ended at 10.09.2012 with an inclination of 30 degrees downwards. With these settings, we mainly cover the crown of ash and maple. For the period 2 (11.09.2012 - 16.10.2012), we increased the inclination to 40 degrees downward to take also the beech 
crown into account. The field-of-view projected to the ground is $8 \times 6$ meters for period one and $10 \times 9$ meters for period two. The geometric resolution based on the distance between camera and canopy surface is $14 \mathrm{~mm}$. To get a nearly stable daily temperature distribution, we took images at a 10 min interval over defined time periods of several days that were stored in a raw format with a dynamic range of 16 bit. For the emissivity, we assume a constant value of 0.98 (Rubio et al. 1997) [13] representing a value, which is averaged over various forest vegetation type. In total, we took 1238 images over a period from September to October to derive a time series under different environmental conditions. The image section covered the crowns of four trees from three tree species, ash, maple and beech. Because the field-of-view is limited, only parts of the crown of ash and beech could be included. For data processing and statistical analysis, the software products Irbis 3 Plus (InfraTec, Dresden, Germany) and R (R Development Core Team, 2014)[12] were used. The internal calculation of the absolute temperature depends on a constant surrounding temperature. Therefore, every thermal image was corrected with the air temperature that was simultaneously at canopy height.

This paper analyses thermal images taken after sunset when incoming shortwave radiation is equal to zero and before sunrise. Within this time slot we could avoid the influence of changing environmental conditions, in particular the changing sun conditions. An important step for further processing is delineation of the tree crowns which has been done manually (see Fig. 1) in order to separate the crowns of the sample trees and tree species.

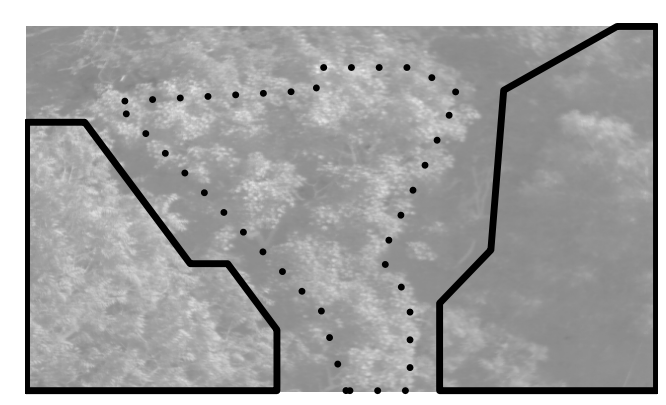

(a) Separation of tree crowns in period 1

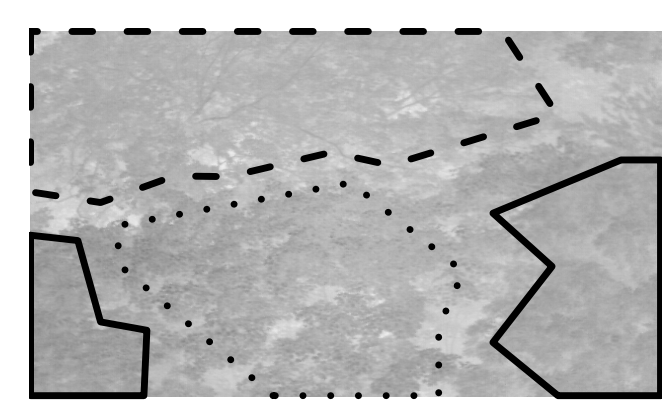

(b) Separation of tree crowns in period 2

Figure 1. Manual delineation of tree crowns. The solid line represents the ash tree, the dashed line the beech tree and the dotted line the maple tree.

\subsection{Overview of Methodological Approach}

The temperature pattern in a tree crown, when viewed from above, is highly variable. This has to do with gaps, branches and, in general, many different illumination situations that are regularly changing during the day due to changing illumination intensity (clouds) and angle (sun). A first methodological challenge in leaf temperature determination is, therefore, to extract "observation fields" out of the canopy thermal image that can meaningfully be compared. A common method to extract canopy leaf temperature is a manual selection (see Leuzinger [6]), avoiding trunks, branches, and gaps. However selecting observation fields manually for each thermal picture is time-consuming in particular when larger areas or larger time series are to be analysed. In this study, therefore, an automatic segmentation method is applied. There are two statistical questions that are addressed in this study: (1) "How to stratify automatically the canopy of one tree 
(species) into sub-regions such that these can meaningfully be compared to the same type of sub-regions of other tree species?" and (2) "How to compare time series of canopy surface temperature values within these observation fields between different species?" The statistical approaches described in the next sections that are employed here are novel to the context of analysing canopy surface temperatures.

\subsection{Classifying Thermal Signals}

In contrast to the delineation of tree crowns which can be done manually due to the low number of trees on the images, the separation of different elements of tree crowns can only be done in an automated fashion due to the large number of pixels in each image. The separation is required since each crown consists of a variety of different structures that are more or less suited to study temporal profiles of leaf temperature. In the following, we will differentiate between background pixels (comprising for example branches and trunks), pixels that represent a mixture of background and leaf surface and pixels only related to leaf surface structures. Since both background pixels as well as pixels with a mixture of background and leaf surface do not provide reliable information on leaf temperatures, we aim at the separation of these three classes for the remainder of the analyses.

To obtain a data-driven, automatic pixel classification, we consider the nonparametric unsupervised clustering approach developed by Otsu in [11]. We assume that the pixels of (a part of) an image can be clustered in $M$ segments based on the histogram of their temperature measurements (with $M=3$ in our example). The optimal thresholds between the segments are determined by maximizing the between class variance of the segments.

To make this more precise, assume that there is a total of $N$ observations on pixel temperatures for a given time point and tree species and that the distinct, ordered temperature values are given by $T_{(1)}<\ldots<T_{(J)}$ (where we suppress dependence on time and species notationally). Assume furthermore that the relative and absolute frequencies of these distinct temperature values are given by $n_{j}$ and $p_{j}=n_{j} / N, j=1, \ldots, J$, respectively, such that $n_{1}+\ldots+n_{J}=N$ and $p_{1}+\ldots+p_{J}=1$. Now the observations should be classified into $M$ segments by $M+1$ thresholds $T_{(1)}=\kappa_{0}<\kappa_{1}<\ldots<\kappa_{M-1}<$ $\kappa_{M}=T_{(J)}+\epsilon$ (with a small positive value $\epsilon>0$ ) such that each segment is given by an interval

$$
C_{m}=\left[T_{\left(\kappa_{m-1}\right)}, T_{\left(\kappa_{m}\right)}\right), \quad m=1, \ldots, M
$$

The relative fraction of observation in such an interval is then given by

$$
\omega_{m}=\sum_{j: T_{(j)} \in C_{m}} p_{j} \quad m=1, \ldots, M
$$

and the segment-specific means $\mu_{m}$ as well as the overall mean $\mu$ are given by

$$
\mu_{m}=\sum_{j: T_{(j)} \in C_{m}} T_{j} \frac{p_{j}}{\omega_{m}} \quad \text { and } \quad \mu=\sum_{j=1}^{J} T_{(j)} p_{j}
$$


Correspondingly, the variance within each segment is given by

$$
\sigma_{m}^{2}=\sum_{j: T_{(j)} \in C_{m}}\left(T_{(j)}-\mu_{m}\right)^{2} \frac{p_{j}}{\omega_{m}}
$$

Otsu introduced several discriminant criteria measures, which represent the goodness of thresholds. In this paper, we focus on the discriminant criterion

$$
\eta=\frac{\sigma_{B}}{\sigma_{T}^{2}} \quad 0<\eta<1
$$

defined as the ratio of the between segment variance

$$
\sigma_{B}^{2}=\sum_{m=0}^{M} \omega_{m}\left(\mu_{m}-\mu\right)^{2}
$$

and the total variance

$$
\sigma_{T}=\sum_{j=1}^{J}\left(T_{(j)}-\mu\right)^{2} p_{j}
$$

since it is only based on first-order statistics. Optimal thresholds are then obtained by maximizing $\eta$ with respect to the thresholds.

\subsection{Penalized Splines for Smoothing the Temperature Curves}

Based on the separation of pixels, we will now estimate the leaf temperature curves of the three different species included in our data set. The basis will be temperatures averaged over all pixels of a specific type (separated using Otsu's thresholding) for a given species at a given time point such that $T_{d t}$ represents the average leaf temperature at day $d$ and time $t$. Since it is very likely that the daily evolution of temperatures is of a strongly nonlinear form, we assume a model of the form

$$
T_{d t}=g(t)+\epsilon_{d t}
$$

where $g(t)$ denotes the time-dependent temperature curve and $\epsilon_{d t}$ i.i.d. $N\left(0, \sigma^{2}\right)$ are the error terms of the regression specification. This model structure is applied separately for each of the three tree species and only for the pixels identified as leaf structures by Otsu's thresholding. We will then use simultaneous confidence bands around the estimated temperature curves to determine whether there are significant differences between the species-specific temperature curves.

\subsubsection{O'Sullivan Penalized Splines}

O'Sullivan penalized splines [10] are a direct generalization of smoothing splines starting from the optimization problem

$$
\min _{g \in C^{2}([a, b])}\left[\sum_{d, t}\left\{T_{d t}-g(t)\right\}^{2}+\lambda \int\left\{g^{\prime \prime}(t)\right\}^{2} d t\right]
$$


where $C^{2}([a, b])$ denotes the space of all twice differentiable functions on the interval $[a, b]$ and $\lambda \geq 0$ is a smoothing parameter that determines the impact of the integrated squared second derivative penalty on the optimization criterion. Note that we dropped the index $m$ (referring to the different tree species). Intuitively the goal is to find a compromise between goodness of fit as measured by the least squares term and the wiggliness of the function estimate as quantified by the penalty term. In practice, the smoothing parameter $\lambda$ has then to be chosen in a data-driven fashion to obtain the optimal curve estimate.

A classical result on this optimisation problem is that the optimal solution is a natural cubic spline with knots at all distinct time points $t$. To avoid the large number of basis functions resulting from the large number of time points, O'Sullivan uses a subset of knots such that the exact optimality property is lost but numerical efficiency is increased. Still the mean function $g(t)$ can be approximated as a linear combination of cubic B-spline basis functions $B_{k}^{3}(t)$ leading to

$$
g(t)=\sum_{k=1}^{K} \beta_{k} B_{k}^{3}(t)
$$

where $\beta_{K}$ are the regression coefficients and the B-splines are constructed recursively via

$$
\begin{aligned}
& B_{k}^{0}(t)=I\left(\kappa_{k-1} \leq t \leq \kappa_{k}\right) \\
& B_{k}^{l}(t)=\frac{t-\kappa_{k-1}}{\kappa_{k}-\kappa_{k-l}} B_{k-1}^{l-1}(t)+\frac{\kappa_{k+1}-t}{\kappa_{k+1}-\kappa_{k+1-l}} B_{k}^{l-1}(t), \quad l \geq 1
\end{aligned}
$$

based on the sequence of knots $\kappa_{-2}<\ldots<\kappa_{K+3}$. To adjust for the natural boundary coefficients, a slight modification is required for the basis functions at the boundary, see $[1$, p. 450] for details.

The penalty in (4) can be expressed as a quadratic form $\lambda \boldsymbol{\beta}^{\prime} \boldsymbol{\Omega} \boldsymbol{\beta}$ where $\boldsymbol{\beta}$ is the vector of all basis coefficients while the elements of the penalty matrix $\boldsymbol{\Omega}$ are given by

$$
\Omega_{i j}=\int B_{i}^{\prime \prime}(t) B_{j}^{\prime \prime}(t) d t
$$

Then an estimate for $\boldsymbol{\beta}$ is given by

$$
\hat{\boldsymbol{\beta}}=\left(\mathbf{B}^{\top} \mathbf{B}+\lambda \boldsymbol{\Omega}\right)^{-1} \mathbf{B}^{\top} \boldsymbol{T}
$$

where $\mathbf{B}$ is the design matrix obtained from evaluating the B-spline basis functions at the observed time points and $\boldsymbol{T}$ is the vector of all temperature measurements. From this estimate, the temperature curve at any time point $t$ can be reconstructed as

$$
\hat{g}(t)=\sum_{k=1}^{K} \hat{\beta}_{k} B_{k}^{3}(t) .
$$

To complete the estimation of temperature curves, a suitable value of the smoothing parameter $\lambda$ has to be chosen. Here we rely on the representation of O'Sullivan splines as mixed models such that $\lambda$ is determined based on restricted maximum likelihood estimation [14, section 4.5.3]. 


\subsubsection{Simultaneous Confidence Bands}

The mixed model representation of O'Sullivan splines employed for the determination of the smoothing parameter is also valuable for obtaining simultaneous confidence bands for the estimated temperature curves. A simultaneous confidence band $\left[g_{L}(t), g_{U}(t)\right] t \in$ $[a, b]$ with lower and upper bound $g_{L}(t)$ and $g_{U}(t)$, respectively, provides a simultaneous assessment of estimation uncertainty for complete curves such that

$$
P\left(g_{L}(t) \leq \hat{g}(t) \leq g_{U}(t), a \leq t \leq b\right) \geq 1-\alpha
$$

is ensured for all $t \in[a, b]$ simultaneously with a given confidence level $1-\alpha$. From the mixed model representation of penalized splines, a simultaneous confidence band can be determined as

$$
\left[\hat{g}_{m}(t)-c_{1-\alpha} \hat{\sigma}_{\hat{g}}, \hat{g}_{m}(t)+c_{1-\alpha} \hat{\sigma}_{\hat{g}}\right]
$$

where $c_{1-\alpha}$ is a quantile of the limiting process for the penalised splines and $\hat{\sigma}_{\hat{g}}$ represents a measure of estimation uncertainty (see [5] for details). For the construction of the confidence band, we assumed that the approximation bias resulting from the penalised spline specification is negligible such that enough knots have to be used in practice.

\section{Application}

\subsection{Preprocessing}

In a first step, we apply Otsu's thresholding algorithm to delineate different parts of the thermal pictures. To validate the choice of the number of thresholds $M$, we computed the discriminant criterion $\eta$ defined in Eq. (2) for a variety of choices of $M$ (Fig. 2). By construction the discriminant criterion increases with the number of thresholds but the increase is most markable for the transition from one to two thresholds while it then levels off. In addition, the interpretation of the resulting classes of pixels becomes more difficult for an increasing number of thresholds [11, Section 3B]. Therefore, we decided to use two thresholds corresponding to our earlier intuition of background pixels, mixtures of background and leaf structures and pure leaf structures. Fig. 3 illustrates the outcome of the segmentation procedure at two time stamps. Since only the pure leaf category is

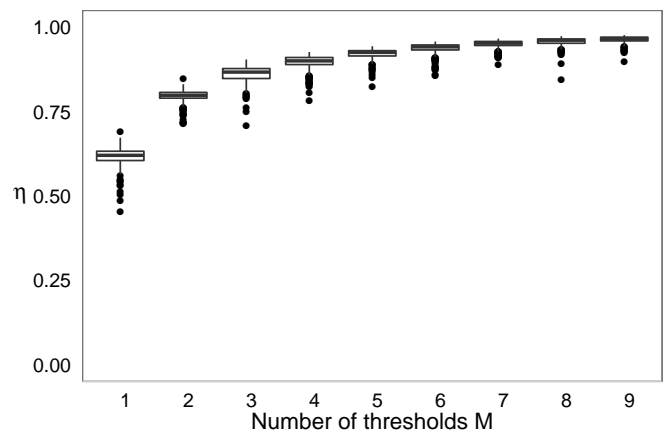

(a) Tree type maple in period 1

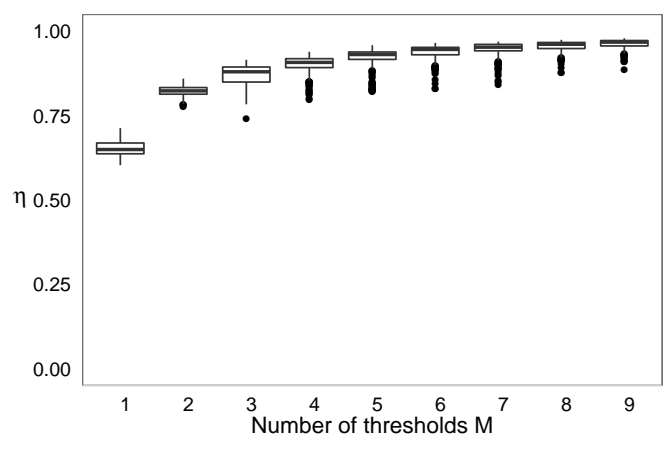

(b) Tree type ash in period 1

Figure 2. The maximized discriminant criterion measure $\eta$ is calculated for different numbers of thresholds and for all time points in period 1. A similar structure is found in period 2.

of interest for comparing leaf temperatures, we restrict ourselves to pixels from this class 
in the following. For each of the tree species, we then compute the average temperatures at a given day $d$ and given time point $t$ by averaging over all pixels assigned for the pure leaf category for a specific tree type (see Fig. 4 for an illustration). Additionally, a seasonal adjustment was performed by subtracting the air temperature $T_{d, t}^{A}$. Finally, since a pattern in the deseasonalised measurements for all three species was still visible, the overall mean averaged over days and tree types was substracted such that we finally obtained measurements $T_{d t}^{s}$ where $s$ denotes one of the three species.

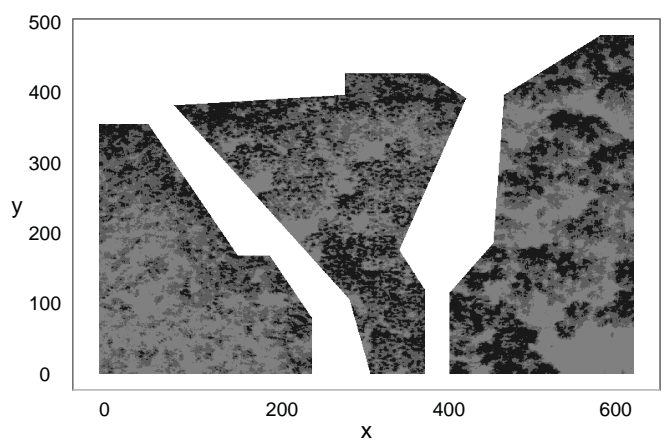

(a) Otsu segmentation on 28-08-2012 19:20 (period 1). Black indicates pixels representing canopy leaf temperature.

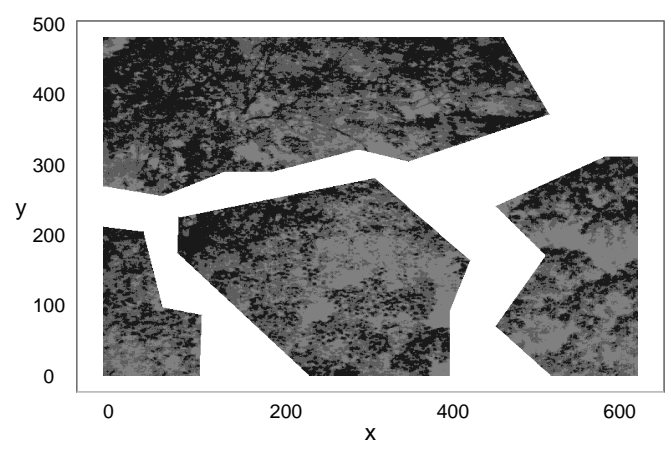

(b) Otsu segmentation on 10-10-2012 00:40 (period 2). Black indicates pixels representing canopy leaf temperature.

Figure 3. Example of Otsu segmentation in period 1 and 2.
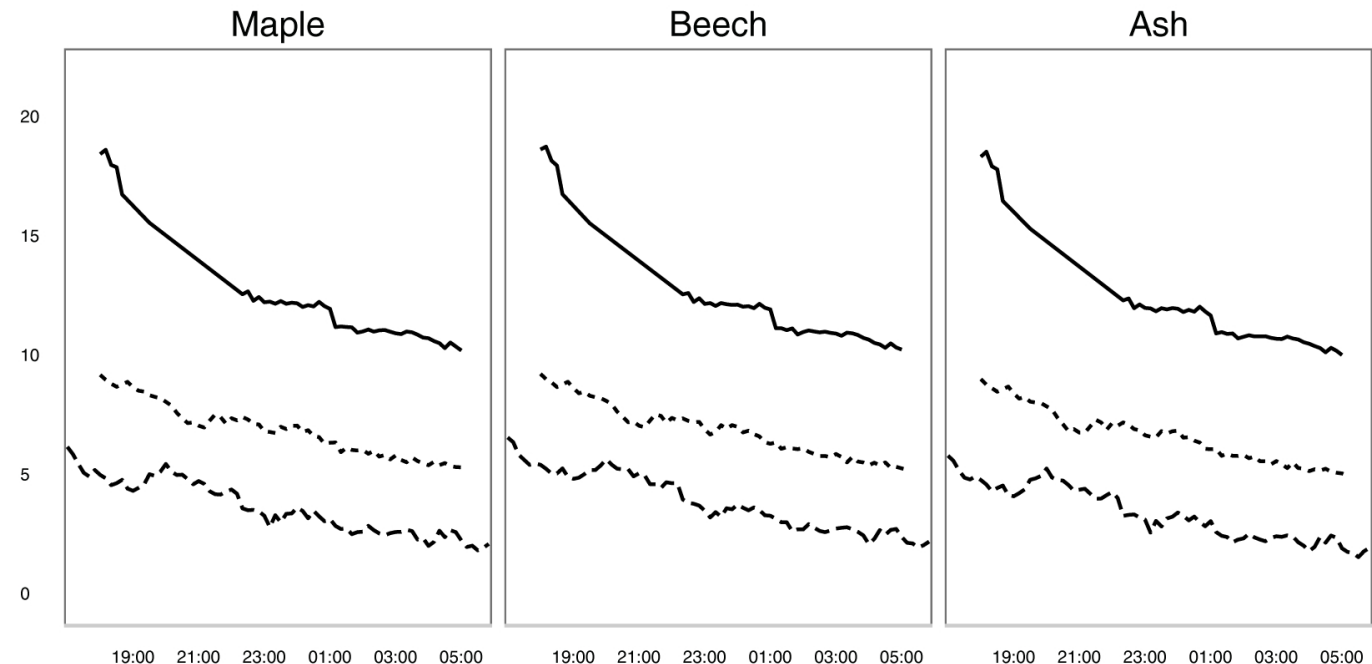

Figure 4. Mean temperature of all tree species in period 2 (still including seasonal effects). The solid line represents a day at the beginning of September, the dotted line a day in the middle of September and the dashed line a day at the beginning of October.

\subsection{Estimation and $S C B$}

After preprocessing the data to obtain average temperatures per species, day and time point, we focus on estimating the trend function $g(t)$ separately for each species using 
penalised splines. We considered cubic splines with an equidistant sequence of ten knots and integrated squared second derivative penalty (corresponding to the default settings in the $\mathrm{R}$ package ConfBands [4]. To estimate the trend functions, we rely on the gam function in $\mathrm{R}$ package mgcv, which makes use of restricted maximum likelihood (REML) approach to determine the smoothing parameter.

Fig. (5) shows clear differences in the temperature profiles of the three tree species. Testing for differences of the latter is based on the simultaneous confidence bands defined in Section 2.5.2. If the estimated bands do not intersect over all time stamps, the null hypothesis of temperature profiles being equal can be rejected. Therefore we come to the conclusion that there are indeed significant differences in canopy leaf temperature among the tree species.

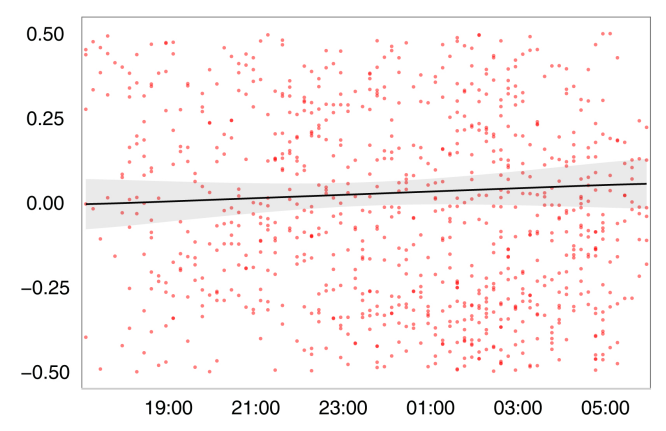

(a) Maple

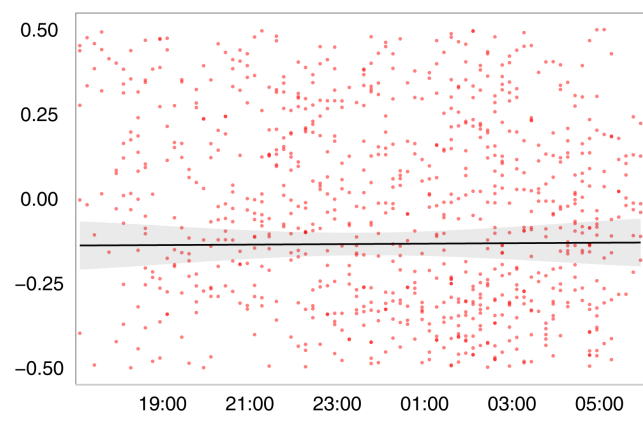

(b) Ash

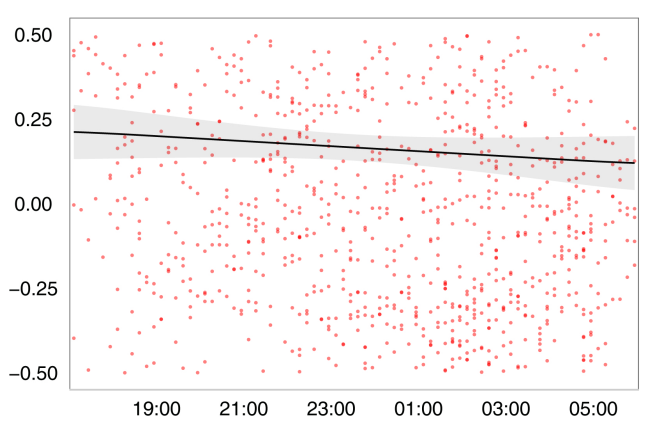

(c) Beech

Figure 5. Estimated temperature trends and associated simultaneous confidence bands.

\section{Concluding Remarks}

Tree canopy surface temperature is highly diverse and affected by many meteorological and plant physiological factors. The resulting complexity of the corresponding data sets is a challenge for applying statistical analyses.

In this paper, we analysed nocturnal thermal imagery of tree canopies with the goal to identify differences in surface temperature. The limitations in using thermal photos of the night when the variance of the canopy surface temperature is more stable, can be justified with the fact that during the night longwave radiation is the sole source of radiant energy from the canopy surface. Within one particular tree crown, there are many different regions with varying surface temperature that belong either to background and branches or leaves. A first challenge is, therefore, to find regions for the different tree 
crowns, for which the surface temperature can reasonably be compared. Otsu thresholding, a technique that comes from computer vision and image processing, was used to separate, based on similar surface temperature levels, leaf from background areas in the thermal images. Compared to manual delineation which is very time-consuming and potentially error-prone, particularly, for larger canopy areas, Otsu's thresholding offering the possibility of segmenting long time- series of thermal images using an automatic image segmentation approach. For this particular application, it seems to be an efficient approach which only requires the number of classes, in this case, three classes as an input.

A further challenge is that the image time series may be incomplete due to missing images and that surface temperature may oscillate in short time periods due to variation of external influences. With the approach of modeling temperature profiles from the extracted data using O'Sullivan-penalized spline, we can overcome short time gaps and such outliers. O'Sullivan-penalized splines can be found in various fields, and the related theory behind is well developed. Utilizing B-splines as a basis brings benefits regarding numerical stability as well as the availability of well-developed implementations such as in R. Furthermore, simultaneous confidence bands can be calculated and, therefore, statistical tests can be conducted. For the comparison of the canopy temperature from three different tree species, we used the simultaneous confidence bands.

Above all, with the presented approach, we lay the foundation for an enhanced analyzing of thermal imagery for a number of future studies mainly in the field of plant physiology. Additionally, further investigation of the different influencing parameters should be conducted to study and quantify their impact on canopy leaf temperature.

\section{Acknowledgement}

We thank the managers of the three Exploratories, Kirsten Reichel-Jung, Swen Renner, Katrin Hartwich, Sonja Gockel, Kerstin Wiesner, and Martin Gorke for their work in maintaining the plot and project infrastructure; Christiane Fischer and Simone Pfeiffer for giving support through the central office, Michael Owonibi for managing the central data base, and Markus Fischer, Eduard Linsenmair, Dominik Hessenmöller, Jens Nieschulze, Daniel Prati, Ingo Schöning, François Buscot, Ernst-Detlef Schulze, Wolfgang W. Weisser and the late Elisabeth Kalko for their role in setting up the Biodiversity Exploratories project. The work has been (partly) funded by the DFG Priority Program 1374 "Infrastructure-Biodiversity-Exploratories" (KL894/14-1). Field work permits were issued by the responsible state environmental offices of Baden-Württemberg, Thüringen, and Brandenburg (according to 72 BbgNatSchG).

\section{References}

[1] L. Fahrmeir, T. Kneib, S. Lang, and B. Marx, Regression: Models, Methods and Applications, Springer, 2013.

[2] H.G. Jones, Use of thermography for quantitative studies of spatial and temporal variation of stomatal conductance over leaf surfaces, Plant, Cell and Environment 22 (1999), pp. 1043-1055.

[3] A. Knohl, Carbon dioxide exchange and isotopic signature (13C) of an unmanaged 250 year-old deciduous forest: Univ., Diss.-Jena, 2003, ????

[4] T. Krivobokova and T. Kneib, ConfBands: Simultaneous Confidence Bands for Penalized Splines, $\mathrm{r}$ package version 0.1-0.

[5] T. Krivobokova, T. Kneib, and G. Claeskens, Simultaneous confidence bands for penalized spline estimators, Journal of the American Statistical Association 105 (2010).

[6] S. Leuzinger, Tree species diversity affects canopy leaf temperatures in a mature temperate forest, Agricultural and Forest Meteorology 9, pp. 29-37.

[7] M.D. Lowman, H.B. Rinker, and T.E. Lovejoy, Forest canopies, 2nd ed., Elsevier, Amsterdam, 2004. 
[8] Markus Fischer, Oliver Bossdorf, Sonja Gockel, Falk Hänsel, Andreas Hemp, Dominik Hessenmöller, Gunnar Korte, Jens Nieschulze, Simone Pfeiffer, Daniel Prati, Swen Renner, Ingo Schöning, Uta Schumacher, Konstans Wells, François Buscot, Elisabeth K.V. Kalko, Karl Eduard Linsenmair, Ernst-Detlef Schulze, and Wolfgang W. Weisser, Implementing large-scale and long-term functional biodiversity research: The biodiversity exploratories, Basic and Applied Ecology 11 (2010), pp. 473485, Available at http://www.sciencedirect.com/science/article/pii/S143917911000099X.

[9] K. Matsumoto, T. Ohta, and T. Tanaka, Dependence of stomatal conductance on leaf chlorophyll concentration and meteorological variables, Agricultural and Forest Meteorology 132 (2005), pp. $44-57$.

[10] F. O'Sullivan, A statistical perspective on ill-posed inverse problems, Statist. Sci. , pp. 502-518.

[11] N. Otsu, A threshold selection method from gray-level histograms, Systems, Man and Cybernetics, IEEE Transactions 9, pp. 62-66.

[12] R Development Core Team, R: A Language and Environment for Statistical Computing, R Foundation for Statistical Computing, Vienna, Austria (2014), Available at http://www.R-project.org, ISBN 3-900051-07-0.

[13] E. Rubio, V. Caselles, and C. Badenas, Emissivity measurements of several soils and vegetation types in the 8-14 mm wave band: Analysis of two field methods, Remote Sensing of Environment 59 (1997), pp. 490-521, Available at http://www.sciencedirect.com/science/article/pii/S003442579600123X.

[14] D. Ruppert, P. Wand, and R. Carroll, Semiparametric Regression, Cambridge Series in Statistical and Probabilistic Mathematics, Cambridge University Press, 2003.

[15] E.D. Schulze, E. Beck, and K. Müller-Hohenstein, Pflanzenökologie, Spektrum Akademischer Verlag Heidelberg, 2002. 
Annex E

Manuscript V 


\title{
Influence of four different digital elevation models on the estimation of tree cover
}

\author{
Hans Fuchs, ${ }^{\text {a Nils Nölke }}{ }^{\mathrm{a}}$ \\ ${ }^{a}$ Chair of Forest Inventory and Remote Sensing, Universität Göttingen, Büsgenweg 5, 37075 Göttingen, Germany
}

\begin{abstract}
Relief plays a crucial role for land surface and atmospheric processes especially in mountainous terrain. Different attributes, such as elevation, slope, and aspect which are highly relevant for forest and environmental management can be extracted from digital elevation models (DEM). During the pre-processing of remote sensing images, DEMs play an important role in ortho-rectification and illumination correction. However, the degree of detail and the data quality differs among the available DEMs and thus directly influence the results of image processing. For this purpose, we will focus on data quality and evaluate four different DEMs in Anhui province, China.
\end{abstract}

Keywords: topographic normalization, RapidEye.

Address all correspondence to: Hans Fuchs, Chair of Forest Inventory and Remote Sensing, Universität Göttingen, Büsgenweg 5, 37075 Göttingen, Germany; E-mail: hfuchs@gwdg.de

\section{Introduction}

Digital elevation models (DEMs) are numerical models of heights above a reference surface which are usually reduced to a regular grid. They are important layers in geographic information systems (GIS) which describe the third dimension of the earth's surface. DEMs can be divided into the following categories: digital terrain model (DTM) which represent the terrain surface and digital surface model (DSM) that include vegetation canopies and buildings. The relief of the earth's surface, represented by the DSM, influences a plethora of environmental processes in the atmosphere, biosphere, hydrosphere, and lithosphere, and therefore needs to be considered in the management of natural resources. The generation and update of DEMs is mainly based on remote sensing technology. At the same time, DEMs are needed for the pre-processing of remotely sensed images, e.g. for accurate geo-referencing and improved land resource classification. Hirt et al. $(2010)^{1}$ compared three free available DEM (ASTER-GDEM ver1, SRTM ver4.1 and GEODATA DEM-9S ver3) over Australia and concluded that in terms of accuracy (RMS around 6m), SRTM 
ver4.1 (90m spatial resolution) constitutes an alternative to GEODATA DEM-9s which has a spatial resolution of around 250m (Wang et al., 2012) ${ }^{2}$ performed a difference analysis for SRTM and ASTER GDEM on global scale. Based on their analyses, they suggested using a fusion method that combines both DEMs. Billemont $(2010)^{3}$ performed a validation of the ASTER GDEM over the Tibetan plateau using Nasa's ICESat elevation data. For flat areas they found a vertical accuracy of $2.8 \mathrm{~m}$.

The illumination of satellite images is strongly influenced by the sun and sensor geometry at acquisition time and the landscape relief. An illumination correction (often also referred to as topographic normalization) aims at equalizing the reflectance measurements of a satellite sensor by brightening shadows and reducing overexposure on directly illuminated slopes. Karathanassi et al. (2000) ${ }^{4}$ compared four different methods for topographic normalization applied on a SPOT imagery which covered a Mediterranean forest. According to their study,the Minnaert method marginally improved the classification. Hale et al. (2003) $)^{5}$ suggest that a combination of Minnaert and aspect partitioning may improve mountain classification. Their study also shows that the Minnaert correction used slope and aspect derived from a DEM and this derivatives are of questionable accuracy.

The assessment of forest resources in mountainous terrains and on steep slopes presents a challenge for field teams since the terrain is largely inaccessible. In such regions remote sensing is the only method for estimating forest cover. Nevertheless, due to the steep slopes the reflectance values from forest areas show large variations. The necessary correction is a real challenge, since although the different methods and their influences are well studied well studied, there are different DEMs available whose influence on the classification of forest areas in particular has not been sufficiently researched yet. 
The purpose of this paper is therefore to survey the data quality and to evaluate the four DEMs for the purpose of an optimized illumination correction of optical RapidEye satellite images. We hypothesize that the resolution and quality of DEMs used for satellite image enhancement influence the quality of the forest area estimation and forest type classification.

\section{Material and Methods}

\subsection{Study area}

The study area is located in Shitai County, Anhui Province, Southeast China (Long $117.48^{\circ}$, Lat $30.21^{\circ}$ ). The geomorphology in Shitai county is characterized by mountains with an altitude range $25-1727 \mathrm{~m}$ MSL. One third of the county area has very steep slopes ( $\geq 50 \%$ ). According to Köppen and Geiger, the climate is classified as warm temperate, fully humid, with hot summers (Cfa) (Kottek et al., 2006). ${ }^{6}$ The rainfall in the summer is influenced by the Southwest monsoon. In winter (December and January) ground frost occurs.

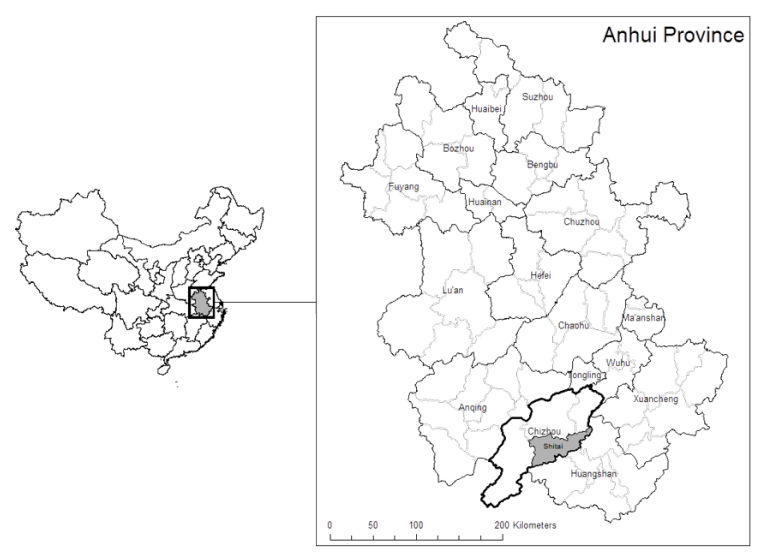

Fig 1 Overview where the study area is located in China. 


\subsection{Elevation Models of Shitai County}

A number of freely available digital elevation models (ASTER, SRTM, GTOPO30) with nearly global coverage exist. Their main differences are the resolution, vertical and geolocation accuracy, and the acquisition techniques and platforms. The most common elevation model is based on the Shuttle Radar Topography Mission (SRTM). This was the first mission thar used a space-borne interferometric SAR to produce near-global DEMs which cover $80 \%$ of the landmass between $57^{\circ} \mathrm{S}$ and $60^{\circ} \mathrm{N}$. Two independent radar instruments were used in the SRTM mission: the U.S. SIR-C which operates in the $\mathrm{C}$ band (3.75 to $7.5 \mathrm{~cm}$ wavelength) and the German-Italian X-SAR operating in the $\mathrm{X}$ band (2.4 to $3.75 \mathrm{~cm}$ wavelength).

Since the data acquisition in 2000 , the SIR-C data have been post-processed several times. The Consortium for Spatial Information (CGIAR-CSI) offers the SRTM version 4.1 (SRTM V4.1) that uses improved interpolation algorithms and enhanced auxiliary DEMs for filling no-data voids. The data was downloaded free of charge and was projected in geographic coordinates (horizontal WGS84 and vertical EGM96 datum) with a resolution of 3-arc second (approximately 90m at the equator). Since 2014, a further product, the SRTM30, is globally available. It is the fundamental SRTM data with 1 arc-second (approximately 30 meters at the equator). The above mentioned SRTM v4.1 was generated by $3 \times 3$ averaging of 1 arc-second data.

A further digital elevation model product SRTM-X is based on the second active sensor XSAR carried on board of the same space shuttle mission. Because of its higher resolution (approx. $25 \times 25 m$ ), the X-SAR ground track was considerably narrower so that there were large gaps between the individual tracks. The Geocoded Terrain Corrected (GTC) data product with the same WGS84/EGM96 geoid was also downloaded at no cost from the DLR (German Aerospace Center) 
Earth Observation data portal EOWEB-NG.

The reference elevation model was not freely available. The digital elevation model with a resolution of $50 \mathrm{~cm}$ was extracted from a very high spatial resolution stereo satellite panchromatic image pair. Therefore, two overlapping homogeneous images were acquired by the Pleiades satellite from two different viewing angle.

\subsection{Remotely Sensed Imagery}

We choose one RapidEye orthorectified Level 3A tile $(25 \times 25 \mathrm{~km})$ with two seasonal acquisition dates from spring (2012-04-01) and autumn (2012-10-17) for detailed studies on the illumination effects. In addition, a stereo satellite image pair covering an area of $10 \mathrm{~km}$ by $10 \mathrm{~km}$ was acquired on the $7^{\text {th }}$ November 2013, under clear sky conditions by the Pleiades 1A satellite. Each image contains four bands (blue: 430 - $550 \mathrm{~nm}$, green: 490 - $610 \mathrm{~nm}$, red: 600 - $720 \mathrm{~nm}$ and infrared: $750-950 \mathrm{~nm}$ ) with $2 \mathrm{~m}$ resolution and one panchromatic band with a resolution of $0.5 \mathrm{~m}$.

\subsection{RapidEye Processing Workflow}

The RMS error of the ground control points (GCP) registered in the RapidEye L3A tile compared to 9 Global Navigation Satellite System (GNSS) receiver points measured on the ground is estimated in the range of $1112 \mathrm{~m}$ (Tab 1) with a maximum residual of $23 \mathrm{~m}$. This is in the range of the expected locational product accuracy reported by Blackbridge (2014), but requires an additional geoemtric correction. Therefore we used the Scale-Invariant Transform (SIFT) algorithm (Lowe, 2004, Zerofrog, 2010) to find control points for the co-registration of the RapidEye L3A tiles and the Pleiades ortho image. Empirical Rational Polynomial Coefficient (RPC) sensor models were generated based on SIFT control points. The rectication process produced different ortho 
images using a sensor model and 4 different DEMS. The raw digital numbers of the ortho images

Table 1 Positional accuracy of $n=9$ GCPs registered in one RapidEye Level L3A tile of two different acquisition dates. Reference: GNSS Trimble JunoB with post-processing

\begin{tabular}{lll} 
Tile-ID 5053016 & $\begin{array}{l}\text { Acquisition Date } \\
\text { Spring }\end{array}$ & $\begin{array}{l}\text { Autumn } \\
\end{array}$ \\
& $2012-04-01$ & $2012-10-17$ \\
\hline Horizontal RMS [m] & 11.9 & 11.3 \\
Mean DX residual [m] & 0.1 & 4.6 \\
Stdev DX residual [m] & 4.2 & 2.4 \\
Mean DY residual [m] & 9.7 & -9.6 \\
Stdev DY residual [m] & 7.4 & 3.9 \\
\hline
\end{tabular}

were transformed to top-of-atmosphere (TOA) reflectances. Next, we applied the rotation model by Tan et al. $(2013)^{7}$ to correct the reflectance values in areas with steep slopes using each of the four DEMs as input. During the image enhancement processing step we calculated a set of indices from the terrain corrected images (e.g. Red Edge NDVI, Greenest NDVI) which highlight the differences in vegetation spectral reflectance between the two acquisition dates in spring and autumn.

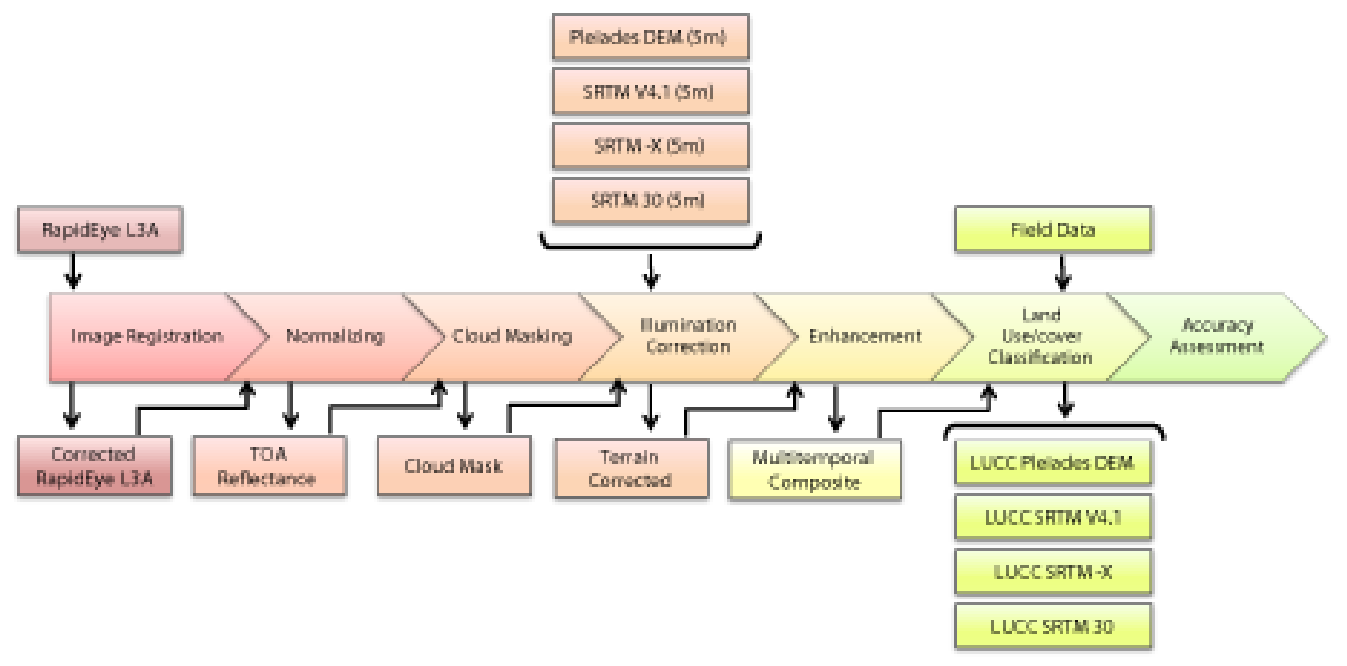

Fig 2 RapidEye imagery processing workflow. 


\subsection{Pleaides Processing Workflow}

For the Pleiades stereo image processing we used the software package PCI Geomatica 2013. To improve the RPC based geometric sensor model we collected up to 16 GCPs with a GNSS receiver (Trimble Juno 3B) and post-processed them to increase the positional accuracy. Additionally, a set of automatic tie points was registered. Using the backward and forward looking images we generated firstly a $0.5 \mathrm{~m}$ DSM , and secondly, a $5 \mathrm{~m}$ DSM using the OrthoEngine. For the orthorectified multispectral image we first performed pan-sharpening using the uncorrected images. For the illumination correction all DEMs had to be resampled to the $5 \mathrm{~m}$ resolution of the RapidEye image. We applied the thin plate spline interpolation implemented in SAGA GIS. This method fitted a surface through available data points by applying the minimal energy principle and was first introduced by Duchon (1976). ${ }^{8}$

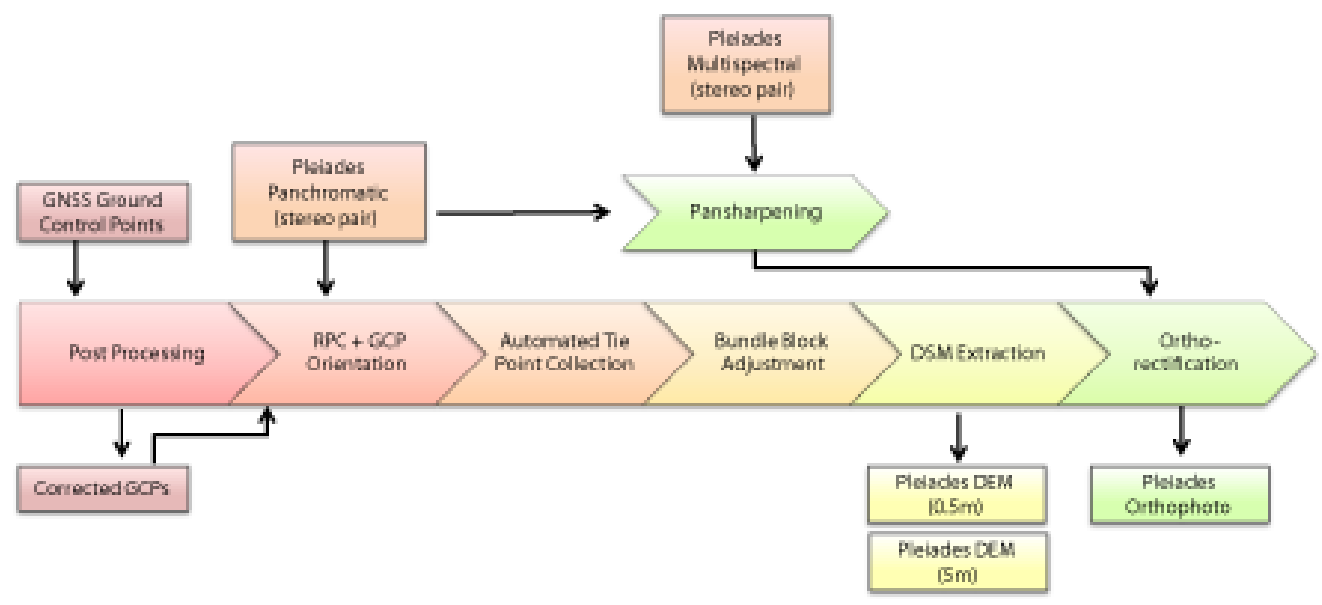

Fig 3 Pleiades stereo image pair processing workflow. 


\subsection{DEM Evaluation}

For the evaluation and validation of the four elevation models we selected the most accurate Pleiades DEM as the reference. First a visual interpretation of the shaded relief calculated from each DEM was performed using the method by Tan et al. (2013). The visual step helped identifying structural irregularities, systematic artifacts and outlier. To compare the four elevation models we applied a line sampling on a $2.5 \times 2.5 \mathrm{~km}$ systematic grid. On each sample point we generated a line with $400 \mathrm{~m}$ width and with random orientation. On a $5 \mathrm{~m}$ interval we extracted the elevation and slope and linear profile plots were drawn and visually analyzed. This method facilitates the identification of regular shifts between the DEMs. Aside from the visual inspection we performed a statistical analysis and calculated not only the mean and root mean square error (RMSE), but also the $90 \%$ linear error (LE90) for the vertical accuracy.

\subsection{Estimation of Tree Cover}

A supervised per-pixel classification was used to produce a binary map product with two classes "tree cover" (TC) and "non-tree cover" (Non-TC). Training data were collected during a field inventory on square $200 \times 200 \mathrm{~m}$ plots laid out on a systematic $3 \times 3 \mathrm{~km}$ grid with the use of standard GNSS receivers. Boundaries of 11 land use/cover classes (broadleaved tree cover, coniferous tree cover, bamboo, shrub/grass, annual crop, tea, open spaces, annual crop, built-up area, water) were identified on ground, drawn on hardcopy colour composites of RapidEye images and later digitized on screen. The minimum mapping was $626 \mathrm{~m}^{2}$. A vector of 7 selected bands was extracted for each pixel inside the mapped training polygons. 500 decision trees were created to build Random Forests models specifically for the 4 different illumination corrected RapidEye images and to classify the final thematic maps, where broadleaved tree cover, coniferous tree cover, and bam- 
boo were aggregated as "tree cover" and the remaining land use/cover classes were relabeled as "non-tree cover".

\subsection{Validation of Thematic Maps}

The validation sampling design was completely independent from the selection of the training data used for building the classification models. The lines for the DEM evaluation on a systematic grid were modified with a buffer of $20 \mathrm{~m}$ on both sides, which resulted in plots with the same size and shape but different orientations on the transect. This plot design is also known as "sausage sampling" (Gregoire and Valentine pp. 361-362) and is applied in terrestrial forest inventories. Here the sampling units are pixels with pixel centers inside the inclusion or buffer zones. The response design is characterized by the use of high spatial resolution Pleiades satellite images as ground truth reference: a false color composite of Pleiades and, in addition, actual true color composites of satellite images on Google maps acquired and published in 2014. The plot area was subdivided and labeled into the classes "TC" and "Non-TC" with standard GIS vectorization tools and visual image interpretation. For the estimation and analysis protocol, the buffer zones may be defined as clusters but were treated here as independently selected pixels with the application of simple random sampling estimators. The quality of the thematic maps was evaluated by a binomial test of the number of agreements (true) or disagreement (false) of the validation pixel samples with the thematic mapped class. The statistics calculated from the confusion matrix are the overall accuracy, unweighted kappa, and their confidence intervals for a 5\% probability of a Type I error. 


\section{Results}

\subsection{Comparison of Digital Elevation Models}

A comparison between the different digital elevation models show that the difference in absolute elevation has a maximum difference in absolute elevation of $112 \mathrm{~m}$ between the SRTM-X and the Pleiades DEM. The smallest absoulute difference of $89 \mathrm{~m}$ was between the SRTM v4.1 and the Pleiades DEM. These extreme values occur most frequently in areas with steeper slopes. For

Table 2 DEM statistics for the study site

\begin{tabular}{lllll} 
& Slope & Mean & RMSE & LE90 \\
\hline SRTM-X & Overall & 7.12 & 16.15 & 26.57 \\
& $<10^{\circ}$ & 2.45 & 6.82 & 11.22 \\
& $10^{\circ}-20^{\circ}$ & 6.38 & 13.96 & 22.96 \\
& $>20^{\circ}$ & 8.94 & 18.99 & 31.24 \\
\hline SRTM v4.1 & Overall & 8.10 & 18.86 & 31.02 \\
& $<10^{\circ}$ & 6.48 & 12.26 & 20.17 \\
& $10^{\circ}-20^{\circ}$ & 5.50 & 15.43 & 25.38 \\
& $>20$ & 10.08 & 22.33 & 36.73 \\
\hline SRTM30 & Overall & 7.71 & 14.82 & 24.38 \\
& $<10^{\circ}$ & 5.40 & 8.97 & 14.76 \\
& $10^{\circ}-20^{\circ}$ & 9.32 & 15.04 & 24.74 \\
& $>20^{\circ}$ & 7.93 & 16.46 & 27.08
\end{tabular}

both the mean value and the root mean square error (RMSE) we detected the smallest values for the SRTM-X (Table 1). The accuracy in Linear Error 90\% is for both the SRTM30 and SRTM$\mathrm{X}$ within the specified vertical accuracy of $\pm 16 \mathrm{~m}$ for areas with a slope below $10^{\circ}$. The error increased and showed the highest values for all three models in the mountainous terrain (slope above $20^{\circ}$ ).

\subsection{Accuracy Assessment}

To compare the accuracy of the thematic maps using different DEMs for the illumination correction, an accuracy assessment was performed. The thematic map with the highest accuracy of 0.82 
used the SRTM30 for topographic correction. The non-corrected TOA image showed the lowest accuracy with a value of 0.79 . The range 0.03 for the overall accuracy .

Table 3 Overall accuracy $(O A)$ and kappa $(k)$ statistics of the binary classification "Tree Cover" and "Non-Tree Cover" using different DEM for illumination correction and no illumination correction (TOA), where $n=$ number of samples, $s=$ standard deviation, $C . I .=$ confidence interval

\begin{tabular}{lllllllll}
\multicolumn{2}{c}{$n$} & OA & $s$ & $95 \%$ C.I. & $k$ & $s[k]$ & $95 \%$ C.I. $[k]$ \\
\hline SRTM30 & 10962 & 0.8218 & 0.0037 & $0.8146 \ldots$ & 0.8290 & 0.6440 & 0.0073 & $0.6296 \ldots 0.6583$ \\
SRTM v4.1 & 10962 & 0.8125 & 0.0038 & $0.8050 \ldots$ & 0.8200 & 0.6239 & 0.0076 & $0.6089 \ldots 0.6389$ \\
SRTM-X & 10962 & 0.8064 & 0.0038 & $0.7990 \ldots 0.8139$ & 0.6122 & 0.0076 & $0.5973 \ldots 0.6270$ \\
Pleiades & 10873 & 0.8000 & 0.0038 & $0.7924 \ldots$ & 0.8075 & 0.5972 & 0.0077 & $0.5822 \ldots 0.6123$ \\
TOA & 10962 & 0.7929 & 0.0039 & $0.7853 \ldots$ & 0.8006 & 0.5814 & 0.0077 & $0.5664 \ldots 0.5965$ \\
\hline
\end{tabular}

\section{Discussion and Conclusion}

DEMs are fundamental geodata with many implications on forest management, landscape and land use planning. It is important to quantify DEM data quality as users of remote sensing products and decision makers are often not sure about the suitability and limitations of DEMs for specific applications. This study shows that when the illumination correction is performed with the SRTM30 the highest accuracy for the estimation of tree cover may be retrieved. Furthermore, the change in tree cover varies up to $2 \%$ and may simply be by the different digital elevation models that range from high to coarse spatial resolution. This leads us to the assumption that scale is a critical issue when removing topographic effects and that there is a linkage between both: the spatial resolution of the satellite imagery as well as of the DEM. The overarching result that the overall accuracy of tree cover estimation based RapidEye imagery which was corrected by four different DEMs is between 0.79 and 0.82 . compared to the range of spatial resolutions and the price, the difference in accuracy is small. From this point of view, the use of the expensive Pleiades DEM is not necessary for the topographic correction of the RapidEye imagery. Zhang et al. (2015) ${ }^{9}$ performed a scientific experiment where simulated satellite imagery with a resolution of $30 \mathrm{~m}$ to $500 \mathrm{~m}$ was corrected 
with DEMs of $5 \mathrm{~m}$ to $500 \mathrm{~m}$ spatial resolution. They concluded that for illumination correction of $30 \mathrm{~m}$ resolution imagery, at least a DEM with $10 \mathrm{~m}$ resolution is necessary. This underlines the assumption, that there is a relationship between both the spatial resolution of imagery and the DEM. This is also proven by our study. The high-resolution elevation model extracted from the Pleaides imagery falls beyond the three SRTM products, in terms of accuracy. One explanation for this purpose is maybe the uncertainty in geometry because the RapidEye Level 3A data already constitute an ortho-rectified product based on a DTED Level 1 SRTM DEM. An overlay above the high-resolution DEM showed small relief displacements at high elevations which may caused a classification error. Another explanation is that may be the degree of detail from Pleiades DEM is to fine compared and not, therefore, represented in RapidEye imagery. We conclude that further research should use RapidEye Level 1B which includes the geometric sensor and a form of radiometric correction. Corrections of terrain distortions can then be supplied by own DEM and GCPs.

\section{Acknowledgments}

We thank DLR for providing the satellite images from the RapidEye Science Archive (RESA) and BMBF for funding. Thanks to the ForestEye Processor Development Team. The support of the Lin2Value team (Prof. Dr. Christoph Kleinn, Dr. Lutz Fehrmann, Dr. Haijun Yang, Sabine Schreiner, Dengkui Mo, Xiaolu Tang, Julia Bning is gratefully acknowledged.

\section{References}

1 C. Hirt, M. Filmer, and W. Featherstone, "Comparison and validation of the recent freely available aster-gdem ver1, srtm ver4. 1 and geodata dem-9s ver3 digital elevation models over 
australia," Australian Journal of Earth Sciences 57(3), 337-347 (2010).

$2 \mathrm{~W}$. Wang, X. Yang, and T. Yao, "Evaluation of aster gdem and srtm and their suitability in hydraulic modelling of a glacial lake outburst flood in southeast tibet," Hydrological Processes 26(2), 213-225 (2012).

3 S. Billemont, "Validation of aster gdem over tibet," Rapport de recherché (2010).

4 V. Karathanassi, V. Andronis, and D. Rokos, "Evaluation of the topographic normalization methods for a mediterranean forest area," International Archives of Photogrammetry and Remote Sensing 33(B7/2; PART 7), 654-661 (2000).

5 S. R. Hale and B. N. Rock, "Impact of topographic normalization on land-cover classification accuracy," Photogrammetric Engineering \& Remote Sensing 69(7), 785-791 (2003).

6 M. Kottek, J. Grieser, C. Beck, B. Rudolf, and F. Rubel, "World map of the köppen-geiger climate classification updated," Meteorologische Zeitschrift 15(3), 259-263 (2006).

7 B. Tan, J. G. Masek, R. Wolfe, F. Gao, C. Huang, E. F. Vermote, J. O. Sexton, and G. Ederer, "Improved forest change detection with terrain illumination corrected landsat images," Remote Sensing of Environment 136, 469-483 (2013).

8 J. Duchon, "Interpolation des fonctions de deux variables suivant le principe de la flexion des plaques minces," Revue française d'automatique, informatique, recherche opérationnelle. Analyse numérique 10(3), 5-12 (1976).

9 Y. Zhang, G. Yan, and Y. Bai, "Sensitivity of topographic correction to the dem spatial scale," IEEE Geoscience and Remote Sensing Letters 12(1), 53-57 (2015). 